Florida International University FIU Digital Commons

9-28-2011

\title{
The Effect of the Business Cycle on the Performance of Socially Responsible Equity Mutual Funds
}

Andrea Roofe Sattlethight

Florida International University, andrea.roofe@fiu.edu

DOI: $10.25148 /$ etd.FI1 1120901

Follow this and additional works at: https://digitalcommons.fiu.edu/etd

\section{Recommended Citation}

Roofe Sattlethight, Andrea, "The Effect of the Business Cycle on the Performance of Socially Responsible Equity Mutual Funds" (2011). FIU Electronic Theses and Dissertations. 525.

https://digitalcommons.fiu.edu/etd/525 


\title{
FLORIDA INTERNATIONAL UNIVERSITY \\ Miami, Florida
}

\section{THE EFFECT OF THE BUSINESS CYCLE ON THE PERFORMANCE OF SOCIALLY RESPONSIBLE EQUITY MUTUAL FUNDS}

\author{
A dissertation \\ submitted in partial fulfillment of the requirements for the degree of \\ DOCTOR OF PHILOSOPHY \\ in \\ BUSINESS ADMINISTRATION \\ by \\ Andrea J. A. Roofe Sattlethight \\ 2011
}


To: Dean Joyce Elam

College of Business Administration

This dissertation, written by Andrea J. A. Roofe Sattlethight, and entitled The Effect of the Business Cycle on the Performance of Socially Responsible Equity Mutual Funds, having been approved in respect to style and intellectual content, is referred to you for judgment.

We have read this dissertation and recommend that it be approved.

Sungu Armagan

William Newburry

$\begin{array}{r}\hline \text { Paulette Johnson } \\ \hline \text { Karen Paul, Major Professor }\end{array}$

Date of Defense: September 28, 2011

The dissertation of Andrea J. A. Roofe Sattlethight is approved.

$\begin{array}{r}\text { Dean Joyce Elam } \\ \text { College of Business Administration } \\ \hline \begin{array}{r}\text { Dean Lakshmi N. Reddi } \\ \text { University Graduate School }\end{array}\end{array}$

Florida International University, 2011 


\section{DEDICATION}

I dedicate this work to the memory of my parents, Alexander Roofe and Madge Hunter Roofe, and my grandparents Sylvester Hunter and Ivy Rose Miller Hunter. Their legacy of hard work, sacrifice, and tenacity provided me with the inner sustenance to persist during my sojourn in academia.

"Cursum Perficio" (I accomplish my course). Hunter Clan motto. 


\section{ACKNOWLEDGMENTS}

Thanks be to God for His grace and sustenance during this period of my life. I am also grateful to my Committee Members for their support and direction while I struggled with the task of writing for an academic audience. Dr. Karen Paul patiently allowed me to find my direction in this process. Dr. Sungu Armagan demystified the academic writing process and asked the tough questions that I needed to answer. Dr. Paulette Johnson allowed me to indulge a long-standing love of statistical analysis by employing me in the Statistical Consulting Department. Dr. William Newburry offered his patience, goodwill, and kindly critique, which served as a huge encouragement during this process. Dr. Kim Coffman and Kristofer Arca, my writing tutors, and the University Graduate School's Writing Center's Dissertation Retreat of 2011, enhanced the creative and writing process. My professors at the University of the West Indies, Jamaica - Professor Emeritus Alfred Francis, Dr. Derick Boyd, Dr. Claude Packer, and Collin Bullock - encouraged my interest in monetary economics and applied economics. The SAS Institute supported my desire to hone my skills in SAS ${ }^{\circledR}$ software by way of grants of books and software, and a Student Ambassadorship in 2008.

Thank you my siblings - Michele, Michael, and Margaret - for sheltering me from the emotional trauma of Mummy's passing. You knew how difficult it was for me to be away at school during her final illness. Margaret, Catherine, Emily, and Tiler, thank you for reminding me of the kinder, gentler side of humanity. Alison and Angela, thanks for reaching out when I was too busy to keep in touch. Finally, thanks to you, my dearest husband, Louis, for your understanding, and patience and for giving me the time, space, and support that I needed to finish this work. I owe each of you a huge debt of gratitude! 


\title{
ABSTRACT OF THE DISSERTATION \\ THE EFFECT OF THE BUSINESS CYCLE ON THE PERFORMANCE OF SOCIALLY RESPONSIBLE EQUITY MUTUAL FUNDS \\ by
}

\author{
Andrea J. A. Roofe Sattlethight \\ Florida International University, 2011 \\ Miami, Florida \\ Karen Paul, Major Professor
}

The current study applies a two-state switching regression model to examine the behavior of a hypothetical portfolio of ten socially responsible (SRI) equity mutual funds during the expansion and contraction phases of US business cycles between April 1991 and June 2009, based on the Carhart four-factor model, using monthly data. The model identified a business cycle effect on the performance of SRI equity mutual funds. Fund returns were less volatile during expansion/peaks than during contraction/troughs, as indicated by the standard deviation of returns. During contraction/troughs, fund excess returns were explained by the differential in returns between small and large companies, the difference between the returns on stocks trading at high and low Book-to-Market Value, the market excess return over the risk-free rate, and fund objective. During contraction/troughs, smaller companies offered higher returns than larger companies $\left(c_{i}=\right.$ $0.26, p=0.01)$, undervalued stocks out-performed high growth stocks $\left(h_{i}=0.39, p\right.$ $<0.0001)$, and funds with growth objectives out-performed funds with other objectives $\left(o_{i}\right.$ $=0.01, p=0.02)$. The hypothetical SRI portfolio was less risky than the market $\left(b_{i}=\right.$ $0.74, p<0.0001)$. During expansion/peaks, fund excess returns were explained by the 
market excess return over the risk-free rate, and fund objective. Funds with other objectives, such as balanced funds and income funds out-performed funds with growth objectives $\left(o_{i}=-0.01, p=0.03\right)$. The hypothetical SRI portfolio exhibited similar risk as the market $\left(b_{i}=0.93, \mathrm{p}<0.0001\right)$. The SRI investor adds a third criterion to the risk and return trade-off of traditional portfolio theory. This constraint is social performance. The research suggests that managers of SRI equity mutual funds may diminish value by using social and ethical criteria to select stocks, but add value by superior stock selection. The result is that the performance of SRI mutual funds is very similar to that of the market. There was no difference in the value added among secular SRI, religious SRI, and vice screens. 


\section{TABLE OF CONTENTS}

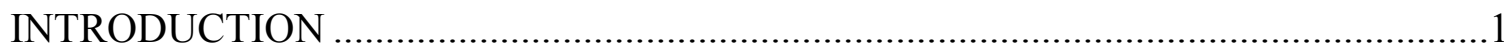

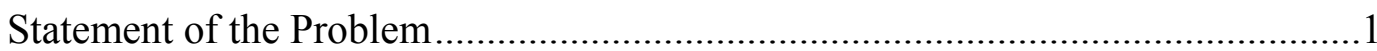

Socially Responsible Investing ..................................................................

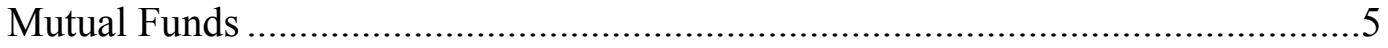

Religious Funds and the Vice Fund ....................................................... 5

The Performance of SRI Funds During Economic Expansions and Contractions ..6

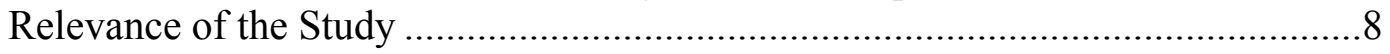

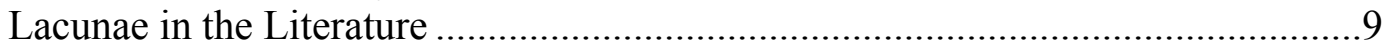

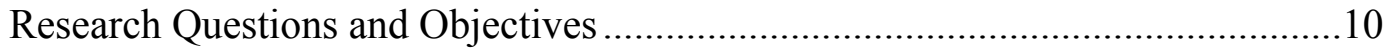

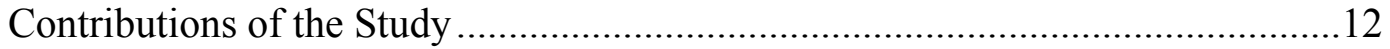

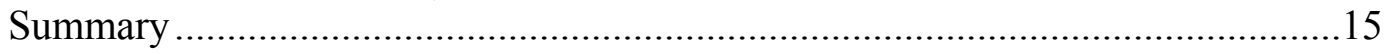

LITERATURE REVIEW ................................................................................ 16

SRI Mutual Funds: Rationale and Organization............................................. 17

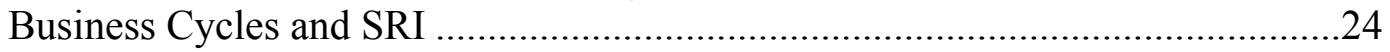

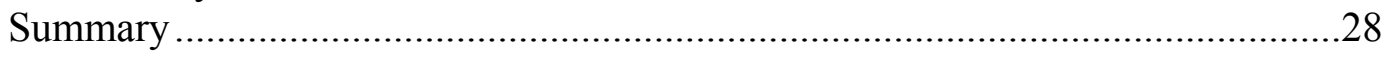

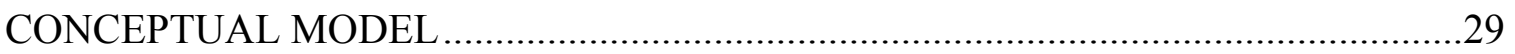

SRI Investment Performance and the Business Cycle .......................................29

SRI Equity Mutual Funds and Benchmark Returns...........................................33

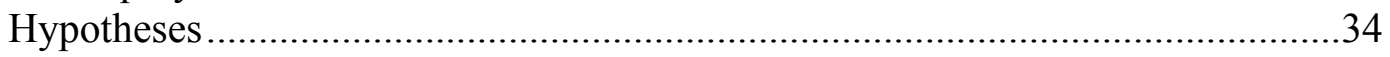

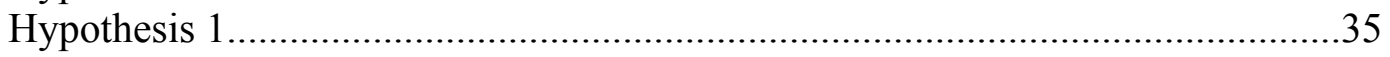

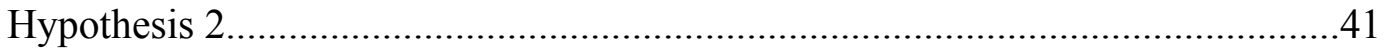

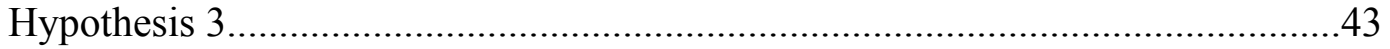

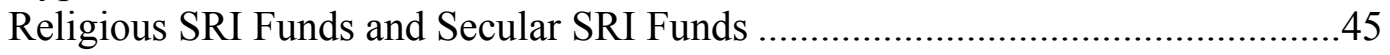

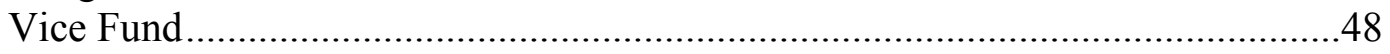

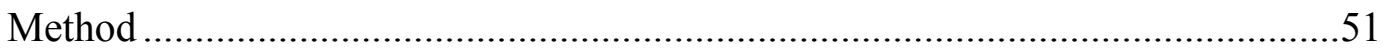

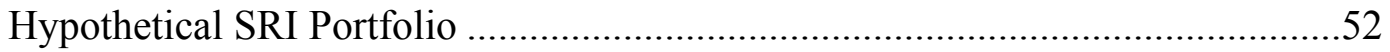

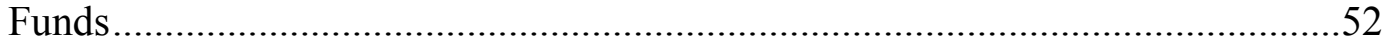

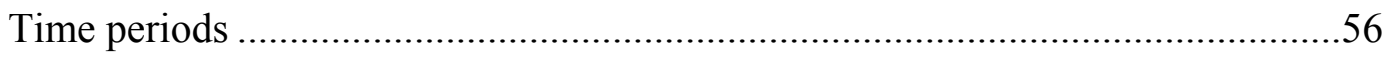

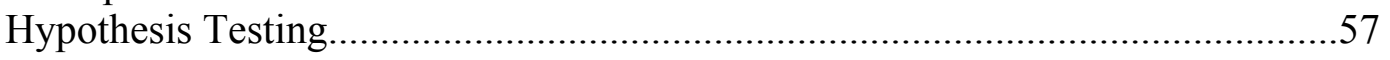

Business Cycle Effects on a Hypothetical SRI portfolio ...................................57

Secular SRI Funds, Religious Funds, and the Vice Fund .................................60

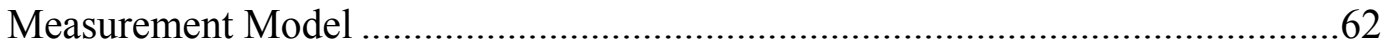

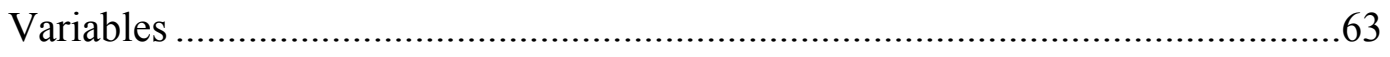

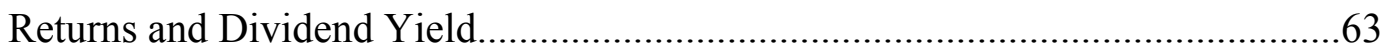

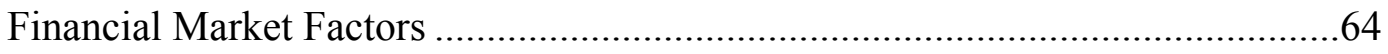

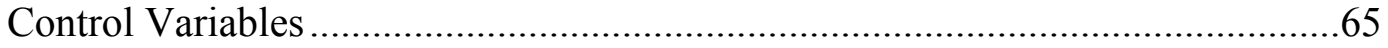

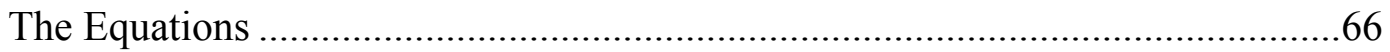

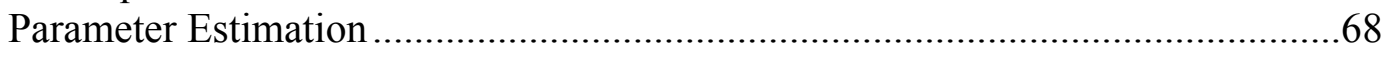

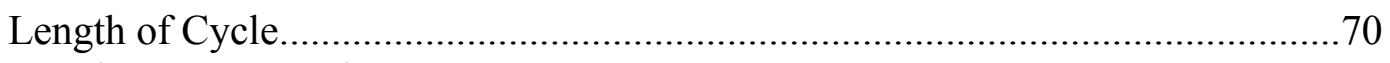

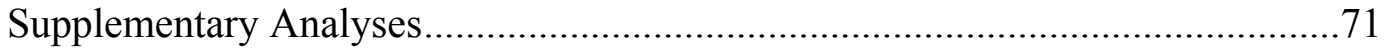

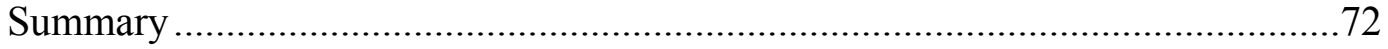


Summary Statistics for a Hypothetical SRI Portfolio for April 1991

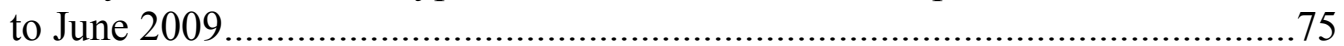

Excess Returns of the Hypothetical SRI Portfolio...................................................77

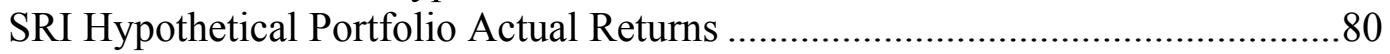

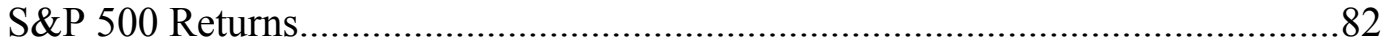

Descriptive Statistics for the Portfolio Risk Factors and Control Variables .........85

Summary Statistics for a Hypothetical Ideological Portfolio for

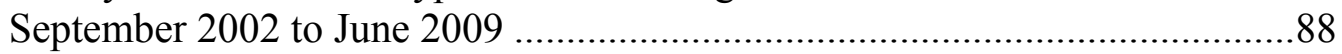

Excess Returns of the Hypothetical Ideological Portfolio .......................................90

Hypothetical Ideological Portfolio Actual Returns.................................................92

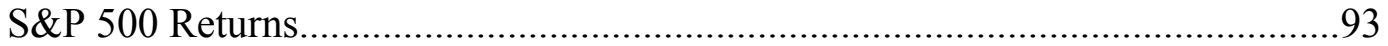

Descriptive Statistics for the Portfolio Risk Factors and Control Variables .........95

Summary Statistics for Individual Cycle Phases ................................................98

Results of the Tests of Hypotheses ................................................................104

Hypothesis 1 Test of Business Cycle Effect .....................................................105

Hypothesis 2 Test of SRI Value Added Proposition ............................................114

Hypothesis 3(a) Comparison of Religious and Secular SRI Funds ......................115

Hypothesis 3(b) Comparison of Secular SRI Funds and the Vice Fund..............117

Hypothesis 3(c) Comparison of Religious Funds and The Vice Fund ................118

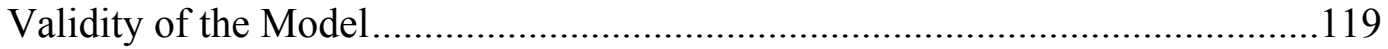

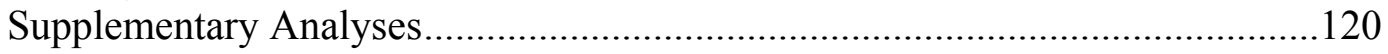

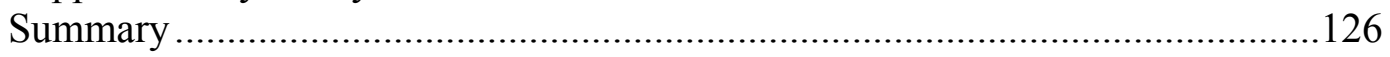

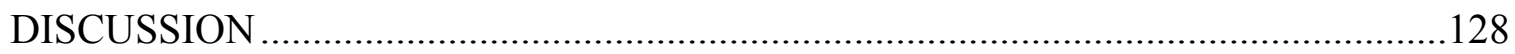

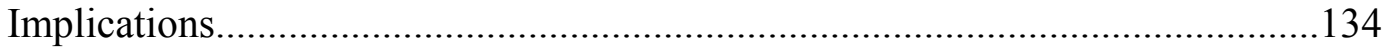

Limitations of the Study and Directions for Future Research .............................138

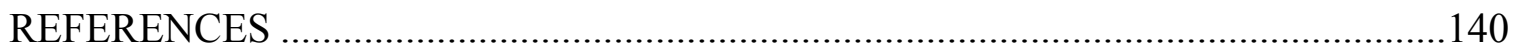

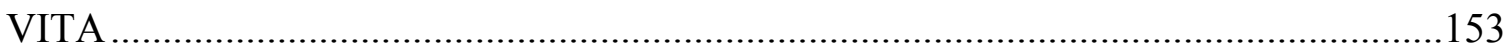




\section{LIST OF TABLES}

Table 1. History of the SRI Movement in the US.......................................................4

Table 2. Research Questions and Objectives........................................................... 11

Table 3. SRI Screened Investments. ................................................................. 18

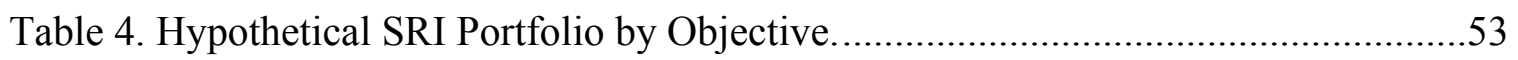

Table 5. Hypothetical SRI Portfolio by Style......................................................... 54

Table 6. Hypothetical Ideological Portfolio by Orientation. ........................................55

Table 7. Business Cycle Phases Announced by the NBER...........................................56

Table 8. Constituents of a Hypothetical SRI Portfolio of Equity Mutual Funds -

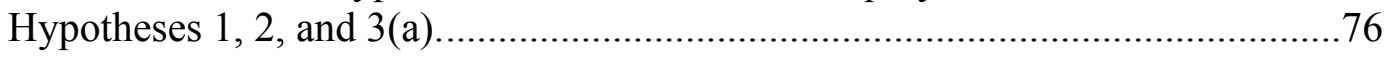

Table 9. Expansion and Contraction Cycle Phases..................................................... 77

Table 10. Descriptive Statistics of a Hypothetical SRI Portfolio and S\&P 500 Returns by Expansion and Contraction Cycle Phase (April 1991 - June 2009 .. 83

Table 11. Results of Tests of Homogeneity of Returns on a Hypothetical SRI Portfolio (April 1991 - June 2009).

Table 12. Descriptive Statistics of Portfolio Risk Factors and Control Variables by Expansion and Contraction Cycle Phase (April 1991 - June 2009).

Table 13. Constituents of a Hypothetical SRI Portfolio of Mutual Funds - Hypotheses 3(b) and 3(c)......

Table 14. Expansion and Contraction Cycle Phases - (September 2002 - June 2009).....90

Table 15. Descriptive Statistics of a Hypothetical SRI Portfolio and S\&P 500 Returns by Expansion and Contraction Cycle Phase (September 2002 - June 2009).

Table 16. Results of Tests of Homogeneity of the Returns of a Hypothetical SRI Portfolio (September 2002 to June 2009).

Table 17. Descriptive Statistics of Portfolio Risk Factors and Control Variables by Expansion and Contraction Cycle Phase (September 2002 - June 2009).

Table 18. Descriptive Statistics by individual cycle phase (April 1991 -- June 2009)....102 
Table 19. Factors determining Excess Returns of a Hypothetical Portfolio of SRI Equity Mutual Funds (April 1991 - June 2009).

Table 20. Factors determining Excess Returns of a Hypothetical Portfolio of Equity Mutual Funds (September 2002 - June 2009).

Table 21. Comparisons of Jensen's Alpha and the Beta Coefficient of a Hypothetical Portfolio of SRI Equity Mutual Funds (April 1991 - June 2009).

Table 22. Comparisons of the Performance of Religious and Secular SRI Equity Mutual Funds.

Table 23. Comparisons of the Performance of Secular SRI Equity Mutual Funds and The Vice Fund.

Table 24. Comparisons of the Performance of Religious SRI Equity Mutual Funds and The Vice Fund.

Table 25. Comparisons of the Means of a Hypothetical Portfolio of SRI Equity Mutual Funds and the S\&P 500 (April 1991 - June 2009).

Table 26. Comparisons of the Volatilities of a Hypothetical Portfolio of SRI Equity Mutual Funds and the S\&P 500 (April 1991 - June 2009)

Table 27. Comparisons of the Coefficients of Variation of a Hypothetical SRI Portfolio and the S\&P 500 (April 1991 - June 2009) 


\section{LIST OF FIGURES}

Figure 1. Conceptual model of the effect of the business cycle on SRI equity mutual funds.

Figure 2. Conceptual model of the effect of the business cycle on secular SRI equity mutual funds, religious equity funds, and the Vice Fund.

Figure 3. Hypothetical SRI portfolio excess returns by expansion and contraction cycle phase (April 1991 - June 2009).

Figure 4. Hypothetical SRI portfolio actual returns by expansion and contraction cycle phase (April 1991 - June 2009) .80

Figure 5. S\&P 500 returns by expansion and contraction cycle phase (April 1991 - June 2009)

Figure 6. Hypothetical ideological portfolio excess returns by expansion and contraction cycle phase - outlier removed (September 2002 - June 2009).

Figure 7. Hypothetical ideological portfolio actual returns by expansion and contraction cycle phase - outlier removed (September 2002 - June 2009)

Figure 8. Hypothetical SRI portfolio excess returns by NBER cycle phase (April 1991 - June 2009).

Figure 9. Hypothetical SRI portfolio returns by NBER cycle phase (April 1991 - June 2009).

Figure 10. S\&P 500 returns by NBER cycle phase (April 1991 - June 2009). .101

Figure 11. Comparisons of a hypothetical SRI portfolio returns and S\&P 500 returns (April 1991 - June 2009). 


\section{GLOSSARY}

Active investing A portfolio management strategy in which the fund manager selects stocks hoping to out-perform an index or other benchmark. Active investing contrasts with index investing (passive investing).

Alpha

B-Corporation

Beta

Blended approach

Blue Chip stocks

Core investing

Core stocks

Correlation

coefficient

Enhanced index investing

Ethical investing

ESG
Alpha compares the expected return of the fund, based on its beta, with its actual return. A positive alpha means that the fund did better than expected, based on its historical beta. This difference is attributable to the skill of the manager.

B-Corporations "...use the power of business to solve social and environmental problems" (B Lab, 2010).

Beta compares the volatility of a fund with that of the market, or other benchmark. A beta exceeding 1 reveals that the fund is more volatile than its benchmark.

See core investing.

See core stocks, core investing.

A portfolio management style in which the portfolio consists of the stock of large, stable companies (blue chip stock). Core investing may also combine value and growth investing. Also known as the Blended Approach.

Core stocks are usually those of large, stable (blue chip) companies, whose prices do not fluctuate dramatically.

The correlation coefficient describes the strength of a linear relationship between fund returns and benchmark returns.

A form of index investing that attempts to out-perform a benchmark index "... by either adding value or reducing volatility through selective stock-picking..." (Morningstar, 2010) See Index Investing.

See Socially Responsible Investing (SRI).

Environmental, Social and Governance criteria, applied to screens used in stock selection for socially responsible investments. 
Excess returns

(gross)

Expense ratio

Expenses

Financial

Performance (FP)

Fund of funds

Fund

Growth stocks

Index investing

Market conditions
The difference between the returns on a financial instrument or index and a benchmark, often referred to as excess returns.

The expense ratio of a fund is accrued on a daily basis. If the fund's assets are small, its expense ratio can be quite high because the fund must meet its expenses from a restricted asset base. Conversely, as the net assets of the fund grow, or if the fund is one of a large family of funds, the expense percentage should ideally diminish as expenses are spread across the wider base. Fund managers may also opt to waive all or a portion of the expenses that make up their overall expense ratio.

(Morningstar, 2010).

"...The expense ratio is the annual fee that all funds or ETFs charge their shareholders. It expresses the percentage of assets deducted each fiscal year for fund expenses, including $12 \mathrm{~b}-1$ fees, management fees, administrative fees, operating costs, and all other asset-based costs incurred by the fund. Portfolio transaction fees, or brokerage costs, as well as initial or deferred sales charges, are not included in the expense ratio." (Morningstar, 2010)

Describes how well a company is doing (present) or has done (past) in using the assets that it owns, to carry out its mission. Indicators may be profits, return on investments, return on assets, or sales may be used to measure financial performance.

A portfolio comprised of mutual funds.

An approach to investing based on the pooling of financial resources by multiple investors. Each fund has a particular management approach - active or passive, an objective such as income or growth and a style such as value or growth investing.

Growth stocks report consistently strong growth in profits.

A style of portfolio management in which a portfolio's composition mirrors that of an index. Index investing is considered a passive form of investing. Also known as passive investing. (opp. active investing).

The conditions prevailing in the financial markets at any given time. 
Morally Responsible Investing (MRI)

Mutual fund

Net excess returns

Negative excess returns

Negative screens

Passive investing

Positive excess returns

Positive screens

Religious fund

Responsible Investing

R-square
Investing activities in which assets are screened based on the values embodied by a religious or other moral code.

A form of pooled investing which a fund management company manages. A mutual fund has a goal to which the manager must adhere in selecting stocks. A SRI mutual fund manager must select stocks in companies that conform to the social or ethical principles stated in the fund's prospectus.

The difference between the returns on a financial instrument or index and a benchmark, minus fund expenses.

Negative excess returns exist where the return on a fund is less than the return of its benchmark.

Negative screens exclude companies from portfolio holdings, eliminating firms that engage in undesirable actions or deficient on specific social and ethical criteria. Negative screens restrict opportunities for diversification (Statman, 2007; Stone, Guerard, Gulteki, \& Adams, 2001).

See Index investing.

Positive excess returns exist where the return on a fund is greater than the returns on its benchmark.

Positive screens include companies that meet desired SRI criteria in portfolio holdings.

A type of SRI fund whose stock selection process includes companies that are consistent with the values of a particular religion.

See Socially Responsible Investing.

The R- square of an SRI fund refers to the difference between its returns and those of its conventional benchmark. Measures the extent to which a change in the fund's returns is attributable to changes in the market or other factors. Mathematically defined as the square of the correlation coefficient. R-squared lies between 0 and 1. A low R-squared is indicative of poor management or comparison with an inappropriate benchmark. 
Russell Mid-Cap

Value Index

Russell 2000 Index

S\&P 500 Index

Social Investing

Socially Responsible Investing (SRI)

Social Performance (SP)

SP-FP

SRI fund

SRI mutual fund

Standard deviation
The Russell Midcap Value Index evaluates the performance of mid-capitalized stocks within the universe of U.S. stocks. It consists of companies which are considered undervalues or whose potential has not been recognized (Russell Investments, 2011).

The Russell 2000 Index measures the performance of 2000 small- to mid-capitalization companies.

The S\&P 500 Index consists of 500 of the largest public companies. It was created in 1957 , and captures $75 \%$ of the US equity market. The S\&P 500 Index is a generally accepted indicator of overall market performance (Standard \& Poor's Financial Services LLC., 2011).

See Socially Responsible Investing.

Socially Responsible Investing “...integrates environmental, social and governance factors into investment decisions" (Social Investment Forum, 2010). Also known as Ethical Investing, Responsible Investing or Social Investing.

The outcome of the corporation's perceived responsibility to its internal and external stakeholders, and the society. This perceived responsibility manifests itself in actions designed to enhance the corporation's relationship with those stakeholders (Orlitzky and Swanson, 2008; Kletz, 2005). Also referred to as Corporate Social Performance (CSP).

Refers to the Social Performance-Financial Performance relationship.

See SRI mutual fund.

A mutual fund that applies SRI screening criteria to the selection of the assets comprising the portfolio.

The standard deviation of a fund or index measures the consistency of its returns. Its square is the variance, an indicator of fund volatility, or the risk embodied in the investment. 
Tracking error

Value stocks

Turnover ratio

Variance of returns

olatility of returns
The tracking error of a fund refers to the extent to which its returns diverge from those of its conventional benchmark. Tracking error is often the result of expenses, excessive cash holdings and broker commissions (Tergesen \& Young, 2004).

Value stocks are generally priced below their true value, namely the Net Present Value of future cash flow or dividends (DeFusco, McLeavey, Pinto, \& Runkle, 2007).

Defined by Morningstar as "...the percentage of the portfolio's holdings that have changed over the past year. A low turnover figure $(20 \%$ to $30 \%)$ would indicate a buy-and-hold strategy. High turnover (more than 100\%) would indicate an investment strategy involving considerable buying and selling of securities." (Morningstar, 2010).

The variance of returns is a measure of the stability of the returns of a fund. Its square root, the standard deviation, is a proxy for the volatility of returns.

The volatility of returns of a fund or index reflects the extent to which the returns deviate from their mean value. 


\section{LIST OF ABBREVIATIONS}

CRSP

Center for Research in Security Prices at the University of Chicago.

CSP

CSR

ESG

FP

NBER

SP

SP-FP

SRI

WRDS
Corporate Social Performance.

Corporate Social Responsibility.

Environmental, Social and Governance.

Financial Performance.

The National Bureau of Economic Research.

Social Performance.

Social Performance-Financial Performance.

Socially responsible investing.

Socially responsible investment(s).

Socially responsible investor.

Wharton Research Data Services at the University of Pennsylvania. 


\section{CHAPTER I}

\section{INTRODUCTION}

\section{Statement of the Problem}

\section{Socially Responsible Investing}

The origins of Socially Responsible Investing (SRI) lie in the abolitionist movement of the 1700s, in which British Methodists and Quakers avoided investing in companies that profited from the slave trade and war (Schueth, 2006). The earliest $20^{\text {th }}$ century SRI activities were based on religious and moral values, opposing gambling, tobacco, and firearms (Domini, 2001; Kinder \& Domini, 1997; Schueth, 2006), but this was before the development of modern financial institutions including mutual funds. Mutual funds were institutionalized in the United States with the Investment Company Act of 1940 that defined their conditions of operations, legal requirements, and financial requirements. In the USA, the earliest SRI funds, the Pax World Fund (PAXWX) and Dreyfus Third Century (DRTHX), started in the early 1970s in support of the anti-war movement, civil rights, and the anti-apartheid movement in South Africa. Activists of this period and into the 1980s were concerned with international and domestic social issues such as apartheid, the Vietnam War, civil rights, and consumer issues, and supported community development financial institutions. Funds emphasizing these issues were created in the 1980s, including the Parnassus Fund (PARNX), New Alternatives (NALFX), and Calvert Social Balanced Fund (CSIFX).

Modern SRI balances the goals of achieving adequate financial returns subject to the risk inherent in the portfolio, with corporate social performance. Given two portfolios 
of the same level of risk and returns, the socially responsible investor selects the portfolio whose constituent stocks meet the ethical, social, or religious criteria on which the fund is based, and which are stated in the fund's prospectus.

Some mutual funds base stock selection on an index that may be a general index such as the S\&P 500 or the Russell 1000, or may be an index customized for the fund. An SRI fund may use an index that conforms to its particular ethical, social, or religious criteria. In the early 1990s the first SRI indices were created - the Domini 400 and the Calvert Social Index. During the 1990s and the first decade of the $21^{\text {st }}$ century issues in corporate governance and sustainability have assumed greater prominence in the SRI movement. As the first decade of the $21^{\text {st }}$ Century nears its end, environmental, social, and governance (ESG) criteria have been used increasingly to define secular social performance criteria. New indices created since 2000 include the FTSE Responsible Investment Indices series and the Dow Jones Sustainability indices.

As SRI became increasingly secular in its goals and practices, investors motivated by religious ideals became available for recruitment into religious funds, and new funds were marketed to Catholics, Muslims, and other religious investors. Protestant funds included the Protestant Evangelical Timothy Plan (TPLNX), founded in 1994, and the Mennonite MMA Praxis family of funds, founded in 1999. Catholic mutual funds include the Ave Maria Catholic Values Fund (AVEMX), founded in 2001, and AHA Funds (now CNI) Socially Responsible Equity Fund (AHSRX), founded in 2005, both following the United States Conference of Catholic Bishops' Socially Responsible Investment Guidelines. The Islamic Amana Trust Income Fund (AMANX) and Growth Fund (AMAGX) were founded in 1986 and 1994 respectively. Islamic fund managers are 
guided by Islamic investment principles (Shanmugam \& Zahari, 2009). The Dow Jones World Islamic Index, introduced in 1999, was one of the first faith based indices developed by a major financial services company. Kinder, Lydenberg, Domini’s KLD Catholic Values 400 Index was introduced in 1998. Table 1 summarizes the history of the SRI movement. 
Table 1

History of the SRI Movement in the US.

\begin{tabular}{|c|c|c|c|}
\hline Era & Key Issues & Key Agencies & Associated Historical Events \\
\hline $\begin{array}{l}\text { Pre- } 20^{\text {th }} \text { century } \\
(1700 \mathrm{~s}-1800 \mathrm{~s})\end{array}$ & $\begin{array}{l}\text { - Slavery } \\
\text { - Wars }\end{array}$ & $\begin{array}{l}\text { - Methodist Church } \\
\text { - Quakers } \\
\text { - Anti-abolitionists }\end{array}$ & $\begin{array}{l}\text { - Abolition of slavery (1807-Great } \\
\text { Britain, 1808-US) } \\
\text { - American Independence (1776) }\end{array}$ \\
\hline $\begin{array}{l}\text { Early to mid } 20^{\text {th }} \\
\text { century }(1960 \mathrm{~s}- \\
1970 \mathrm{~s})\end{array}$ & $\begin{array}{l}\text { - } \text { Vietnam War } \\
\text { - Human rights } \\
\text { - Environment } \\
\text { Anti-apartheid } \\
\text { movement }\end{array}$ & $\begin{array}{l}\text { - Sweatshop debates } \\
\text { - Environmental Law Institute } \\
\text { - Interfaith Center for Corporate } \\
\text { Responsibility } \\
\text { - Amnesty International } \\
\text { - Transparency International } \\
\text { - Social Investment Forum }\end{array}$ & $\begin{array}{l}\text { - Investment Company Act (1940) } \\
\text { - Environmental Protection Agency } \\
\text { (1970) } \\
\text { - Earth Day (1970) } \\
\text { - Civil Rights Act (1964) } \\
\text { - Voting Rights Act (1965) } \\
\text { - Silent Spring by Rachel Carson } \\
\text { (1962) } \\
\text { - Gleneagles Agreement (1977) } \\
\text { - Sullivan Principles (1977) }\end{array}$ \\
\hline $\begin{array}{l}\text { Late } 20^{\text {th }} \\
\text { century-early } \\
21^{\text {st }} \text { century } \\
(1980 \mathrm{~s}-2010 \mathrm{~s})\end{array}$ & $\begin{array}{l}\text { - Corporate } \\
\text { Governance } \\
\text { - International } \\
\text { Banking } \\
\text { - Environment } \\
\text { - Human rights }\end{array}$ & $\begin{array}{l}\text { - The CFA Institute } \\
\text { - International Standards Organization-ISO } \\
\text { - G-10, Basel Committee on Banking } \\
\text { Supervision } \\
\text { - Environmental Law Institute } \\
\text { - UNEP Finance Initiative Asset } \\
\text { Management Working Group } \\
\text { - Social Investment Forum } \\
\text { - Save Darfur }\end{array}$ & $\begin{array}{l}\text { - Comprehensive Anti-Apartheid Act } \\
\text { - } 1986) \\
\text { - Sarbanes-Oxley }(2002) \\
\text { - Basel Accord }(1988,2004) \\
\text { United Nations Principles of } \\
\text { Responsible Investing-UNPRI } \\
\text { (2005) } \\
\text { - ISO/IEC } 17799(2005) \\
\text { - ISO/IEC } 27002(2007) \\
\text { - Volker Rule }(2010)\end{array}$ \\
\hline
\end{tabular}




\section{Mutual Funds}

A mutual fund is a form of pooled investing by individuals and institutions managed by a professional fund manager. One advantage of investing in a mutual fund is diversification, hence, reduced risk for the investor. Another advantage is that professional managers should presumably have greater expertise and more information sources than ordinary investors. A further advantage for SRI investors is that professional managers are legally bound to screen stocks to conform to the ethical, social, or religious criteria stated in the fund's prospectus. The Social Investment Forum (SIF) is a body of professionals, firms, institutions, and organizations that engage in and promote socially responsible investment practices (Social Investment Forum, 2010). This organization includes most, but not all, SRI funds registered with the SEC in the USA.

The conventional mutual fund includes stocks based on financial criteria, but the SRI fund uses financial criteria and ethical, social, or religious criteria. Stocks for the SRI fund may be negatively screened or positively screened. Negative screening filters out companies engaged in targeted activities defined as unacceptable such as tobacco or gambling. Positive screening includes companies that engage in targeted activities defined as desirable such as responsible environmental practices or positive employee relations.

\section{Religious Funds and the Vice Fund}

Religious funds are a particular subtype of SRI based on religious values. Religious funds use their own particular criteria based on tradition or authority. The fund may be based on an index of stocks such as the KLD Catholic Values 400 Index or the 
Dow Jones Islamic Index. The KLD Catholic Values 400 Index includes companies that conform to the teachings of the Catholic Church. The Index applies negative screens to (excludes) companies engaged in activities that breach the US Conference of Catholic Bishops' SRI Guidelines (KLD Research \& Analytics, Inc., 2010). Examples of such activities include abortion, contraceptives, and same sex relationships. The Dow Jones Islamic Index avoids companies engaged in activities not considered halal, or Shariahcompliant, that is, generally in keeping with the tenets of Islam. Gambling, alcohol, pork production and consumption, and income derived from interest are not acceptable, though certain products bearing a predetermined markup or interest rate are gaining acceptance under Islamic Investing principles (Shanmugam \& Zahari, 2009). There is a contrary point of view to SRI, epitomized by the Vice Fund, which had its inception in 2002. The philosophy that underlies this fund assumes that the very activities shunned by SRI investors are the ones that provide enduring economic value for investors. Hence, companies included derive earnings from tobacco, alcohol, gambling, and adult entertainment.

\section{The Performance of SRI Funds During Economic Expansions and Contractions}

The research question underlying the current study is: Has the business cycle affected the performance of socially responsible investments? Specifically, the current study explores the effect of the business cycle on SRI fund performance. The phases of the business cycle influence investor expectations of the level of economic activity and resulting corporate performance (Fama \& French, 1989). The dividend yield is defined as the ratio of corporate dividend payments per share to the share price. High dividend 
yields are associated with a contracting economy, while low dividend yields are associated with an expanding economy.

When the economy is expanding, the risk of loss of capital is lower, due to rising share prices. Expected returns are therefore lower. As the economy contracts and the expectation of loss increases, investors demand higher dividends to compensate for the additional risk (Fama \& French, 1989). The dividend yield is said to reflect the current phase of the business cycle (Fama \& French, 1989; Lynch, Wachter, \& Boudry, 2002). As the economy contracts and stock prices fall, dividends remain high relative to stock prices, resulting in high dividend yields.

Some previous studies have found a positive SP-FP relationship; others have found a negative SP-FP relationship, while others show no association. However, the periods for SP-FP studies have been chosen rather arbitrarily, without consideration of business cycle effects. Since the FP of mutual funds generally is affected by the business cycle (Kosowski, 2006), studies of SRI funds should include phase of the business cycle as a part of the analysis. Growth stocks were found to out-perform the market (have positive net excess returns compared to the market) in times of expanding markets and to underperform the market in times of market downturns (Kosowski, 2006). Since SRI funds and indices have more risk than their conventional counterparts, due to their limited universe, we might expect them to out-perform the market in times of economic expansion and to underperform the market in times of economic contraction (Fama \& French, 1989; Kosowski, 2006; Lynch et al., 2002; Moskowitz, 2000).

One measure of the performance of a mutual fund is its excess return. The excess return of the fund over that of the benchmark is the difference between the fund's return 
to the return of its benchmark, e.g., the S\&P 500. Another definition of the fund's excess return compares fund returns with the risk-free rate. The risk-free rate is an indicator of the risk-free alternative to the investment. Under both variations of its definition, the fund's excess return provides an indicator of the value added by the stock selection ability of the fund's manager. In the first instance, where the excess return is measured relative to a benchmark, the fund's return is compared with the benchmark. In the latter instance, where the excess return is measured relative to the risk-free rate, the fund's return is compared with that of the risk-free alternative. The net excess return is measured by the excess return, minus the administrative costs of the fund. The current study also considers the FP of several religious funds and the Vice Fund over several years. Since the religious funds and the Vice Fund all have relatively recent inception dates, the level of analysis that can be done at this time, taking into account business cycle phases, is limited. However, since very few studies have been done of these funds, this analysis may provide a useful basis for further discussion.

\section{Relevance of the Study}

The SRI industry grew from 55 funds with assets of \$12 billion in 1995 to 260 mutual funds with assets of $\$ 200$ billion in 2007 . In 2009 , approximately $11 \%$ of assets under management were invested in SRI funds (Social Investment Forum, 2010). From its early days as a movement supported largely by non-traditional investment houses, individuals, and a few institutional investors, the SRI movement now includes 70 financial services companies. Yet studies of the relationship between social performance and financial performance (SP-FP) have continued to yield mixed results, and the 
recently developed religious funds remain relatively unstudied. According to the Social Investment Forum, the largest SRI funds follow secular goals (Social Investment Forum, 2010). Consequently, religiously motivated investors had a need for funds conforming to their particular moral requirements. As a result, since the 1990s, religious funds have gained greater prominence as a means of allowing morally conservative investors to express their values through their investments (Timothy Partners, 2007). In addition, the study includes the recently concluded Great Recession, which was cited as the longest recession since World War II (National Bureau of Economic Research, 2010b).

Three SRI funds have received consistently high Lipper ratings. The Lipper Fund Awards recognize mutual funds in several categories based on the consistency with which they deliver returns. The Amana Growth (AMAGX) Fund and Ave Maria Growth Fund (AVEMX) won the Lipper Fund Awards in the Multi-Cap Core US Funds 3 year category, and the Multi-Cap Growth US Funds 3 and 5 year categories, respectively, in 2009 (Thomson Reuters, 2009; Thomson Reuters, 2010). The Calvert Long Term Income Fund A (CLDAX) retained the top spot in the 3 year Corporate Debt BBB US rated funds category in 2009 and 2010 (Thomson Reuters, 2009; Thomson Reuters, 2010).

\section{Lacunae in the Literature}

The study of SRI investing mirrors the SP-FP relationship experienced by corporations, and reflects some paradoxes in management thought and theory. On the one hand, strong corporate governance is said to have a positive influence on equity prices because it produces more efficient operations (Gompers, Ishii, \& Metrick, 2003; King \& Lenox, 2001). On the other hand, CSR activities unrelated to the company's core 
business may be wasteful of corporate resources and adversely affect the value of the firm (M. Friedman, 1970). Empirical studies of the FP - SP link have yielded mixed results (Margolis \& Walsh, 2001; Orlitzky, Schmidt, \& Rynes, 2003; UNEP Finance Initiative Asset Management Working Group, 2006; UNEP Finance Initiative Asset Management Working Group, 2007). Nevertheless, a majority of the studies support the presence of a modest but positive relationship between social and financial performance (Margolis \& Walsh, 2001; UNEP Finance Initiative Asset Management Working Group, 2007; Waddock \& Graves, 1997). An unexplored question is whether the difference in findings may be the result of the use of different time periods, whereas the level of economic activity depends on the current phase of the business cycle (Abramson \& Chung, 2000; Chong, Her, \& Phillips, 2006; Moskowitz, 1972).

Previous research compared secular SRI, religious, and vice funds with conventional benchmarks (Chong et al., 2006; Ghoul \& Karam, 2007; Girard, Rahman, \& Stone, 2007; Hoepner \& Zeume, 2009). Typically, research in SRI funds used data from the 1990s to early 2000s when the SRI industry experienced rapid growth. This period also coincided with a prolonged period of expansion of the US economy. Economic climate may have masked differences in performance. Failure to control for business cycle changes may have contributed to the inconclusive findings reported in these studies.

\section{Research Questions and Objectives}

The main question considered by this study is this: Has the business cycle affected the performance of socially responsible investments? Secondary questions are: 
To what extent does SRI investing add financial value which cannot be attributed to the market's performance? Does the orientation of the fund affect its performance? These questions give rise to the need to consider the factors influencing the performance of SRI funds and the extent to which different factors may influence fund performance over different phases of the business cycle. Specifically, the study evaluates the factors influencing the excess returns on SRI funds and the effect of religious screening. Table 2 summarizes the research questions and objectives of the study.

Table 2

Research Questions and Objectives.

Research Questions

1. Has the business cycle affected the performance of socially responsible investments? What factors govern the performance of socially responsible mutual funds during the expansion and contraction phases of the business cycle?

2. Does SRI investing add to, or detract from value during the expansion and contraction phases of the business cycle?

3. Does the orientation of the fund affect its performance?

(a) Do religious funds perform differently from secular SRI funds, across phases of the business cycle?

(b) How do religious funds compare to the Vice Fund across phases of the business cycle?

(c) How do secular funds compare to the Vice Fund across phases of the business cycle?
Objective

To compare the factors influencing the performance of selected SRI funds over phases of the business cycle. Did they perform differently during expansion and contraction phases of the business cycles identified between April 1991 and June 2009 ?

Do SRI screens add value during expansion and contraction phases of the business cycles identified between April 1991 and June 2009?

To compare the performance of religious funds with that of secular SRI funds, and that of the Vice Fund over phases of the business cycle, and that of secular SRI funds with the Vice Fund. Did the funds perform differently during expansion and contraction phases of the business cycles identified between April 1991 and June 2009 ? 


\section{Contributions of the Study}

The current study extends the work of Kosowski (Kosowski, 2006) and Lynch, Wachter and Boudry (Lynch et al., 2002), which evaluate the performance of mutual funds in general during phases of the business cycle, with no special consideration of SRI or religious funds. The study's relevance is highlighted by concerns arising from ethically questionable corporate practices arising in the late 1990s to 2000s, concerns on "Main Street" regarding corporate excesses and high unemployment in the aftermath of the Great Recession, and the historical growth of SRI mutual funds as an investment vehicle for the socially conscious investor. A key contribution of the study is the identification of a business cycle effect on the performance of selected SRI equity mutual funds. Since previous studies of the SP-FP relationship have not included the business cycle effect, the current study bridges this gap in the literature and may help explain the mixed findings of previous research. The business cycle effect is most relevant in light of the Great Recession that ended in June 2009 (National Bureau of Economic Research, 2010a). The Great Recession is said to be the longest US recession since World War II (National Bureau of Economic Research, 2010b).

A search of the literature revealed that several studies of the value of social investing were conducted during a lengthy period of economic expansion in the 1990s when a number of SRI funds had their inception, and several years of exceeding the performance of their benchmarks. Only Hemley, Morris and Gilde (2005) controlled for business cycle phase, which included only a brief period of economic contraction during the early 2000s. A search of the literature identified no studies of the performance of SRI funds during periods of severe economic decline. The current study includes two 
complete business cycles. When the economy is weak, the expected return on stocks and equity mutual funds is higher than when the economy is strong (Fama \& French, 1989). Investors become more cautious, moving away from equities to bonds and cash. Siegel identifies returns that may be attributable to the market and that which is attributable to the skill of the manager (Siegel, 2009).

The current study submits that SRI screening is an outcome of the SRI fund management process, which result in returns that can be attributed to management skill. If CSP results in superior financial performance, then SRI screening filters out inefficient companies, hence SRI mutual funds will generate superior returns compared to the market. However, if CSP diverts corporate resources away from the fulfillment of the corporate mission and erodes profitability, then SRI mutual funds will under-perform the market. Since 1990, the NBER has announced two complete business cycles (National Bureau of Economic Research, 2010a). The research will identify periods of expansion and contraction of the business cycles from April 1991 to June 2009, analyzing the components listed above to see if the performance of SRI equity mutual funds is influenced by the same or different factors in contracting or expanding market phases.

The returns of conventional stock and bond markets and conventional mutual funds are affected by the current phase of the business cycle through information extracted from the dividend yield (Fama \& French, 1989; Kosowski, 2006; Lynch et al., 2002). As the economy contracts and stock prices fall, the dividend yield increases relative to dividend payments. In addition, falling stock prices mean greater risk of loss. Higher returns are required to compensate for the increase in risk. If high social performance is associated with superior financial performance, then the SRI fund yields 
superior returns compared to the market. The benefits of SRI investing arise from the manager's stock selection ability, following the application of social screens.. This study anticipates that when the economy is weak SRI funds should out-perform the market. The performance of a mutual fund is generally compared to a benchmark specified in its prospectus. However, for SRI funds, the screening, monitoring, and general fund administration processes increase the cost of managing the fund. The current research contributes to the literature by analyzing the factors influencing the net excess return on the SRI investment over the phases of the business cycle.

The current study extends the work of previous scholars (Kosowski, 2006; Lynch et al., 2002), which evaluated the performance of mutual funds in general, during phases of the business cycle. The study also extends previous work comparing the performance of secular SRI funds with religious funds and the Vice Fund (Chong et al., 2006; Fabozzi, Ma, \& Oliphant, 2008; Hemley et al., 2005; Hoepner \& Zeume, 2009; Kurtz \& diBartolmeo, 2005; Naber, 2001; Shank, Manullang, \& Hill, 2005), which produced mixed findings. This comparison permits the identification of the relative value added by the criteria of SRI screens and the value added by giving preference to the "sin" stocks usually excluded from SRI funds. Previous studies of SRI fund performance omitted controls for fund characteristics such as size and style (McWilliams \& Siegel, 1997). The current study refines previous approaches to the study of SRI fund performance by including controls for style (Bauer, Koedijk, \& Otten, 2005), expenses (Wermers, 2000), fund objective (Kosowski, 2006; Lynch et al., 2002), and the size of the fund (Clark, 2004; Lipper, 2003). Factor based models of financial returns can be enhanced by 
controlling for these potentially confounding variables (DeFusco, McLeavey, Pinto, \& Runkle, 2007).

\section{Summary}

The study identifies the extent to which the application of SRI criteria provides value attributable to social performance in selected US based SRI equity mutual funds over multiple business cycles between 1991 to 2009. In other words, this study considers the effect of the business cycle on SRI fund returns over two complete business cycles beginning in 1991 through the end of the Great Recession in June 2009. The study is especially relevant given the recently concluded deep and prolonged US recession, which began in December 2008 and ended in June 2009. The study's importance is highlighted by the need to explore the effect of changes in the business cycle on the factors governing the performance of SRI equity mutual funds under different economic conditions. The study applies the Carhart four-factor model (Carhart, 1997) as the framework for the analysis. Carhart identifies market and financial factors that influence excess returns. The study includes controls for fund characteristics such as style, objective, expenses, and size. Finally, the study compares the effect of conventional SRI screening with specific screening for religious criteria and with a portfolio created to endorse "vice", and compares their performance over multiple business cycles. 


\section{CHAPTER II}

\section{LITERATURE REVIEW}

This chapter establishes the basis for the proposed research by exploring the link between social performance (SP) and financial performance (FP) and the effect of business cycle on fund performance. Financial performance is an important criterion in

the selection of assets for inclusion in an investment portfolio for both conventional and SRI investors. However, in SRI investing, the investment must be profitable while meeting social criteria that vary by fund, but must be stated in the fund's prospectus. Numerous empirical studies have considered the SP-FP relationship. Of twenty articles reviewed in a study commissioned by the UNPRI (UNEP Finance Initiative Asset Management Working Group, 2007), ten found a positive SP-FP relationship, seven found either a neutral or indeterminate relationships, and three found a negative SP-FP relationship. Similar mixed results were identified in surveys of the academic literature (Margolis \& Walsh, 2001; Orlitzky et al., 2003; Wood \& Jones, 1995).

Some reasons for the mixed results between SP and FP may lie in the different methodologies used such as the estimation of a linear rather than curvilinear or S shaped relationship (Chong et al., 2006), the economic climate during the period under study, the stages of the business cycle during which the events occurred (Abramson \& Chung, 2000; Chong et al., 2006), and study design issues, (e.g. the absence of appropriate control variables). This study extends existing research by considering business cycle effects, and comparing secular funds, religious funds, and a "vice" fund. 


\section{SRI Mutual Funds: Rationale and Organization}

This section discusses the way SRI investment works. The capital market serves as the means of satisfying the demand for investible funds by companies in need of capital. The capital market also serves as an outlet for surplus funds generated by individuals and institutional investors. The SRI investor is defined as one whose decision to acquire a company's shares was influenced by perceptions of CSP, and whose investment decision takes into account a company's SP and FP, rather than taking into account only the FP (Williams, 2005a; Williams, 2005b). The SRI investor acquires a financial interest (Social Investment Forum, 2010; UNEP Finance Initiative Asset Management Working Group, 2009) directly by buying stock in a company, or alternatively as part of a mutual fund, pooling resources with likeminded investors. The second approach can provide a platform for engaging the company in dialogue to adhere to desirable environmental social and governance criteria (Domini, 2001; Social Investment Forum, 2010; UNEP Finance Initiative Asset Management Working Group, 2009) and permits diversification, generally considered advantageous in attaining financial goals. The current study focuses on SRI equity mutual funds consisting of stocks that meet SRI criteria. Investors in those funds may be individuals or institutions. Table 3 highlights the four options for SRI screened investments based on the form of the investment and the type of investor. This study focuses on pooled investments by individuals and institutions in the form of equity mutual funds. 
Table 3

SRI Screened Investments.

\begin{tabular}{lcc}
\multicolumn{1}{c}{ Type of Investor } & Type of Investment & \multicolumn{1}{c}{ Pooled investment } \\
\hline Individual & $\begin{array}{l}\text { Investment by an individual in } \\
\text { an entity with a high SP rating. }\end{array}$ & $\begin{array}{l}\text { Investment by an individual } \\
\text { in an SRI fund. }\end{array}$ \\
Institutional & $\begin{array}{l}\text { Investment by an institution in } \\
\text { an entity with a high SP rating. }\end{array}$ & $\begin{array}{l}\text { Investment by an institution } \\
\text { in an SRI fund. }\end{array}$
\end{tabular}

The SRI fund's performance may be compared to a benchmark, which serves as a barometer of the fund's performance. A popular benchmark is the Standard and Poor 500 (S\&P 500) Index, consisting of a basket of 500 of the largest listed companies listed on the New York Stock Exchange (NYSE) and NASDAQ. The S\&P 500 is a subset of the universe of all stocks available in the USA. Each company is assigned a weight in the index based on its market capitalization. The constituents of the index also represent different sectors of the economy. Each sector is assigned a weighting based on its representation in the market overall. The S\&P 500 and other major US stock market indices are measures of the stock market's performance and are bellwethers of the US economy (The Conference Board, 2010).

In theory, capital markets serve as a capital-rationing device, separating the investor from the company. This is defined by the Fisher separation theorem, in which the investor's wealth is maximized without regard for individual preferences. According to the Fisher separation theorem, the financial intermediation process separates the investor from the act of investing (I. Fisher, 1954). Traditional portfolio theory assumes 
construction of a portfolio based on a risk-return trade-off, the dimensions of asset allocation being purely financial. SRI investing takes place under conditions where the Fisher separation theorem is partly invalidated as the fund manager aims to follow an investment allocation process representing the ethical or social criteria of the fund. In addition, higher costs may be associated with initial screening for ethical or social criteria and the subsequent monitoring of the portfolio. These costs are part of the financial intermediation process (Copeland \& Weston, 1988).

Some arguments in favor of a positive relationship between SP and FP are based on the rationing of capital (Heinkel, Kraus, \& Zechner, 2001; Sauer, 1997). One basis for the argument is that SP effectively reduces the company's financial risk through more efficient practices which improve profitability (Bauer \& Hann, 2010; Dowell, Hart, \& Yeung, 2000; Repetto \& Austin, 2000). For example, firms that engage in actions that have a negative effect on the environment, experience the negative consequences of poor SP through higher legal costs and a poor public image, resulting in the diversion of capital away from such companies toward firms that engage in sound environmental practices (Heinkel et al., 2001; Sauer, 1997). In particular, companies whose practices protect the environment are said to have low financial risk and to benefit from lower interest rates (Bauer \& Hann, 2010).

Another rationale for a positive SP-FP relationship assumes that social performance is simply another form of efficient operations and production management, whose adoption should result in improved FP (Bauer, Derwall, Guenster, \& Koedijk, 2006; Dowell et al., 2000; Repetto \& Austin, 2000). Disclosures of risks linked to SRI criteria facilitate the delivery of superior returns by the fund manager (Bauer et al., 2006; 
S. Lydenberg, 2005). Companies that value social performance may have lower overall risk, and may deliver superior performance (Bauer \& Hann, 2010; Williams, 2009). Factors contributing to this reduced risk may include better employee relations and morale, fewer lawsuits, and higher quality products. From this perspective, SP serves as a proxy for general management competence.

Theories of SRI accept the inclusion of a third dimension, 'affect', in the investment decision process (Statman, 2008; Statman, Fisher, \& Anginer, 2008), or the social utility of investing. In other words, SRI investors receive psychological or social benefits from investing in "good" companies. Some theorists contend that the social utility of investing is independent of demographics and lifestyle choices (Williams, 2005b), while others assert a close relationship of investment preference with demographics and values (Ray \& Anderson, 2000). Consequently, some SRI investors may derive sufficient compensatory benefit from SRI so that the FP-SP relationship is not a priority. Other SRI investors assume or hope to find a positive SP-FP relationship.

The screening process applies the SP and FP criteria to identify stocks to be included in the SRI portfolio. Screening is responsible for the social utility of SRI investing. There are two types of screens: positive screens and negative screens. Positive screens include companies that meet desired SRI criteria in the dimensions specified in the fund prospectus. Negative screens exclude companies that engage in undesirable actions such as alcohol, tobacco, pornography, or weapons production. Both positive and negative screens restrict opportunities for diversification (Statman, 2007; Stone, Guerard, Gulteki, \& Adams, 2001), hence might increase portfolio risk and potentially erode performance because of the relatively fewer opportunities for diversification (Renneboog, 
2008). Screens increase fund management costs because of the need for greater diligence needed to identify areas of non-compliance. However, screens may also remove from consideration companies engaging in inefficient practices and result in reduced risk and improved fund performance (Edmans, 2009).Typical secular SRI screening is based on acceptable ratings on environmental, governance, and social criteria. Religious funds apply criteria based on the religious values of the fund.

By avoiding non-compliant firms, investors divert capital toward compliant firms. This exclusion could, in theory, ration capital by lowering the market value of the offending firms and raising their cost of capital. Higher capital costs erode FP. However, a certain minimum amount of SRI investing would be needed to influence capital rationing among firms (Heinkel et al., 2001; Sauer, 1997). A complementary approach would be for legislative or regulatory bodies to act in concert to require social performance reporting as external stakeholders (Freeman, 1984; Kletz, 2005). The reputational effect on companies of SRI funds acting in concert has the potential to affect corporate FP (Heinkel et al., 2001). Similarly, consumer boycotts can affect the company's profits (Gardberg \& Newburry, 2010). Employee well-being, a common SRI dimension for screening, has been found to be positively related to shareholder wealth (Edmans, 2009).

The factors associated with the performance of SRI equity mutual funds also include many elements common to all mutual funds, e.g., the imperfection of the match between the benchmark index and the fund portfolio and the impact of cash inflows and outflows under different market conditions. However, SRI funds have added costs not found in other mutual funds. The cost of the management service, or contracted expense 
ratio, includes the cost of screening and monitoring actions that deliver and maintain the characteristics of the SRI fund (Copeland \& Weston, 1988; Holmstrom \& Milgrom, 1987; Lambert, 2001), and the cost of administering the fund. Screening costs include those of doing research to rate companies on the ethical and social criteria or contracting this research and the cost of dialogue with companies about ethical or social issues to a third party. Administrative costs common to all mutual funds include transactions costs (brokerage fees), legal fees, marketing expenses, and general administration. Insofar as financial returns are important to the investor, the manager's performance is evaluated based on the outcome of stock selection skills and the returns generated by the investment. Insofar as SRI is important, the fund's representation of desired ethical or social causes, the reputation of the fund's personnel, and the ability to articulate the underlying ethical values of the fund, may affect the investors' judgment of the manager's performance and deliver value apart from financial returns. One consequence is that investors in SRI funds may be more loyal than other investors (Bollen, 2007), generally resulting in smaller transactions costs.

The current study also highlights religious funds and a vice fund, fund types based on opposing views of morality. Religious funds rely on a combination of positive and negative screens to ensure compliance with a religious value system, while a vice fund includes stocks of companies based on vice or "sin" activities such as alcohol, gambling, and tobacco. Secular funds that came to dominate the SRI industry in the 1990s are not linked to a particular religious or moral value system. Subsequently, specialized SRI funds such as religious funds developed, applying either negative or positive screens, or both, to identify investments consistent with a belief system. Religious funds include 
those that support Protestant, Catholic, and Islamic religious values. Religious funds have been found to exhibit greater stability of flows (loyalty of investors) than non-religious SRI funds, probably because of the holders' commitment to the religious values underlying the funds rather than to financial returns (Peifer, 2010; Statman, 2005). The stocks of companies that derive significant income from or endorse the use of alcohol, tobacco, gambling, and adult entertainment are generally excluded by religious funds. Catholic funds avoid entities that support or benefit from activities that derive their income from abortion and avoid investing in companies that provide benefits for samesex partners. Islamic funds avoid investing in traditional Western financial lending institutions because a significant portion of income is derived from interest. They also avoid companies involved in the production and consumption of pork and alcohol.

However, the findings surrounding the returns of religious funds are mixed. One early study found there were no significant differences between the risk-adjusted performance of Catholic funds and unscreened funds, since a portfolio of companies screened for Catholic values yielded lower levels of nominal risk (and returns) than their unscreened counterparts (Naber, 2001). According to Naber, where screening is based on more filters, as obtains with Catholic and Islamic funds compared to secular SRI funds, this increased screening is rewarded by risk-adjusted returns that compare favorably with unscreened mutual funds. Similarly, in the 2000s, Dow Jones Islamic Indexes outperformed their conventional counterparts (Eye of Dubai, 2010). A comparison of the merits of religious and secular SRI screens revealed that religious funds offer fewer opportunities for diversification than a secular SRI fund (Ghoul \& Karam, 2007; 
Renneboog, Ter Horst, \& Zhang, 2006). Another study found that religious funds in general underperformed their secular SRI and conventional counterparts (Peifer, 2010).

Vice or "sin" investing represents a contrary perspective to SRI, especially religious investing (Hoepner \& Zeume, 2009). A portfolio invested in vice or "sin" applies positive screening to include companies engaging in vice, such as gambling, alcohol, tobacco, and adult entertainment. When compared to a portfolio invested in Catholic stocks, a "sin" portfolio reported higher risk-adjusted returns (Hemley et al., 2005; Naber, 2001). A portfolio invested in vice industries appeared more stable than its conventional benchmark (Hemley et al., 2005). However, studies comparing portfolios built on vice and SRI found that a portfolio built on vice did not out-perform the Domini Social Equity Fund (Hoepner \& Zeume, 2009) or the S\&P 500 (Fabozzi et al., 2008; Hemley et al., 2005; Hoepner \& Zeume, 2009; Shank et al., 2005). A study of bull and bear markets during the period 1990-2002 concluded that the Vice Fund exhibited less risk than the S\&P 500 (Hemley et al., 2005); hence lower returns would be consistent. However, research on "sin" industries and the Vice Fund is very limited.

\section{Business Cycles and SRI}

The expected excess return on an investment (compared to the risk free alternative) is linked to the business cycle troughs and peaks based on the expected availability of opportunities after a turning point (Fama \& French, 1989). In summary, expected excess returns move in opposition to the expected level of economic activity. The dividend yield represents the risk of loss of the equity investment, and, along with other publicly available information such as bond rates, is used to track the business cycle 
(Ferson \& Schadt, 1996; Lynch et al., 2002). The rates on bonds and treasury bills represent the expected return on an alternate (fixed income) investment. Dividend yields, also known as yields, represent the income stream component of expected return on the equity mutual fund. The yield on a stock is represented by the ratio of its dividend stream to its price. Yields are said to be at their lowest near and just after a business peak, due to rising equity prices (the denominator component of the yield). As the economy contracts and the economic downturn progresses, fewer anticipated opportunities for investments result in lower expected/excess returns (Fama \& French, 1989). When economic activity is at its lowest, during the trough of the cycle and shortly thereafter, investor expectations are revised upward in anticipation of improved conditions. This is the result of rising dividend yields due to falling prices. An alternative explanation offered by Fama and French is that the dividend yield is a proxy for investment risk (p. 43). As the economy expands, there is less risk of loss, hence more opportunity for investments. Under the conventional risk-return tradeoff, the expanding economy is associated with lower returns. As the economy contracts, there is greater risk of loss, because there are fewer investment opportunities. The contracting economy therefore attracts higher expected returns to compensate for the higher risk.

Style encompasses a fund's objectives and the strategy used to achieve the objective. A mutual fund assumes the characteristic of the stocks that comprise the majority of its portfolio. Mutual fund objectives as defined by Lipper are categorized as growth or value objectives. Fund investment strategies are based on the selection of large or small capitalization companies. A mutual fund invested in growth stocks anticipates strong capital appreciation. SRI funds having growth objectives (growth funds) acquire 
stocks that report consistently strong growth in profits. Large, stable companies are likely to be associated with long-term stability. A fund based on value objectives identifies stocks that are undervalued, that is, they are priced below their true value. Value is based on the net present value of discounted cash flows. Ideally, value and price should be equivalent. Small companies undergoing successful expansion may exhibit strong earnings growth and may be under-valued. However, the risk associated with small companies is likely to be higher than that of a large stable company with a solid earnings record. Smaller companies may be more vulnerable to an economic downturn due to an inadequacy of accumulated earnings and financial capital. A larger company with a long history of success, adequate accumulated earnings, a solid capital base, and a product line that is recession resistant is less vulnerable to an economic downturn than a company with a weaker capital base and less capital reserves, and whose product line is vulnerable to changes in demand.

Excess returns on mutual funds with value objectives improve in times of economic downturn, while growth funds perform better in times of high economic growth (Lynch et al., 2002). When the economy is expanding, the expected return on stocks (and equity mutual funds) is higher as the market's peak approaches. As the expected return increases, so does the risk of loss. However, in times of economic recession, the rational investor adopts a more conservative stance, preferring to hold interest bearing assets, rather than equities (Kosowski, 2006; Lynch et al., 2002; Siegel, 2009). As a result, in times of economic recession, fund volatility increases across all investment styles (Kosowski, 2006). It is therefore reasonable to expect that, during economic contractions, the fund manager's skills, especially market timing and 
forecasting, are especially required to maintain returns that closely track or exceed that of the fund's benchmark (Henriksson \& Merton, 1981; Kosowski, 2006; Siegel, 2009), as the risk of loss may be significant (Berry, 2009).

Wealth preservation assumes more importance than growth during a recession, as market timing and forecasting skills are of greater importance than during an expansion. Jensen's alpha of mutual funds is observed to be significantly higher in times of economic downturn than in times of economic expansion (Kosowski, 2006). Jensen's alpha measures the contribution to the excess return of an asset, in this case, an SRI fund, that is attributable to the manager's skill. This component of excess return (Jensen's alpha) is different from the excess return, which is earned by the asset because of the market's performance (Siegel, 2009). The component of the fund's excess return, which is due to the market is known as beta. According to Kosowski, in times of economic expansion, mutual funds tend to underperform their benchmarks. Actively managed mutual funds generally deliver lower net returns than indexed funds due to higher transactions costs and higher management expenses associated with active trading (Dolan, 2010; Wermers, 2000). Consequently, during an economic recession, superior excess returns may be eroded by transactions costs (Moskowitz, 2000).

Market returns are especially volatile just before and after turning points in the business cycle as the market adjusts to changing conditions. At such times, rebalancing reduces the relative risk of the portfolio, so that the fund's beta becomes more aligned with that of the market (Ferson \& Schadt, 1996). However, rebalancing necessarily involves transaction costs, as do redemptions that result from investors making withdrawals. 


\section{Summary}

The mixed findings surrounding the SP-FP relationship identified in the literature may disguise the presence of a business cycle effect. SRI reflects the securitization of the SP-FP relationship, as corporate social performance criteria are used to screen investments held by SRI funds. The literature identifies contrasting views of the value of SP -- as a capital-rationing device that encourages corporate efficiency, or a diversion of corporate resources from their primary purpose of creating shareholder value. SRI adds a third dimension to the conventional risk-return trade-off, which is affect, or the utility of investing in a vehicle whose underlying company's values are consistent with the investor's personal beliefs. Social performance screening adds to the cost of managing an SRI fund, but this cost may add value to the SRI investment process.

The current research evaluates the performance of socially responsible equity mutual funds with different social performance criteria. The funds studied are religious funds and secular funds. Their performance is compared with the Vice Fund, the contrary perspective of socially responsible investing. Business cycle effects are identified ex ante by the dividend yield. Investor expectations adjust themselves as the business cycle transitions from one phase to another. The current research extends the literature on SRI mutual funds by evaluating the effect of changes in the business cycle on their performance. 


\section{CHAPTER III}

\section{CONCEPTUAL MODEL}

This chapter outlines the conceptual model underlying the study and the associated measurement model. The overall research question is: Does the performance of SRI funds vary across phases of the business cycle? The conceptual model explores the relationship between changes in the business cycle and the performance of a hypothetical, unit-weighted portfolio of SRI mutual funds. The goal is to determine the effect of changes in the business cycle on SRI portfolio risk and return. The conceptual model assumes that the investor experiences a tradeoff between financial returns and risk, subject to corporate social performance. The measurement model discusses the variables or indicators used to measure the constructs identified in the conceptual model. The measurement model includes two indicators of fund performance - excess returns and volatility.

\section{SRI Investment Performance and the Business Cycle}

The mixed findings on the SP-FP relationship offer support to contrasting views of the SP-FP relationship. On the one hand, if SP is viewed as a strategy designed to minimize operational risk, it can be theoretically linked to higher profitability, and hence higher actual returns (King \& Lenox, 2001). This is in keeping with findings supporting a positive SP-FP relationship (M. Moskowitz, 1972; Porter, 2006; Statman, 2007; Waddock \& Graves, 1997). The stocks of companies that have a high rating in corporate governance have demonstrated superior returns (Gompers et al., 2003). On the other hand, if SP is viewed as an unwarranted cost to the firm, it can be theoretically linked to 
lower profitability, and hence lower actual returns on the underlying stock. This viewpoint of the negative SP-FP relationship arises from the view that SP carried out for purely ideological reasons does not contribute to corporate efficiency but rather expends valuable resources on activities that do not improve shareholder wealth (Entine, 2007; M. Friedman, 1970). Yet another perspective is proposed by McGuire, Sundgren and Schneeweis (1988) who argue that corporate social performance is related to prior financial performance. This would suggest that corporate social performance is funded by prior year earnings, therefore is preceded by financial performance. The majority of studies of the SP-FP relationship used data from the 1990s, a period of economic expansion in the US which coincided with the growth of the SRI industry (Margolis \& Walsh, 2001; UNEP Finance Initiative Asset Management Working Group, 2007). The period of study included few periods of economic contraction. As such, a generally positive linear trend could be extracted from SRI fund performance metrics. The Great Recession of January 2008 to June 2009, which lasted for 18 months, presents an invaluable opportunity to evaluate the performance of SRI equity mutual funds during a period of relatively prolonged economic downturn. Since studies of conventional mutual funds indicate the presence of a business cycle effect (Kosowski, 2006; Lynch et al., 2002), the current study hypothesizes that there should also be a business cycle effect for SRI mutual funds.

Business cycles consist of an expansion phase and a contraction phase. The expansion phase is characterized by increasing levels of economic activity. After attaining a 'peak', the economy begins to contract. This phase is known as the contraction phase. The contraction phase is characterized by diminishing levels of economic activity, 
and culminates in a 'trough'. During the trough, economic activity is at its lowest overall level. After a trough, the expansion phase re-commences. The movement from one phase to another is known as a turning point. A business cycle has two turning points - a peak and a trough. The peak occurs where economic activity is at its highest, while the trough occurs where economic activity is at its lowest. Both expansion and contraction may take place slowly or rapidly. As a limitation of previous studies is the exclusion of a business cycle effect, the current study posits that the inclusion of a business cycle effect will yield more realistic results (Abramson \& Chung, 2000; Chong et al., 2006).

Figure 1 summarizes the conceptual model and its underlying hypotheses. Hypotheses 1 and 2 test hypotheses about the effect of business cycle expansion and contraction phases on the performance of SRI equity mutual funds in general. Hypothesis 1(a), 1(b), 1(c), and 1(d) evaluate the factors influencing the excess return of SRI funds over expansion and contraction cycle phases. Hypotheses 2(a) and 2(b) evaluate the value added by the stock selection process to SRI fund excess returns over the expansion and contraction phases of the business cycle. Hypotheses 3(a), (b), and (c) compare the performance of secular funds, religious funds, and the Vice Fund over expansion and contraction phases of the business cycle. 


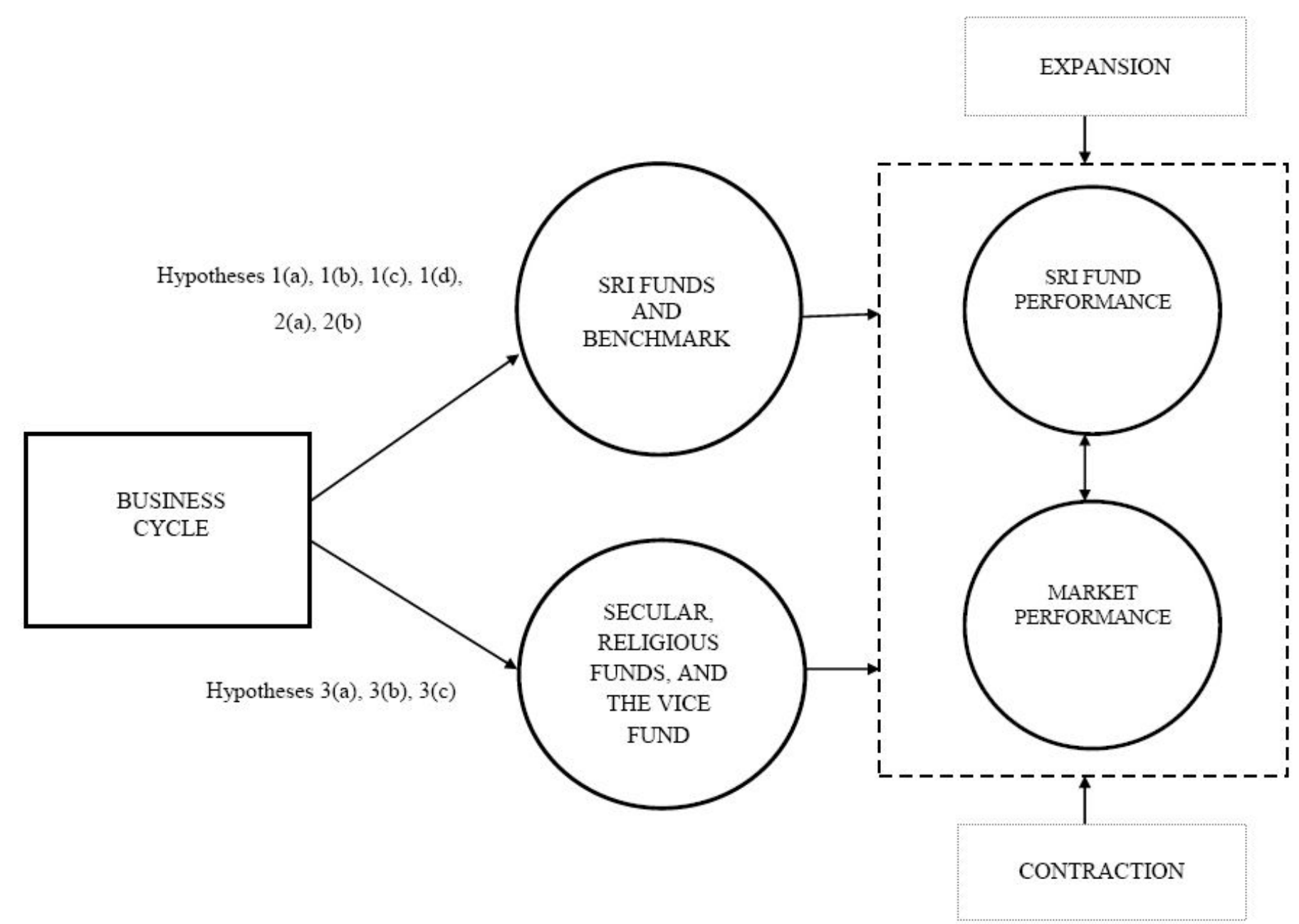

BUSINESS CYCLE EFFECT

OUTCOMES

Figure 1. Conceptual Model of the Effect of the business cycle on SRI equity mutual funds. 


\section{SRI Equity Mutual Funds and Benchmark Returns}

This section offers a theoretical discussion of the returns on SRI equity mutual funds and the market, and the proposed hypotheses underlying the research. An SRI equity mutual fund is a pooled fund composed of stock in companies meeting SRI criteria. The equity mutual fund incurs management fees, transactions costs, deferred expenses, and other components that influence overall returns. The current study submits that an SRI equity mutual fund may or may not incorporate less risk than the market. Arguments in favor of higher risk may be based on the restricted universe of holdings available to SRI funds and the smaller capitalization of the constituents of the fund. Many SRI portfolios are weighted toward smaller capitalization companies, or companies engaged in technology or research and development $(R \& D)$ activities, such as green investing (Bauer et al., 2005; Maginn, Tuttle, Pinto, \& McLeavey, 2007). Smaller companies, by virtue of their size, are likely to be more risky than larger companies. R \& $\mathrm{D}$ activities are themselves risky ventures.

The arguments for lower risk include the lower operational risk and efficiencies of good management, fewer lawsuits, more satisfied employees, and satisfied stakeholders (Gardberg \& Newburry, 2010; Lydenberg, 2009; Lydenberg \& Paul, 1997; Stone et al., 2001). Regardless of size and industry, efficient business practices result in reduced corporate risk (Hickman, Teets, \& Kohls, 1999). These efficiencies may be the direct result of best practices, or they may be achieved indirectly by the avoidance of negative publicity due to boycotts, lawsuits or other adverse events. From the investment perspective, the additional screening of SRI portfolios may identify companies with 
lower operational risk (Hickman et al., 1999; Statman, 2006) because of their more efficient practices or better management.

The volatility of fund returns is affected by the phases of the business cycle (Fama \& French, 1989; Hamilton \& Lin, 1996). However, according to Hamilton and Lin, this effect tends to lag. The lag period may vary depending on whether the economy is expanding or contracting. Hamilton and Lin argue that a recession results in ten times more volatility than an economic expansion (Hamilton \& Lin, 1996). The current study submits that the excess returns of the SRI fund will exceed that of the market in times of economic expansion, but, in times of economic decline, the SRI fund will not differ significantly from its conventional benchmark, as the SRI fund manager's investment strategy balances corporate SP and FP criteria. As the screening process is likely to identify companies for which SP is part of a long-term corporate strategy, SP is unlikely to decrease because of a downturn in the economy. Generally, the SRI investor is thought to acquire an investment anticipating returns that are at least equivalent to conventional investments (Krumsiek, 1997). The current study submits that the long-term effect of SRI screening on an SRI fund may offset the adverse effects of an economic contraction on the volatility of mutual fund returns and produce less negative returns than the market. The current study also submits that the effect of market and financial factors will differ during times of economic expansion and contraction.

\section{Hypotheses}

In order to carry out this analysis, the current study applies Carhart's (1997) fourfactor model, an extension of the Fama-French three-factor model (1993; 1996). The 
Fama-French component of Carhart's model proposes that a fund's excess returns are influenced by the excess returns of the market over the risk-free alternative, the risk factors associated with the differential in returns on a portfolio comprised of small versus large capitalization stocks, and the differential in returns on a portfolio comprised of high versus low book-to-market value stocks. Fama and French describe the differential in returns between small and large capitalization stocks as the portfolio risk factor associated with company size. The differential in returns between high versus low bookto-market value stocks is a proxy for the portfolio risk factor associated with the acquisition of under-valued and over-valued stocks. A stock with a high book-to-market

value is under-valued, while a fully priced or over-valued stock has a unit or low book-tomarket value. The value of the fund is the net present value of future cash flows of the companies whose stocks comprise the portfolio. Carhart's fourth factor is momentum, an indicator of the persistence or consistency of returns. This factor was first identified by Jegadeesh and Titman (1993), and is defined as the short term and long term fluctuations in returns commonly attributed to investors' initial over-reaction to corporate information.

\section{Hypothesis 1}

The current study proposes that different factors influence the excess returns of SRI funds during periods of economic expansion and economic contraction. The business cycle is anticipated to have an effect on the excess returns of the hypothetical SRI portfolio and its benchmark. The current study uses the S\&P 500 Index as a conventional benchmark because it is the most widely used measure of overall market performance. 
The SRI fund could be compared to a SRI index, but since the current study emphasizes the market in general, the conventional index is used. The usual indicator of market conditions is the difference between the performance of the stock market and the risk-free rate of return. The relevant measure of the market can be a conventional stock market index such as the S\&P 500 or the Dow Jones Industrial Average, or a socially responsible index such as the Calvert Social Index or the Domini 400 Social Index. The risk-free rate of return represents the rate of interest associated with the least risky alternative to stocks, usually the 3-month Treasury Bill rate.

The influence of the market excess return over the risk-free rate is measured by the beta coefficient, defined as the sensitivity of the returns of the hypothetical SRI portfolio to changes in the market (DeFusco et al., 2007). According to modern portfolio theory, diversification results in an efficient portfolio, one that attains the highest possible level of returns for a given level of risk (Markowitz, 1952). SRI funds are based on a smaller universe of stocks than a conventional portfolio, and would be considered more risky than a fully diversified portfolio. With a smaller universe and theoretically more volatile characteristic, the covariance between the returns on the hypothetical SRI portfolio and that of the market will exceed unity. As a result, the excess returns on the hypothetical portfolio over the risk-free rate will surpass that of the market during expansion/peaks, while the excess return on the market over the risk-free rate will exceed that of the hypothetical portfolio during contraction/troughs. That is, the returns on the hypothetical SRI portfolio will be very sensitive to changes in the market during both contraction/trough and expansion/peak phases. 
If SRI screens exclude less efficient and less profitable companies, then SRI funds hold only the best performing companies, then during contraction/troughs and expansion/peaks the returns on an SRI fund should be less risky than the market because of the superior performance of its constituent companies. The current study submits that the financial outcome of CSR may be the result of a long-term commitment to SP by the companies engaged in such activities. The SP rating results from public and expert perceptions of this commitment. During difficult times, a company's SP rating identifies its long-term commitment to corporate social responsibility. The current study submits that, if social performance is associated with superior financial performance, then companies that have a high social performance rating will maintain this rating during a contraction/trough, and be less sensitive to changes in the market during both contraction/troughs and expansion/peaks. The above discussion results in competing forms of Hypothesis 1(a), designed to capture more than one potentially viable option (Heuer, 1999).

H1.1(a): The excess returns of a hypothetical SRI portfolio will be more sensitive to changes in the market during a contraction/trough than during an expansion/peak. H1.2(a): The excess returns of a hypothetical SRI portfolio will be less sensitive to changes in the market during a contraction/trough than during an expansion/peak.

According to Fama and French, the differential in returns derived from holdings of small versus large capitalization stocks is smaller in times of economic expansion and larger in times of economic decline, because larger companies are less risky overall than smaller companies. This factor measures the risk associated with holdings of small versus 
large capitalization stocks. The smaller company may be more vulnerable to an economic downturn, because of a lack of resources and access to capital. The current study submits that the SRI investor may focus on smaller companies because of their innovations, despite their inherent risk. Smaller companies may, by virtue of their size, be more flexible in their operations and able to adjust more rapidly to change.

During a contraction/trough, the larger company may not be able to reduce its operating overheads as quickly as a smaller company. The more flexible, smaller company may reduce the scale of its activities quicker than a larger company, and potentially retain its profitability. Yet the larger company, with its access to more resources than the smaller company, is in a position to finance and maintain CSP. During an expansion, the smaller company may compete for resources with its larger counterpart, with less success. If smaller companies have a higher social performance rating, then a portfolio weighted toward holdings of smaller companies during a contraction/trough will therefore yield higher excess returns than a portfolio weighted toward holdings of larger companies. As a result, a portfolio consisting of smaller companies yields lower excess returns than a portfolio consisting of larger companies during an expansion/peak. That is, if small companies yield higher returns than large companies, then the risk factor associated with size will be positively related to the excess returns on a hypothetical SRI portfolio. If larger companies have a higher social performance rating, then a portfolio that is weighted toward holdings of larger companies during a contraction/trough will yield higher excess returns than a portfolio that is weighted toward holdings of smaller companies. Therefore, a portfolio consisting of larger companies will yield lower excess returns than a portfolio consisting of smaller companies during an expansion/peak. If 
large companies yield higher returns than small companies, then the risk factor associated with size will be negatively related to the excess returns on a hypothetical SRI portfolio. Hypothesis 1(b) tests the above competing propositions.

H1.1(b): The incremental return on holdings of smaller vs. larger companies will be positively related to the excess returns on a hypothetical SRI portfolio during both contraction/trough and expansion/peak.

H1.2(b): The incremental return on holdings of smaller vs. larger companies will be negatively related to the excess returns on a hypothetical SRI portfolio during both contraction/trough and expansion/peak.

Fama and French also propose that portfolio holdings shift toward fully priced or over-valued stocks in times of economic expansion (1996, p.77). During an expansion/peak, the market price of stocks is inflated above the net present value of anticipated future cash flows, often known "irrational exuberance" (Shiller, 1995). However, in times of economic contraction, portfolio holdings of an equity mutual fund shift toward under-valued stocks, whose dividend yield is higher than over-valued stocks, and/or stocks that offer the potential for future capital gains, depending on the style of the fund. The current study proposes that the SRI investor may behave similarly, as long as the subject company maintains a high social performance rating. Ultimately, the performance of the investment will depend on the SRI fund manager's ability to interpret market conditions and make appropriate and timely decisions to buy, sell, or hedge an investment. Hypothesis 1(c) evaluates this proposition. 
H1.1(c): The incremental return on holdings of under-valued vs. over-valued or fully priced stocks will have a positive effect on the excess returns of a hypothetical SRI portfolio during a contraction/trough.

H1.2(c): The incremental return on holdings of under-valued vs. over-valued or fully priced stocks will have a negative effect on the excess returns of a hypothetical SRI portfolio during a expansion/peak.

Momentum affects the volatility of returns delivered by an equity mutual fund based on the extent of the manager's reaction to company information. In the case of SRI equity mutual funds, as in conventional funds, the momentum factor would usually be associated with news of corporate SP and FP. Jegadeesh and Titman (1993) found that abnormal returns based on momentum dissipate within two years. Chan, Jegadeesh, and Lakonishok (1995) describe two types of momentum related to stock price and earnings. Momentum based on price arises when the market is slow to incorporate known information into a stock's price. Earnings momentum occurs when the market is slow to incorporate recently announced information affecting corporate earnings into the stock's price. Momentum-based strategies are said to deliver superior returns (Carhart, 1995; Grinblatt, Titman, \& Wermers, 1995).

Momentum as a risk factor in determining the excess returns on a mutual fund is affected by prevailing economic conditions (Au \& Shapiro, 2010; Chordia \& Shivakumar, 2002; Cooper, Gutierrez, \& Hameed, 2004; Kosowski, 2006). However, the current study submits that the SRI fund manager makes investment decisions based on social performance along with the conventional risk-return tradeoff. The current study 
further submits that for SRI funds, momentum may be especially affected by social performance, and that the SRI fund manager may react more quickly to news of social performance than the market or may not react to news of financial performance as rapidly as the market. As such, abnormal returns due to momentum may be positive or negative. Hypothesis $1(\mathrm{~d})$ evaluates this proposition.

H1.1(d): Momentum will have a positive effect on the excess returns of a hypothetical portfolio of SRI funds during a contraction/trough and during an expansion/peak. H1.2(d): Momentum will have a negative effect on the excess returns of a hypothetical portfolio of SRI funds during a contraction/trough and during an expansion/peak.

\section{Hypothesis 2}

The systematic component of the Carhart model can be simplified into two components, namely, that which can be attributed to variations in the market (beta), and that which cannot be attributed to variations in the market (Jensen's alpha). This form of the Carhart model is actually the original Capital Asset Pricing Model (CAPM), developed by William Sharpe to explain the relationship between the returns on an asset and market risk (Sharpe, 1964). Jensen's refinement of the CAPM focused on the component of the returns, which could not be attributed to the market (Jensen, 1969). The component of excess returns that cannot be attributed to variations in the market is said to be the result of management skill. Management skill determines the portfolio's skew toward high or low book-to-market value stocks, or toward small or large capitalization stocks, and the extent of management's response to corporate information (momentum). 
The fund manager's reaction to corporate news (earnings momentum) and underlying company values (price momentum) is also an indicator of management skill. In the current study, Jensen's alpha provides an indicator of the financial value added by SRI screening and the manager's ability to apply specialist knowledge of market and financial factors to generate superior returns.

$\mathrm{H} 2(\mathrm{a})$ and $\mathrm{H} 2$ (b) are competing hypotheses relating to the Jensen's alpha of the hypothetical SRI portfolio during contraction/trough and expansion/peak phases. On the one hand, if social performance results in superior financial performance, then the application of SRI screens should select efficient and high-performing companies under all economic conditions. SRI screening should yield financial value that exceeds the cost of screening and monitoring. The returns on the SRI fund should exceed the returns of the market. Jensen's alpha of an SRI equity mutual fund is expected to be positive during both contraction/troughs and expansion/peaks, because of superior returns.

On the other hand, if, as the opponents of CSR argue, social performance detracts from corporate value because of the high cost of ethical practices, and SRI screening and monitoring add to the expense of the fund with no commensurate financial reward, then the financial value added by SRI screening may be negative. As a result, alpha may be negative during both contraction/troughs and expansion/peaks. The current research submits that the proposed alternatives are equally probable and a search of the literature identified no attempts to compare the Jensen's alpha of SRI mutual funds. As a result, Hypothesis 2 is presented in the form of competing hypotheses. H2(a): Jensen's alpha of a hypothetical SRI portfolio will be positive during both a contraction/trough and an expansion/peak. 
H2(b): Jensen's alpha of a hypothetical SRI portfolio will be negative during both a contraction/trough and an expansion/peak.

\section{Hypothesis 3}

Hypotheses 3(a), 3(b), and 3(c) will compare the performance of secular funds with religious funds from April 1991 to June 2009, and also from September 2002 to June 2009, and the performance of the Vice Fund with secular SRI funds and religious SRI funds between September 2002 and June 2009. In each of these comparisons, the business cycle effect (contraction/trough vs. expansion/peak) is considered. The current study also answers the research question: Do religious SRI funds, secular SRI funds, and the Vice Fund perform differently during a contraction/trough and expansion/peak? In addition to the Vice Fund, the hypothetical portfolio includes two types of SRI funds, religious SRI funds and secular SRI funds. Religious funds are those SRI funds whose screening criteria are based primarily on religious values. Religious SRI funds differ from secular SRI funds in their focus on religious values as against secular ethical criteria. This study also compares the performance of the Vice Fund to the performance of religious and secular funds during different phases of the business cycle. This comparison is relevant, as the Vice Fund is the contrary perspective of ethical investing.

Opponents of SRI maintain that SRI screening takes away value, so logically the contrary perspective of SRI investing should add value. One study demonstrates that religious individuals hold a broader view of social performance, which includes a moral dimension (Donaldson \& Preston, 1995), forged by personal religious views of one's relationship to fellow human beings, financial resources, and the environment (Evan \& 
Freeman, 1998; Freeman \& Gilbert, 1988; Freeman, 1984; Ghoul \& Karam, 2007). In contrast, Brammer, Williams, and Zinkin (2005) studied an international cross-section of individuals of different religions, and found that religious individuals do not hold a broader view of social performance than non-religious individuals. If SRI screens select companies with efficient operations and financially prudent managers, then a larger number of screens will select the most efficient and financially prudent companies with high social performance ratings. Therefore, while a smaller universe results in fewer opportunities for diversification, the portfolio will consist of high performing companies with a lower probability of loss of value. Such a portfolio will deliver higher returns than a portfolio with fewer screens.

However, a more nuanced argument can be developed if we assume risk is a basic factor. Because of the added criteria for social performance used by religious SRI funds, the number of screens used by religious SRI funds is greater than those of the typical secular SRI fund. This results in a smaller universe of stocks from which to select the portfolio's constituents. Religious SRI funds, secular SRI funds, and the Vice Fund all apply screens that are consistent with the social performance criteria of the fund.

Accordingly, religious SRI funds operate within a smaller universe than secular SRI funds and the Vice Fund operates within the smallest universe of all. Given fewer opportunities for diversification, the risk embodied in the fund increases as compared to a more diversified portfolio. With increased risk, the returns of the Vice Fund are expected to be higher than the returns on secular and religious SRI funds during an expansion/peak, and lower than the returns on secular and religious SRI funds during a contraction/trough. Hypothesis 3(a) compares the performance of religious and secular 
SRI funds, using opposing hypotheses based on these alternative views. There are mixed findings surrounding the relationship between religious values and attitudes toward corporate social responsibility.

\section{Religious SRI Funds and Secular SRI Funds}

The current study includes two religious funds, both of which are Islamic. Other religious funds include Catholic funds and funds created to support Protestant values such as the Mennonites, Evangelical Christians, and Episcopalians. As no other religious SRI equity mutual funds existed in 1991 that met the selection criteria of the study, only the two Islamic funds were included in the study. A major difference between Islamic funds and other SRI funds is the avoidance of stocks whose underlying companies derive significant income from interest earning activities. As a result, Islamic funds are likely to perform differently from secular funds in times of economic contraction, when the financial sector and allied industries are most at risk.

Catholic funds, another type of religious fund, differ in their screening criteria from secular funds by their avoidance of industries that derive significant income from activities related to abortion or birth control and which support same sex relationships by providing benefits to partners of the same sex. Other Protestant funds such as those endorsing an evangelical value system include screens that eliminate from consideration companies that support gambling, pro-choice activities, same sex domestic partnerships, and adult entertainment. Such companies, the current study proposes, are likely to be producers of consumer products and potentially recession-resistant. Such companies are 
likely to be well-accepted by the secular funds, which generally support a woman's right to choose and recognize domestic partnerships involving members of the same sex.

On the one hand, religious SRI funds operate within a more restricted universe than secular SRI funds. However, studies have shown that Catholic funds delivered riskadjusted returns that were not significantly different from the market during the period of expansion of the 1990s (Naber, 2001). However, of the SRI funds evaluated by Lipper Analytical Services, three religious funds - Amana Income (AMANX) and Growth Funds (AMAGX), both based on Islamic principles, and Ave Maria Catholic Values Fund (AVEMX) - consistently maintained the top spot in their respective categories during the Great Recession which began in 2007 (Thomson Reuters, 2010).

The current research proposes that a view of social performance that encompasses morality results in a smaller universe of stocks following the application of religious screens. The narrower universe results in a portfolio with fewer opportunities for diversification and more risk compared to a more diversified portfolio. With higher levels of risk, there are higher expected levels of return. Following the earlier discussion on portfolio diversification, risk, and expected returns, religious SRI funds should embody higher levels of risk, and hence, higher expected returns than secular SRI funds during an expansion/peak. Higher levels of risk result in the possibility of greater loss than a more diversified portfolio during a contraction/trough. In addition, an examination of the holdings of some religious funds reveals a tendency to invest in smaller companies with prospects for long-term growth. Additional evidence of this tendency is that the benchmark of the AMANA Growth Fund is the Russell 2000 index, which measures the performance of 2000 small- to mid-capitalization companies. 
On the other hand, if religious values are associated with greater financial prudence, then social performance as defined in a religious SRI context will be associated with superior performance that surpasses that of the secular SRI investing during contraction/trough and expansion/peak phases. As both outcomes are conceptually equally likely, Hypothesis 3(a) assumes the form of competing hypotheses. H3.1(a): Religious SRI funds will out-perform secular SRI funds during expansion/peaks and under-perform secular SRI funds during contraction/troughs. H3.2(a): Secular SRI funds will out-perform religious SRI funds during both contraction/troughs and expansion/peaks.

Hypotheses 3(b) and (c) compare the performance of the Vice Fund and secular SRI funds, and compare the performance of the Vice Fund and religious SRI funds. The current study proposes alternative views of their performance based on portfolio diversification and risk, and the SP-FP relationship. On the one hand, the Vice Fund is based on the most restricted universe of the funds comprising the hypothetical portfolio. Following the absence of a fully diversified portfolio, the Vice Fund could be considered the most risky of the funds comprising the hypothetical portfolio, and therefore likely to deliver higher expected returns than secular SRI and religious SRI funds. On the other hand, the history of the Vice Fund has also been tainted with illegal trades (Friedman, 2003), which may have facilitated superior returns, but which have damaged its reputation. If social performance is associated with greater efficiency and profitability, and corporate reputation is driven by social performance (Brammer \& Pavelin, 2006), 
then secular SRI and religious SRI funds should out-perform the Vice Fund during all phases of the business cycle.

\section{Vice Fund}

Previous research findings on the performance of the Vice Fund are mixed. A comparison of the financial performance of the stocks of companies engaged in the tobacco, gambling, and alcohol sectors revealed lower risk than the S\&P 500 per unit of return, suggesting that vice industries, by virtue of their risk profile, could play a defensive role during an economic downturn (Hemley et al., 2005). However, any defensive advantage of the Vice Fund's holdings may be offset by the legal risks and controversy associated with some of its base activities such as gambling and tobacco. Other evidence also contradicts the notion of superior returns by vice investing during an economic downturn (Shank et al., 2005). Although the studies covered the same period, the companies studied by Hemley might not be representative of the industry or similar to the Vice Fund studied by Shank et al. Therefore, the findings may not be comparable.

The Vice Fund had its inception at the end of August 2002, and invests in stocks that derive a significant percentage of their income from gambling, tobacco, alcohol, and national defense. SRI funds generally avoid these industries. For comparative purposes, the data set used to test these hypotheses will begin with August 2002, when the Vice Fund commenced operations. September 2002 to June 2009 represents an 82-month series per fund. The period covers all phases of a single business cycle, including the Great Recession that started in 2007. Therefore, the data will not be influenced by the prolonged period of economic expansion of the 1990s, and the technology bubble of the 
mid to late 1990s. However, the data will capture the influence of the Great Recession that ended in 2009. Given the mixed findings surrounding the performance of secular and religious SRI funds and the Vice Fund, the current study tests the hypotheses using an expanded definition of social performance that considers religious values.

Based on the above discussion, Hypotheses 3(b) and 3(c) compare the performance of the Vice Fund with the performance of religious and the performance of secular SRI funds as competing hypotheses.

Hypothesis 3(b)

H3.1(b): The Vice Fund will out-perform secular SRI funds during both contraction/troughs and expansion/peaks. H3.2(b): Secular SRI funds will out-perform the Vice Fund during both contraction/troughs and expansion/peaks.

Hypothesis 3(c)

H3.1(c): Religious SRI funds will out-perform the Vice Fund during both contraction/troughs and expansion/peaks.

H3.2(c): The Vice Fund will out-perform religious SRI funds during both contraction/troughs and expansion/peaks.

Figure 2 depicts the relationships considered in Hypotheses 3(a), 3(b), and 3(c). 


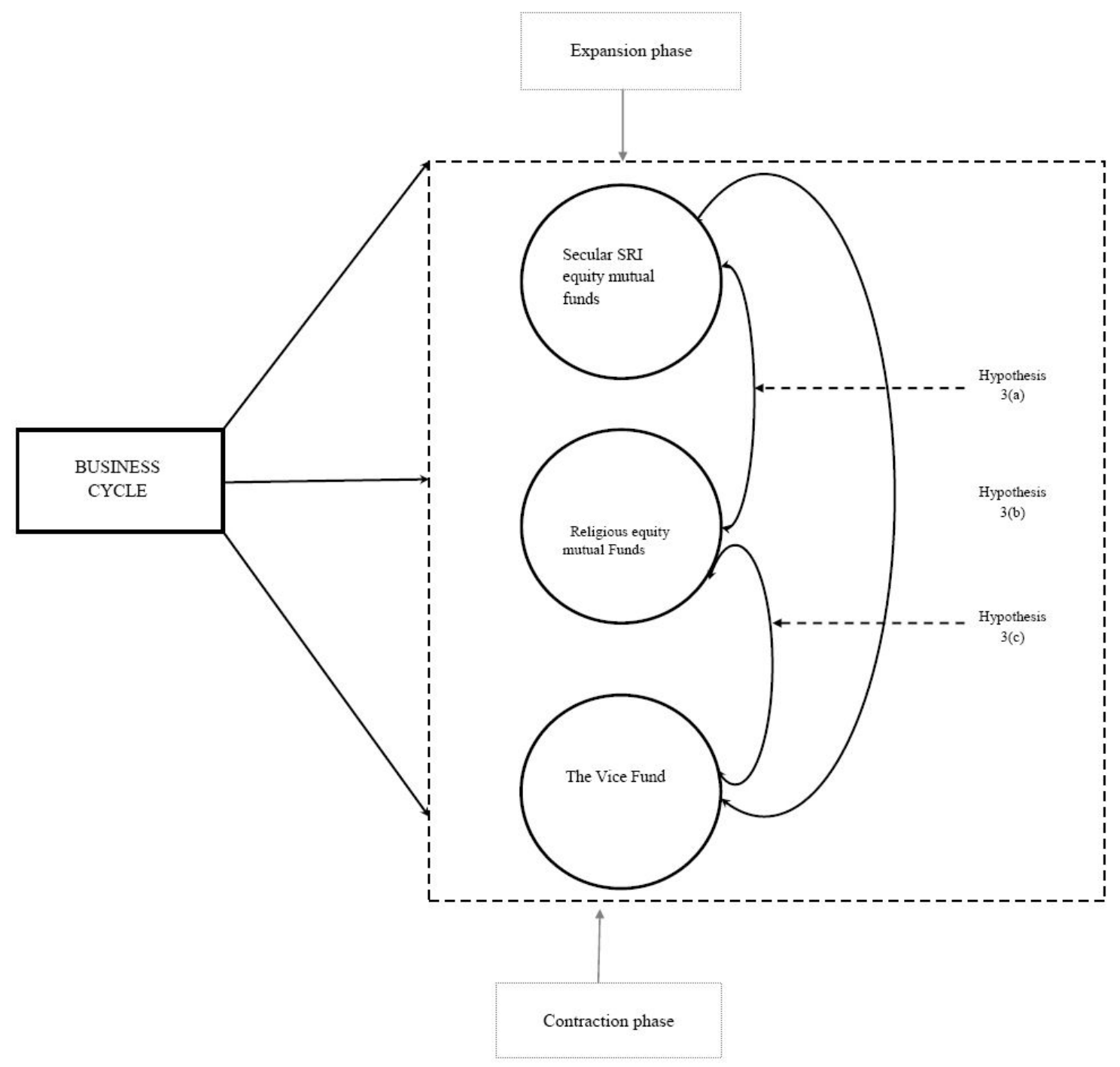

Figure 2. Conceptual Model of the Effect of the Business Cycle on Secular SRI Equity Mutual Funds, Religious Equity Funds, and the Vice Fund.

In Figure 2, the business cycle is said to influence the performance of secular SRI equity mutual funds, religious equity mutual funds, and the Vice Fund. Hypothesis 3(a) compares the effect of the business cycle on the performance of secular and religious equity funds. Hypothesis 3(b) compares the effect of the business cycle on the performance of secular equity funds and the Vice Fund. Hypothesis 3(c) compares the 
effect of the business cycle on the performance of religious equity funds and the Vice Fund.

\section{Method}

The study compares the factors influencing excess returns on a hypothetical SRI portfolio, over phases of the business cycle announced by the National Bureau for Economic Research between April 1991 and June 2009. The study also compares the performance of secular SRI funds and religious equity funds, religious equity funds and the Vice Fund, and secular SRI funds and the Vice Fund over phases of the business cycle identified between September 2002 and June 2009. Because the NBER announces business cycle phases after the fact, the dividend yield is used as a real-time indicator of the business cycle (Fama \& French, 1989; Fama \& French, 1993; Lynch et al., 2002). The dividend yield identifies the transitions in the cycle. The transitions identify the turning points where a contraction becomes a trough, and where the expansion becomes a peak. The trough marks the end of the contraction phase and the start of the expansion phase. The expansion phase culminates in a peak then the contraction re-commences.

Computations are performed using the MODEL PROCEDURE of SAS version 9.2. Data on monthly SRI fund returns, the S\&P 500, and the risk-free rate were obtained from the WRDS online database provided by the Wharton Research Data Services (WRDS) of the University of Pennsylvania (Wharton Research Data Services, 2010). The WRDS maintains stock market and mutual fund data compiled by the University of Chicago's Center for Research in Security Prices (CRSP). Monthly dividend yields were obtained from the web site of Robert Shiller's "Irrational Exuberance" (Shiller, 2010). 
Monthly data on market returns and financial environmental factors were downloaded from the Kenneth R. French Data Library of Dartmouth University (University of Dartmouth, 2009). The monthly horizon coincides with the usual review period for corporate and individual portfolios.

\section{Hypothetical SRI Portfolio}

\section{Funds}

Hypotheses 1, 2, and 3(a), consider a hypothetical portfolio of ten SRI equity mutual funds, which were active between April 1991 and June 2009. They were identified using a purposeful sampling technique. Purposeful sampling permits the researcher to select "information-rich cases" that highlight a phenomenon for more detailed study (Patton, 2001). Purposeful sampling is based on specific criteria. These funds were selected from the universe of US based domestic equity mutual SRI funds listed by the Social Investment Forum (Social Investment Forum, 2009), and which existed during the last two full business cycle phases of April 1991 to June 2009. The hypothetical SRI portfolio could be considered a unit-weighted portfolio of equity mutual funds. At least ten funds are needed to create a well-diversified asset portfolio (Louton \& Saraoglu, 2008). Funds that did not meet these criteria, for example, international funds, balanced funds, and income funds, as well as funds that did not exist during the entire period under review were excluded from the analysis.

The funds studied will henceforth be referred to as a 'hypothetical SRI portfolio'. This hypothetical portfolio consists of SRI equity mutual funds of different objectives, styles, and sizes. Under Hypotheses 3(b) and 3(c), a hypothetical fund based on ideology 
(secular SRI, religious SRI, and the Vice Fund) consists of 11 funds, to permit comparisons of the three types of fund. This 'hypothetical ideological portfolio' will also be evaluated under Hypothesis 3(a) for comparison. Tables 4 - 6 summarize the characteristics of the hypothetical portfolio by objective, style, and orientation (religious, secular, and vice).

Table 4

Hypothetical SRI Portfolio by Objective.

\begin{tabular}{lrr} 
Objective & No. of funds & $\%$ of sample \\
\hline Growth Funds & 7 & 70 \\
Other objectives & 3 & 30 \\
\hline Total & 10 & 100 \\
\hline
\end{tabular}

Growth funds focus on companies whose earnings are expected to grow at a faster rate than other companies listed in the major stock market indices. Other objectives of the funds included in the hypothetical portfolio include balanced funds and growth and income funds. The objective of a balanced fund is the preservation of the original investment, and balance the risk associated with stock holdings with income from bonds. Funds with a combination of growth and income balance the desire to profit from capital gains derived from rapid growth with dividend income. Of the funds comprising the hypothetical portfolio, the growth funds were the Ariel Appreciation Fund, the AHA/CNI Diversified Equity Fund, the Calvert Social Investment Fund's Equity Portfolio, the Domini Social Trust Fund, Legg Mason's Social Awareness Fund B, the Parnassus Fund, and New Alternatives Fund. The Amana Mutual Fund Trust's Income Fund and Growth Fund, and the Calvert Social Index Fund: Class I shares had other objectives. 
Table 5

Hypothetical SRI Portfolio by Style.

\begin{tabular}{lcc} 
Style & No. of funds & $\%$ of sample \\
\hline Large Growth & 6 & 60 \\
Other Style & 4 & 40 \\
\hdashline Total & 10 & 100 \\
\hline
\end{tabular}

The hypothetical SRI portfolio consists of six funds whose style is based on Large Growth companies. According to the CRSP, Large Cap Growth Funds are defined as

"...Funds that, by portfolio practice, invest at least $75 \%$ of their equity assets in companies with market capitalizations (on a three-year weighted basis) greater than $300 \%$ of the dollar-weighted median market capitalization of the middle 1,000 securities of the S\&P SuperComposite 1500 Index. Large-cap growth funds typically have an above-average ... price-to-book ratio... compared to the $S \& P$ 500 Index." (Center for Research in Security Prices, 2007, p. 21).

Other styles consist of combinations of capitalization and value-based approaches to investing. Capitalization approaches are associated with large, medium, and small capitalization companies. Value based approaches are high growth and value investing. The high growth approach selects companies with high market value to book value ratios, or stocks whose values are expected to rise rapidly. Value investing focuses on undervalued companies, or companies with a high book value to market value ratio. Of the funds comprising the hypothetical SRI portfolio, the Large Growth approach were cited by the Amana Mutual Fund Trust's Income Fund and Amana Mutual Fund Trust's Growth Fund, the AHA/CNI Diversified Equity Fund, the Calvert Social Index Fund: 
Class I shares, Legg Mason's Social Awareness class B shares, and the Parnassus Fund. Funds citing other approaches were the Calvert Social Investment Fund's Equity Portfolio, the Ariel Appreciation Fund, the Domini Social Trust Fund, and the New Alternatives Fund.

Table 6

Hypothetical Ideological Portfolio by Orientation.

\begin{tabular}{lrr}
\hline Orientation & No. of funds & $\%$ of sample \\
\hline Religious & 2 & 27 \\
Secular & 10 & 64 \\
Vice & 1 & 9 \\
\hline Total & 11 & 100 \\
\hline
\end{tabular}

Religious funds comprising the hypothetical ideological portfolio were the Amana Mutual Fund Trust's Income Fund and Growth Fund. The secular funds were the AHA/CNI Diversified Equity Fund, the Ariel Appreciation Fund, the Calvert Social Index Fund: Class I shares, and the Calvert Social Investment Balanced Fund Class A shares, the Calvert Social Investment Fund's Equity , Portfolio, the Domini Social Trust Fund, Legg Mason's Social Awareness class B shares, the Parnassus Fund. The Vice Fund focuses on activities that are generally avoided by the SRI industry.

The 1990s represented a period of growth of the SRI industry, during which SRI indices were introduced and new funds offered to the public. The mid 1990s also saw the growth of religious funds. The 2000s saw increased focus on corporate governance, human rights, and environmental concerns, which were reflected in the interests of the SRI industry. In addition, the Vice Fund was formed in 2002, to offer an opposing 
alternative to religious and secular SRI funds to investors with an interest in vice. The latter years of the 2000s also saw the Great Recession, which lasted for 18 months, the longest recession after the Great Depression of the 1930s. The Great Recession of January 2008 to June 2009 presents an opportunity to study the performance of SRI funds during a period of economic contraction.

\section{Time periods}

Table 7 highlights the phases of the business cycles between April 1991 and June 2009 announced by the NBER. The current study encompasses 219 months between April 1991 and June 2009, the end of the Great Recession, according to the NBER (National Bureau of Economic Research, 2010b), with turning points in the business cycle retroactively announced.

\section{Table 7}

Business Cycle Phases Announced by the NBER.

\begin{tabular}{lr}
\hline Cycle phase & No. of months \\
\hline April 1991-March 2001 (expansion/peak) & 120 \\
April 2001-November 2001 (contraction/trough) & 8 \\
December 2001-December 2007 (expansion/peak) & 73 \\
January 2008-June 2009 (contraction/trough) & 18 \\
Total & 219
\end{tabular}

The measurement model, therefore, incorporates the dividend yield as an indicator of current economic information at the time of the investment decision. Monthly data are preferred since investors and financial advisors tend to make monthly portfolio reviews, 
along with reviews of market factors. Hypotheses 1 through 3 evaluate the excess returns on a hypothetical portfolio consisting of ten SRI funds. Ten funds are the minimum number of mutual funds required to create a well-diversified asset portfolio (Louton \& Saraoglu, 2008). Therefore, this hypothetical fund of funds is a well-diversified SRI portfolio.

\section{Hypothesis Testing}

\section{Business Cycle Effects on a Hypothetical SRI portfolio}

Hypothesis 1 answers the research question: Has the business cycle affected the performance of socially responsible investments? Specifically, what factors govern the performance of socially responsible mutual funds during the expansion and contraction phases of the business cycle? The analysis compares the factors that explain the excess returns of SRI funds over multiple business cycles, using Carhart's four-factor model $(1997 ; 1995)$. The four factors are the excess return of the market over the risk-free rate, the differential in returns between portfolios comprised of small and large capitalization companies, the differential in returns between portfolios comprised of high and low book-to-market values, and momentum, or the extent to which the fund manager incorporates publicly available information in the investment decision. As such, Hypothesis 1 is evaluated in four parts, each part testing one of the four factors of the Carhart model. 
Hypothesis 1(a)

H1.1(a): The excess returns of a hypothetical SRI portfolio will be more sensitive to changes in the market during a contraction/trough than during an expansion/peak. H1.2(a): The excess returns of a hypothetical SRI portfolio will be less sensitive to changes in the market during a contraction/trough than during an expansion/peak.

Hypothesis 1(b)

H1.1(b): The incremental return on holdings of smaller vs. larger companies will be positively related to the excess returns on a hypothetical SRI portfolio during both contraction/trough and expansion/peak.

H1.2(b): The incremental return on holdings of smaller vs. larger companies will be negatively related to the excess returns on a hypothetical SRI portfolio during both contraction/trough and expansion/peak.

Hypothesis 1(c)

H1.1(c): The incremental return on holdings of under-valued vs. over-valued or fully priced stocks will have a positive effect on the excess returns of a hypothetical SRI portfolio during a contraction/trough.

H1.2(c): The incremental return on holdings of under-valued vs. over-valued or fully priced stocks will have a negative effect on the excess returns of a hypothetical SRI portfolio during an expansion/peak. 
Hypothesis 1(d)

H1.1(d): Momentum will have a positive effect on the excess returns of a hypothetical portfolio of SRI funds during a contraction/trough and during an expansion/peak.

H1.2(d): Momentum will have a negative effect on the excess returns of a hypothetical portfolio of SRI funds during a contraction/trough and during an expansion/peak.

Hypothesis 2 answers the research question: Is Jensen's alpha of an SRI fund positive or negative during contraction/troughs and expansion/peaks? Hypothesis 2 identifies the value added by SRI screening under periods of economic expansion and contraction, with value added measured by Jensen's alpha. Jensen's alpha is one of two components of SRI fund excess return defined by the CAPM. The alpha of an SRI fund measures the excess returns attributable to SRI (Maginn et al., 2007). It is the “...residual after returns to systematic risk have been removed..." (Yau, Schneeweis, Robinson, \& Weiss, 2007). If alpha is positive, SRI screening adds value. If Jensen's alpha is negative, SRI screening detracts from the value of the portfolio.

The other component of fund excess return in the CAPM is the fund's beta. The beta of an SRI fund measures the extent of its co-movement with the benchmark (Barberis, Shleifer, \& Wurgler, 2002), and measures the sensitivity of the SRI fund's return to changes in the market. It is considered a measure of systemic risk (Chance, Grant, \& Marsland, 2007; Copeland \& Weston, 1988), defined as the ratio of the covariance of the returns or the fund and the benchmark to the variance of the benchmark returns. If the fund or index is perfectly correlated with the benchmark, beta equals 1 . If the fund covariance is greater than that of the benchmark, the fund beta is $>1$, indicating 
that the fund is more volatile than the benchmark. If the fund or index covariance is less than that of the benchmark, the fund beta is $<1$, indicating that the fund or index is considered to be less volatile than the benchmark. Hypothesis 2 is evaluated as two competing hypotheses.

H2(a): Jensen's alpha of a hypothetical SRI portfolio will be positive during both a contraction/trough and an expansion/peak. H2(b): Jensen's alpha of a hypothetical SRI portfolio will be negative during both a contraction/trough and an expansion/peak.

\section{Secular SRI Funds, Religious Funds, and the Vice Fund}

Hypotheses 3(a), 3(b), and 3(c) answer the research question: Does the orientation of the fund affect its performance? The analysis compares the performance of secular SRI funds with religious funds and the Vice Fund. The method used to test the hypotheses is similar to that used in the test of Hypothesis 1, but identifies the orientation of the fund (secular, religious or vice) using relevant dummy variables. The Vice Fund had its inception at the end of August 2002, and invests in stocks that derive a significant percentage of their income from gambling, tobacco, alcohol and defense contracting. SRI funds tend to avoid these industries. For comparative purposes, the data set used to test these hypotheses begins with August 2002, when the Vice Fund commenced operations. September 2002 to June 2009 represents an 82-month series period per fund. The period covers all phases of a single business cycle, including the Great Recession that started in 2007. Therefore, the data will not be influenced by the prolonged period of economic 
expansion of the 1990s and the technology bubble of the mid to late 1990s. However, the data capture the influence of the Great Recession that ended in 2009. Given the mixed findings of previous research surrounding the performance of secular and religious SRI funds and the Vice Fund, the current study tests the hypotheses using an expanded definition of social performance that considers religious values.

Hypothesis 3(a)

H3.1(a): Religious SRI funds will out-perform secular SRI funds during expansion/peaks and under-perform secular SRI funds during contraction/troughs.

H3.2(a): Secular SRI funds will out-perform religious SRI funds during both contraction/troughs and expansion/peaks.

Hypothesis 3(b)

H3.1(b): The Vice Fund will out-perform secular SRI funds during both contraction/troughs and expansion/peaks.

H3.2(b): Secular SRI funds will out-perform the Vice Fund during both contraction/troughs and expansion/peaks.

Hypothesis 3(c)

H3.1(c): Religious SRI funds will out-perform the Vice Fund during both contraction/troughs and expansion/peaks.

H3.2(c): The Vice Fund will out-perform religious SRI funds during both contraction/troughs and expansion/peaks. 


\section{Measurement Model}

The hypotheses mentioned were evaluated via a system of equations. The focus of the system is a non-linear specification of the Carhart four-factor model (Carhart, 1997). The expansion and contraction phases are identified using the Markov switching regime (also known as the D-Method) developed by Goldfeld and Quandt (1973a; 1973b). The D-Method computes the parameters of the non-linear model by maximizing a likelihood function. The error term minimizes the negative of the log likelihood function. The loglikelihood function assumes a normal distribution of the error term.

Switching takes place between the expansion and contraction cycle phases. A business cycle goes through transitions in the cycle from peak to trough, and from trough to the next peak. The switching regime regression tracks the transitions based on an information variable. The current study applies the dividend yield as the source of information on the business cycle. Switching regression is an improvement over the use of binary dummy variables, which assume only one value or another. A state 's', with probabilities ranging from 0 to 1 , captures the transitions from peak to trough of a cycle, using the dividend yield in a regression model that takes into account the cyclical nature of the phenomenon. The state variable is the first derivative of the log likelihood function $f^{\prime}(x)$, and identifies the state 's'. Following Goldfeld and Quandt (1973a; 1973b), if $f^{\prime}(x) \leq 0$, the economy is said to be in a state of contraction or decline. If $f^{\prime}(x)>0$, the economy is said to be in a state of expansion or growth.

The D-Method makes adjustments for autocorrelation in the error terms, within each regime and at the transition points. Previous studies of stock market volatility and fund performance under different phases of the business cycle have applied similar 
switching regression methods (Hamilton \& Lin, 1996; Kosowski, 2006). The approach proposed by Goldfeld and Quandt (1973a; 1973b) assumes a single rate of transition between regimes, where $\mathrm{D}$ is a step function assuming values of 0 or 1 depending on the presence of one of two states. Because the dividend yield tracks the business cycle, it is often used by the investor as a proxy for current information on the business cycle (Lynch et al., 2002). In using a measure of the information available to the fund manager at the time of the investment decision, the study emphasizes the explanatory role of the model in identifying the factors that explain the performance of socially responsible mutual funds. The acceptance criterion is a maximum $p=0.05$ of the parameters under the two regimes.

\section{Variables}

The current study evaluates the performance of the SRI portfolio based on its excess returns over the risk-free rate, and a proxy for the volatility of the fund, namely its standard deviation. The dependent variable of the measurement model is the excess return on the portfolio, or the average of the excess returns of the funds comprising the hypothetical portfolio.

\section{Returns and Dividend Yield}

The excess return on each fund is measured by the difference between its monthly returns $\left(\mathrm{R}_{\mathrm{it}}\right)$ and the monthly risk free rate $\left(\mathrm{R}_{\mathrm{f}}\right)$. The monthly returns are defined by the CRSP Mutual Fund Database Guide (Center for Research in Security Prices, 2007) as the returns earned by the fund for the month, or the monthly gain or loss in Net Asset Value. 
Monthly returns include reinvested dividends, and exclude 12-b (marketing and distribution) fees and management expenses. The S\&P 500 monthly returns are the monthly percentage growth in the value-weighted S\&P 500 composite index, created by Standard \& Poors in 1957 (Center for Research in Security Prices, 2008). The risk free rate is that of the three-month Treasury Bill $\left(\mathrm{R}_{\mathrm{f}}\right)$. In the system of equations, the excess return is defined as $\mathrm{R}_{\text {it }}-\mathrm{R}_{\mathrm{f}}$. The 3-month Treasury Bill is the most liquid risk-free alternative investment to the hypothetical portfolio. Similarly, the excess return on the market is measured as the difference between the monthly return on the value weighted S\&P 500 Composite Index $\left(\mathrm{R}_{\mathrm{m}}\right)$ and that of the risk-free rate, namely the three-month Treasury Bill. The system of equations defines the excess return on the S\&P 500 as $R_{m}-$ $\mathrm{R}_{\mathrm{f}}$. The dividend yield is based on that of the S\&P 500 Index, extracted from Shiller's "Rational Exuberance" (2010). The dividend yield is calculated as the ratio of the dividends paid out by each of the companies comprising the S\&P 500, to the index closing level at the end of the month.

\section{Financial Market Factors}

Fama and French (1993) measure the differential between the returns on small and large capitalization firms (SMB) as the difference between the average returns on three portfolios consisting of small capitalization companies and the average returns on three portfolios consisting of large capitalization companies. The returns exclude transactions costs. The differential in returns between high and low book-to-market Value (HML) stocks is measured as the difference between the average returns on two portfolios constituted on a value strategy, or high book-to-market value, and two 
portfolios constituted on a growth strategy, or low book-to-market value. The momentum factor $(\mathrm{MOM})$ is calculated as the difference between the average of the returns on a portfolio yielding past high returns consisting of equal numbers of small capitalization stocks and large capitalization stocks, and the average of the returns on a portfolio yielding past low returns consisting of equal numbers of small and large capitalization stocks. The portfolios used to create the momentum factor consist of stocks listed on the American Stock Exchange (AMEX), the New York Stock Exchange (NYSE), and NASDAQ, formerly known as the National Association of Securities Dealers Automated Quotations (Fama \& French, 1993; University of Dartmouth, 2009).

\section{Control Variables}

The maximum expense ratio charged by the fund is stated in its prospectus. However, the turnover ratio, defined as “...the percentage of the portfolio's holdings that have changed over the past year...." (Morningstar, 2010), is used in the current study as a proxy for fund variable expenses including transactions costs. The turnover ratio provides a more accurate picture of the true cost of managing the fund, as the fund sponsors are known to absorb any costs that exceed the contractual expense ratio. The turnover ratio is calculated as the "...minimum (of aggregated sales or aggregated purchases of securities), divided by the average 12-month Total Net Assets of the fund...." (Center for Research in Security Prices, 2007, p. 9). According to Morningstar's Glossary of Investment Terms, a turnover of $20-30 \%$ is indicative of a buy and hold strategy, or a passively managed fund. The lower boundary of turnover for active fund management is 
over $30 \%$. Actively managed funds sometimes exhibit turnover ratios exceeding $100 \%$ (Morningstar, 2010).

The current research categorizes the funds into "Growth" and "Other" fund objectives, based on the Lipper fund objective classification in the WRDS database (Center for Research in Security Prices, 2007). For purposes of this research, fund objective is coded as a binary variable with 1 for "Growth Funds" and 0 for "Funds with other objectives". The variable for Size is based on the Net Asset Value (NAV) of the fund at the last day of the month. The NAV is calculated as the total assets minus the total liabilities of the fund. The NAV cited by the CRSP excludes fund operating expenses. Style was defined using the categories identified by Lipper in the CRSP database. The study grouped the fund styles represented by the portfolio constituents into "Large Cap Growth" and "Other" styles. Fund style is defined as a binary variable with "Large Cap Growth" coded as 1 and "Other Styles" coded as 0.

\section{The Equations}

Adapting Kosowski's notation (Kosowski, 2006), the Carhart four-factor model is defined as:

$R_{i t}-R_{f}=a_{i}+b_{i} *\left(R_{m}-R_{f}\right)_{t}+c_{i} S M B_{t}+h_{i} H M L_{t}+m_{i} M O M_{t}+e_{i t}$ where

$a_{i}$ is the intercept

$R_{i t}-R_{f}$ is the excess return on the portfolio over the risk free rate.

$b_{i}$ is the portfolio's beta.

$R_{m}$ is the returns on the benchmark index, a measure of the market's performance. 
$R_{m}-R_{f}$ is the excess return on the market over the risk free rate-an indicator of prevailing market returns, defined by Fama and French.

$S M B_{t}$ is the differential between small and large capitalization companies, defined by Fama and French.

$H M L_{t}$ is the differential between high and low book-to-market value, defined by Fama and French.

$M O M_{t}$ is the momentum factor identified by Carhart.

$e_{i t}$ refers to random factors not considered in the model.

When defined as $R_{i t}-R_{f}=a_{i}+b_{i} *\left(R_{m}-R_{f}\right)$, the original Capital Asset Pricing Model, $\alpha_{\mathrm{i}}$ is the fund's alpha, also known as Jensen's alpha;

The Carhart model is modified to include a business cycle effect on all components, as follows:

$R_{i t}-R_{f}=a_{i} s_{t}+b_{i} s_{t} *\left(R_{m}-R_{f}\right)_{t}+c_{i} s_{t} S M B_{t}+h_{i} S_{t} H M L_{t}+m_{i} s_{t} M O M_{t}+e_{i t}$

where $s_{t}$ defines a state or regime that may be 1 or 2 depending on the regime (expansion or contraction state). For convenience, the Carhart model is rewritten as:

$r_{i t}=a_{i} s_{t}+b_{i} s_{t} R M R F_{t}+c_{i} s_{t} S M B_{t}+h_{i} s_{t} H M L_{t}+m_{i} s_{t} M O M_{t}+e_{i t} ;$

where $r_{i t}=R_{i t}-R_{f}$ and $R M R F_{t}=\left(R_{m}-R_{f}\right)_{t}$

Kosowski's study accounts for the different fund objectives, such as growth, income and balanced objectives, using a multivariate approach (Kosowski, 2006). However, the current study applies a univariate approach in which the fund characteristics are included as control variables in the equation, as suggested in previous recommendations for adapting the Capital Assets Pricing Model and its derivations (DeFusco et al., 2007; McWilliams \& Siegel, 1997). Accordingly, control variables are 
fund expenses (Abramson \& Chung, 2000; Renneboog et al., 2006; Renneboog, 2008;

Renneboog, Ter Horst, \& Zhang, 2008; Statman \& Glushkov, 2008), fund size (Wermers, 2000) and fund style (Bauer et al., 2005; Hoepner \& Zeume, 2009). The current study includes the ideology of the constituent funds, namely the secular, religious, or vice orientation. The model to be estimated is defined as:

$r_{i t}=a_{i} s_{t}+b_{i} s_{t} R M R F_{t}+c_{i} s_{t} S M B_{t}+h_{i} s_{t} H M L_{t}+m_{i} s_{t} M O M_{t}+i_{i} s_{t} E X P+r_{i} s_{t} R E L+$

$o_{i} s_{t} O B J+z_{i} S_{t} S I Z+y_{i} s_{t} S T Y L E_{t}+e_{i t}$ where

$E X P_{t}$ is the fund's expenses.

$R E L_{t}$ is the fund's orientation-religious, secular, or vice.

$O B J_{t}$ is the fund's objective.

$S I Z_{t}$ is the natural log transformation of the fund's size.

$S T Y L E_{t}$ is the fund's style.

\section{Parameter Estimation}

The parameters are estimated using a maximum likelihood approach, in which a $\log$ likelihood function is minimized subject to the constraints of the two regimes $\left(r_{1}, r_{2}\right)$, which are tracked by the dividend yield, and the probabilities associated with each state, namely $(1-d)$ and $d$. The first step is to estimate the monthly change in the dividend yield - is its slope positive or negative? The dividend yield is the source of information through which the business cycle stage is transmitted to the fund manager. We suggest that the method of switching regression approximates the true situation encountered by the fund manager. As the purpose of the research is to explain the factors underlying the performance of SRI equity mutual funds, an attempt was made to replicate, as closely as 
possible, the conditions prevailing at the time of the decision. The change in the dividend yield is assumed to follow a normal probability distribution.

The model was estimated for both expansion and contraction regimes. A composite regression equation linked the probabilities to the model of each regime. The resulting negative log likelihood function is derived from Goldfeld \& Quandt's (1973b) D-method. The negative log likelihood function was minimized subject to the normality constraint and the definition of the state variable. Finally, the model is fit using the Marquardt-Levenberg method, which evaluates the improvement in the objective function at each iteration and adjusts the function by a factor. The Marquardt-Levenberg method also takes into account collinearity among the parameters (Marquardt, 1963). The Moore-Penrose pseudo-inverse GINV=G4 option in the FIT statement in the MODEL PROCEDURE of Base SAS version 9.2 allows the matrix of covariances to be inverted where temporally correlated errors may exist (Lee, Nelder, \& Patiwan, 2006). The returns $\mathrm{r}_{\mathrm{t}}$ were assumed to be normally distributed with a finite mean and variance, both dependent on the state and rate of growth of the economy. Adapting Kosowski's notation, this written as $r_{t} \mid s_{t} \sim N\left(\mu_{s t}, \Omega_{s t}\right), s_{t}=1,2$

Negative log likelihood function minimized: $f(x)=\frac{1}{\sqrt{2 \pi \sigma^{2}}} e^{-\frac{(x-\mu)^{2}}{2 \sigma^{2}}}$ State variable: $f^{\prime}(x)=\frac{-x}{\sqrt{2 \pi \sigma^{2}}} e^{-\frac{(x-\mu)^{2}}{2 \sigma^{2}}}=s_{t}$ Dividend yield tracking (SAS code): $\mathrm{a}=\mathrm{p} * \operatorname{dif}($ yield $) ; \quad / *$ Upper bound of integral */; $\mathrm{d}=$ probnorm $(\mathrm{a}) ; \quad / *$ Normal CDF as an approximation of the switch */; 
The excess return $r_{i t}$ is assumed to be state dependent. The parameters under each regime are compared using the Lagrange Multiplier test (Gallant, 1987) in which the negative of a log likelihood function is minimized, subject to the state variable assuming one of two values, and the business cycle tracked by the dividend yield. A switching regression evaluated Hypotheses 1, 3 (a), 3(b), and 3(c), while controlling for fund expenses, the ideology of the fund, fund objective, fund size, and style.

$r_{i t}=a_{i} s_{t}+b_{i} s_{t} R M R F_{t}+c_{i} s_{t} S M B_{t}+h_{i} s_{t} H M L_{t}+m_{i} s_{t} M O M_{t}+i_{i} s_{t} E X P+r_{i} s_{t} R E L+o_{i} s_{t}$ $O B J+z_{i} s_{t} S I Z+y_{i} s_{t} S T Y L E+e_{i t}$

where $\mathrm{e}_{\mathrm{it}}$ is an error term representing factors not included in the model.

Similarly, hypothesis 2 was evaluated using the CAPM model as follows:

$R_{i t}-R_{f}=a_{i} s_{t}+b_{i} s_{t} R M R F_{t}+e_{i t}$

where

$a_{i}=$ Jensen's Alpha, and

$b_{i}=$ the beta coefficient of the hypothetical SRI portfolio.

Finally, the model's validity is evaluated according to the assumptions of regression analysis.

\section{Length of Cycle}

Of the period under study, the expansion cycle phases are significantly longer than the contraction phases. Consequently, the sample period is weighted toward the expansionary phase of the business cycle. It is possible that the findings will be influenced by this phenomenon. As a result, the preliminary analysis identifies whether or 
not the length of the cycle phase may confound the findings of the study by applying the time series approach to the Analysis of Variance (ANOVA) proposed by Yang and Carter (1983). Yang and Carter approximate a time series by its average over time. As such, the mean of the monthly values for each fund substitutes for the 219 monthly values. A correlation analysis compares the means derived by this method with the length of individual cycle phases to determine if the duration of the cycle is associated with changes in the excess return of the portfolio.

\section{Supplementary Analyses}

A supplementary analysis compares the means and volatility of the returns of the portfolio of SRI funds during the expansion/peak and contraction/trough phases of the business cycle, and during the individual phases of the business cycle announced by the NBER. Fund volatility is measured by the standard deviation of the funds' returns - that is, the average difference between each fund's return and that of the average return of all funds taken together. Welch's ANOVA is considered the most appropriate test of the difference between means, as the statistic takes into account the relative difference in the number of observations in each category (Welch, 1951).

Tests of the homogeneity of variance compared the variances of the fund's returns over the expansion and contraction cycle phases, and among the individual cycle phases identified by the NBER. The current study makes use of Levene's test (Levene, 1960), the most popular test for homogeneity of variance, O’Brien's test (O'Brien, 1979), and the Brown-Forsythe test (Brown \& Forsythe, 1974). The three tests are robust to deviations from normality in the distribution. Levene's test compares the deviations of 
the returns from the group mean, and is robust to deviations from normality in the data. O'Brien's test takes into account the kurtosis of the distribution, while the BrownForsythe test measures the absolute deviation from group medians. In a comparison of the different tests of homogeneity of variance, Olejnik and Algina (1987) recommend the use of O'Brien's or the Brown-Forsythe procedure where the distribution is heavy-tailed. The Brown-Forsythe test is also recommended when the group sizes are unequal (Conover, Johnson, \& Johnson, 1981). The tests were generated by SAS v. 9.2 as part of the GLM PROCEDURE using the HOVTEST option. The current study considered p-values less than 0.05 to be suitable criteria for the rejection of the null hypothesis of equal group variances.

\section{Summary}

The hypotheses evaluated the factors that determined the performance of a hypothetical SRI portfolio over the expansion and contraction phases of the business cycles identified by the NBER between April 1991 and June 2009. The performance criterion used to evaluate the portfolio is the excess returns of the constituent funds. As described previously, each constituent fund was assigned a unit weight to identify the composition of the hypothetical SRI and Ideological funds. The hypotheses also compare the performance of secular SRI funds, religious funds, and the Vice Fund over the expansion and contraction phases of the business cycle. The measurement model tests fund and market specific factors using Carhart's four-factor model $(1997 ; 1995)$ in the 
context of Goldfeld and Quandt's (1973b) switching regression approach. A

supplementary analysis compares the volatility and risk-return characteristics of the fund of funds with those of the S\&P 500. 


\section{CHAPTER IV}

\section{FINDINGS}

The study considered changes in the performance of a hypothetical portfolio of SRI equity mutual funds over different stages of the business cycle. The underlying research answered the question - Does the business cycle affect the performance of SRI funds? Subsidiary questions considered the value added by social screening and the effect of the orientation (religious, secular, or vice) on the performance of the fund. Hypotheses 1(a), 1(b), 1(c), and 1(d) considered the factors influencing the excess returns of the portfolio studied during expansion and contraction phases and over the individual cycle phases identified between April 1991 and June 2009. Hypotheses 2(a) and 2(b) considered whether or not there was value added by SRI screens over the same period. Hypotheses 3(a), 3(b), and 3(c) considered an expanded portfolio of funds identified based on ideology. The analysis compared the performance of religious funds, secular funds, and the Vice Fund. This chapter describes the results of the tests of these hypotheses. Supplementary analyses compared the returns and volatility of the hypothetical SRI portfolio over individual phases announced by the NBER, and compared the returns and volatility of the hypothetical SRI portfolio with the S\&P 500. The subsequent chapter discusses the conceptual and managerial implications of the findings. 


\section{Summary Statistics for a Hypothetical SRI Portfolio for April 1991 to June}

2009

The period analyzed under Hypotheses 1, 2(a), 2(b), and 3(a) covered 219 months from April 1991 to June 2009 for a hypothetical portfolio comprising ten SRI equity mutual funds. A unit weight was assigned to each fund, which means that the portfolio holds equal numbers of units of each fund. Accordingly, Table 8 describes the constituent funds of the hypothetical SRI portfolio, including inception date, ideology, style, objective, and benchmark. 
Table 8

Constituents of a Hypothetical SRI Portfolio of Equity Mutual Funds - Hypotheses 1, 2, and 3(a).

\begin{tabular}{|c|c|c|c|c|c|c|c|}
\hline Fund & Fund Sponsor & Symbol & Inception Date & Ideology & Objective & Style & Benchmark(s) \\
\hline $\begin{array}{l}\text { AHA/ CNI Diversified } \\
\text { Equity Institutional Class }\end{array}$ & $\begin{array}{l}\text { CCM Advisors, } \\
\text { LLC }\end{array}$ & AHDEX & Oct, 20, 1988 & Secular & Growth & $\begin{array}{l}\text { Large } \\
\text { Growth }\end{array}$ & S\&P 500 \\
\hline Ariel Appreciation Fund & $\begin{array}{l}\text { Ariel Investments, } \\
\text { LLC }\end{array}$ & CAAPX & Dec. 1,1989 & Secular & Growth & Other & Russell Mid cap \\
\hline Amana Trust Growth & $\begin{array}{l}\text { Saturna Capital } \\
\text { Corp (Wash.) }\end{array}$ & AMAGX & Feb. 3, 1994 & Religious & Other & $\begin{array}{l}\text { Large } \\
\text { Growth }\end{array}$ & Russell 2000 \\
\hline Amana Trust Income & $\begin{array}{l}\text { Saturna Capital } \\
\text { Corp (Wash.) }\end{array}$ & AMANX & June 23, 1986 & Religious & Other & $\begin{array}{l}\text { Large } \\
\text { Growth }\end{array}$ & S\&P \\
\hline $\begin{array}{l}\text { Calvert Social } \\
\text { Investment Equity A }\end{array}$ & $\begin{array}{l}\text { Calvert } \\
\text { Investments }\end{array}$ & CSIEX & Aug. 24, 1987 & Secular & Growth & Other & S\&P 500 \\
\hline $\begin{array}{l}\text { Calvert Social Index } \\
\text { Fund I }\end{array}$ & $\begin{array}{l}\text { Calvert } \\
\text { Investments } \\
\end{array}$ & CSIFX & circa 1982 & Secular & Other & $\begin{array}{l}\text { Large } \\
\text { Growth }\end{array}$ & S\&P 500 \\
\hline Domini Social Equity I & $\begin{array}{l}\text { Domini Social } \\
\text { Investments, LLC }\end{array}$ & DSEFX & June 3, 1991 & Secular & Growth & Other & S\&P 500 \\
\hline Parnassus Fund & $\begin{array}{l}\text { Parnassus } \\
\text { Investments }\end{array}$ & PARNX & Dec. 27,1984 & Secular & Growth & $\begin{array}{l}\text { Large } \\
\text { Growth }\end{array}$ & S\&P 500 \\
\hline New Alternatives & $\begin{array}{l}\text { New Alternatives } \\
\text { Fund, Inc. }\end{array}$ & NALFX & Sept. 3, 1982 & Secular & Growth & Other & $\begin{array}{l}\text { S\&P 500 } \\
\text { Russell } 2000\end{array}$ \\
\hline $\begin{array}{l}\text { Legg Mason Social } \\
\text { Aware B }\end{array}$ & $\begin{array}{l}\text { Legg Mason } \\
\text { Partners Fund } \\
\text { Advisor, LLC }\end{array}$ & SESIX & Feb. 2, 1987 & Secular & Growth & $\begin{array}{l}\text { Large } \\
\text { Growth }\end{array}$ & S\&P 500 \\
\hline
\end{tabular}


Table 9

Expansion and Contraction Cycle Phases (April 1991 - June 2009).

\begin{tabular}{lrr} 
Cycle phase & No. of months & \% of total \\
\hline Contraction phase/trough & 26 & 12 \\
Expansion phase/peak & 193 & 88 \\
Total & 219 & 100
\end{tabular}

Table 9 describes the duration of the expansion and contraction phases taken together. Between April 1991 and June 2009, the U.S. economy experienced 193 months of expansion and 26 months of economic contraction. That is, $88 \%$ of the period under review represented periods of economic expansion, while $12 \%$ represented periods of economic contraction. Preliminary analysis of the data revealed the absence of a significant relationship between the length of individual cycle phases and the mean returns of the hypothetical SRI portfolio $(\mathrm{r}=0.69, p=0.31)$.

\section{Excess Returns of the Hypothetical SRI Portfolio}

The excess returns of the hypothetical portfolio over S\&P 500 Index is defined as the difference between the returns on the hypothetical SRI portfolio and the returns on the S\&P 500. In this study, the data contained three missing values for monthly returns. As a result, the computed excess returns also contained three missing values. 


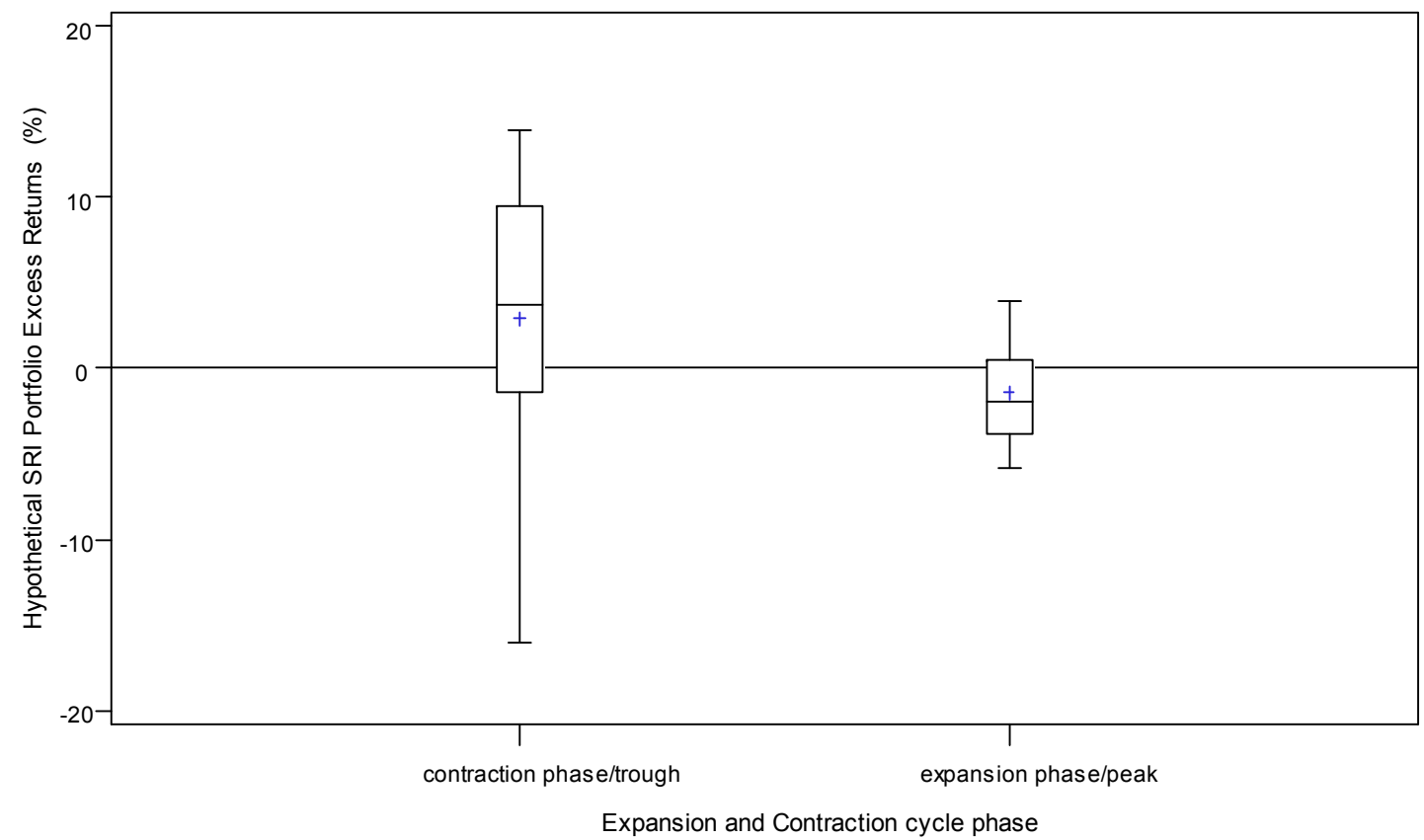

Figure 3. Hypothetical SRI portfolio excess returns by expansion and contraction cycle phase (April 1991 - June 2009).

Figure 3 summarizes the excess returns generated by the hypothetical portfolio of ten SRI equity mutual funds, during the contraction/trough and expansion/peak phases between April 1991 and June 2009, by means of a box plot and an indicator of zero excess return. Points lying above the zero return indicator represented conditions where excess returns are positive. That is, the returns on the hypothetical portfolio exceeded that of the market - in this case, S\&P 500 Index. Below the indicator, excess returns were negative, or the returns on the hypothetical portfolio are less than that of the S\&P 500 Index. Where the excess return was positive, the hypothetical SRI portfolio yielded returns exceeding that of the $\mathrm{S} \& \mathrm{P} 500$ - that is, the portfolio out-performed the market. The contraction phase/trough demonstrated a larger variability than that of the expansion/peak phases. The expansion/peak phase was represented by a narrower box 
and shorter whiskers around the median, indicating less variability than that of the contraction/trough.

During the periods of economic contraction, the average excess returns of the portfolio of SRI funds was 2.9\%. During the periods of economic expansion, the average excess returns of the portfolio was $-1.4 \%$. The excess return was defined as the difference between the returns generated by the hypothetical portfolio and that of the market (S\&P 500). Welch's ANOVA, based on the means of each fund during each expansion/peak and contraction/trough phase, identified a statistically significantly difference between the excess returns of the hypothetical portfolio between the contraction/trough phases and the expansion/peak phases $F(1,38)=5.12$, $p=0.03$. 


\section{SRI Hypothetical Portfolio Actual Returns}

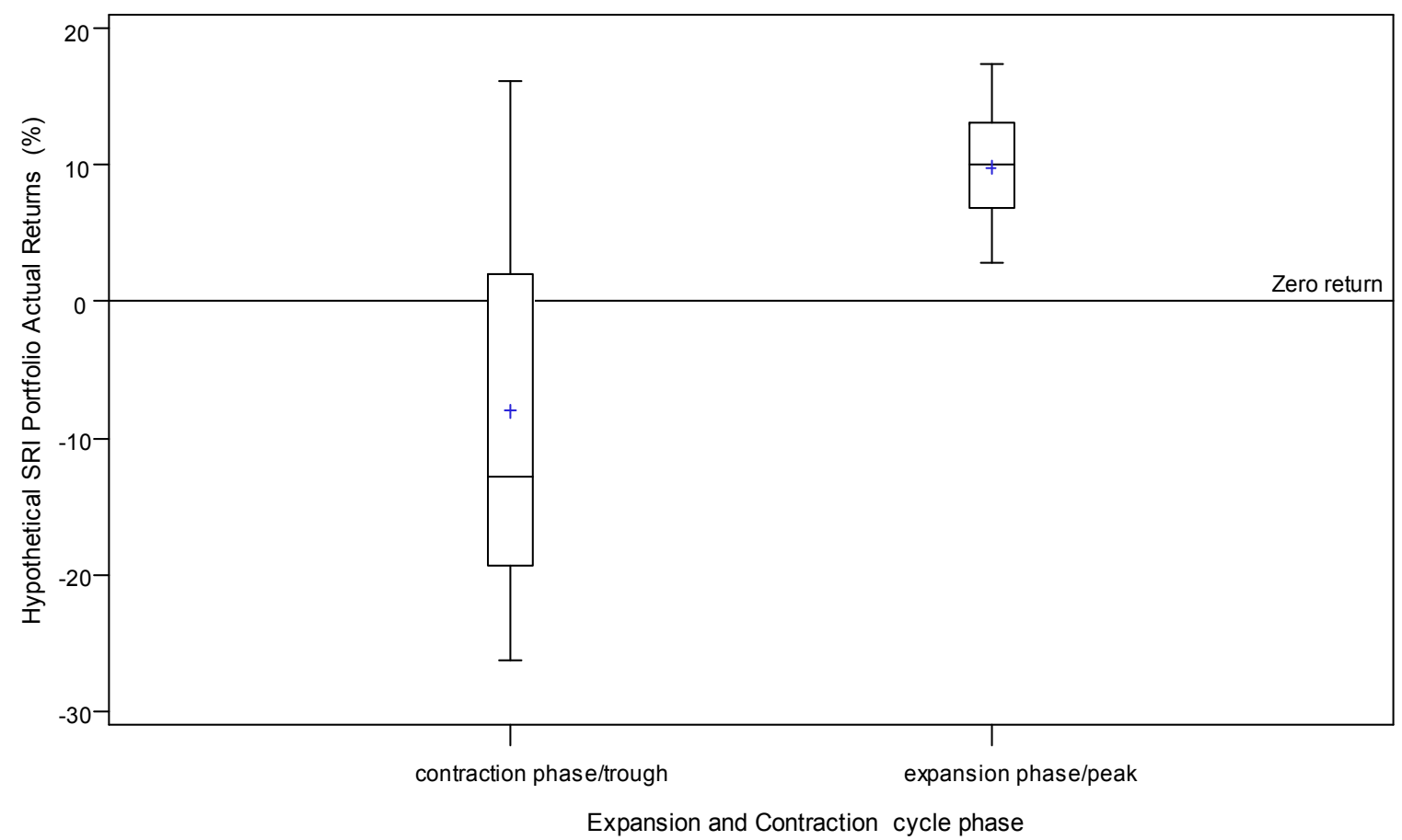

Figure 4. Hypothetical SRI portfolio actual returns by expansion and contraction cycle phase (April 1991 - June 2009).

Figure 4 summarizes the distribution and measures of central tendency of the actual returns on the hypothetical portfolio of ten SRI equity mutual funds during the cycles identified between April 1991 and June 2009 by box plot and an indicator of zero return. The mean and standard deviations are derived from the means of each fund for each contraction/trough and expansion/peak cycle phase. On average, the hypothetical portfolio yielded negative returns during the contraction/trough phases and positive returns during the expansion/peak phases. The contraction phase/troughs demonstrated a larger deviation in actual returns than that of the expansion/peak phases. During the periods of economic contraction, the average actual returns of the portfolio of SRI funds 
was $-8 \%$. During the periods of economic expansion, the average actual returns of the portfolio was $9.8 \%$. The mean difference was statistically significant, $\mathrm{F}(1,38)=29.98, p$ $<0.0001$, according to Welch's ANOVA. The test yielded a standard deviation of 14 percentage points, or a variance of 196 percentage points during the contraction/trough phase. The expansion/peak phase was associated with a standard deviation of 4 percentage points, or a variance of 16 percentage points. The findings were also as expected. The mean difference was statistically significant, $\mathrm{F}(1,38)=29.98, p<0.0001$, according to Welch's ANOVA. 


\section{S\&P 500 Returns}

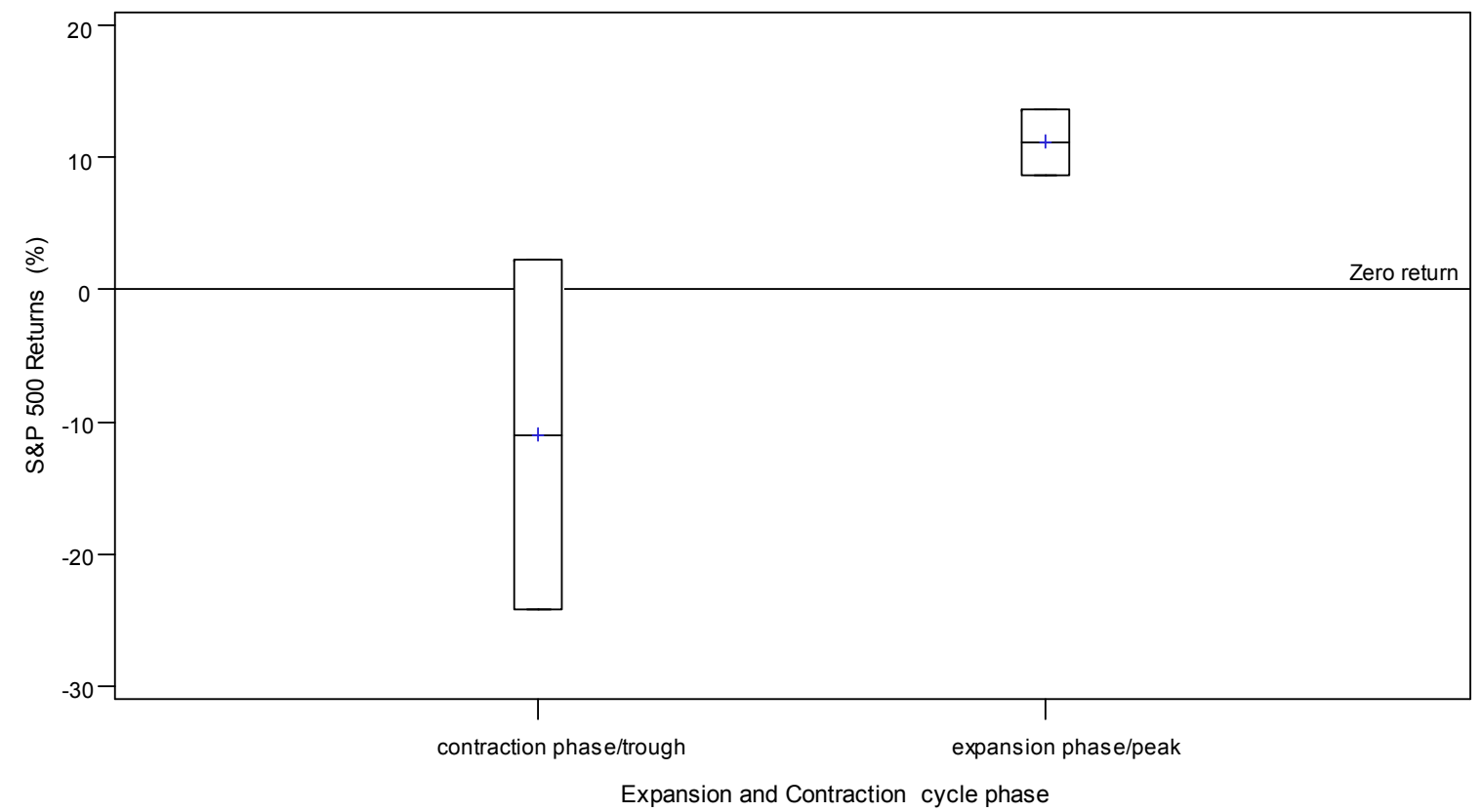

Figure 5. S\&P 500 returns by expansion and contraction cycle phase (April 1991 - June 2009).

Figure 5 summarizes the distribution and measures of central tendency of the actual returns on the S\&P 500 during the contraction/trough and expansion/peak phases between April 1991 and June 2009. On average, the S\&P 500 yielded negative returns during the contraction/trough phases and positive returns during the expansion/peak phases. Like the actual returns on the hypothetical SRI portfolio, the S\&P 500 exhibited a larger standard deviation during the contraction phase/trough than that of the expansion/peak phases, as evidenced by the wider box. The expansion/peak phases were represented by a narrower box compared to the contraction/trough phases. During the periods of economic contraction, the returns of the S\&P 500 was $-10.98 \%$. During the periods of economic expansion, the returns of the S\&P 500 was $11.2 \%$. This difference is 
statistically significant $\mathrm{F}(1,20.36)=51.78, p<0.0001$. Welch's ANOVA, which takes into account the differences in the number of observations in each category, reported a significant difference in all indicators over the expansion/peak and contraction/trough phases identified by the NBER between April 1991 and June 2009. Table 10 summarizes the means and standard deviations mentioned earlier.

Table 10

Descriptive Statistics of a Hypothetical SRI Portfolio and S\&P 500 Returns by Expansion and Contraction Cycle Phase (April 1991 - June 2009).

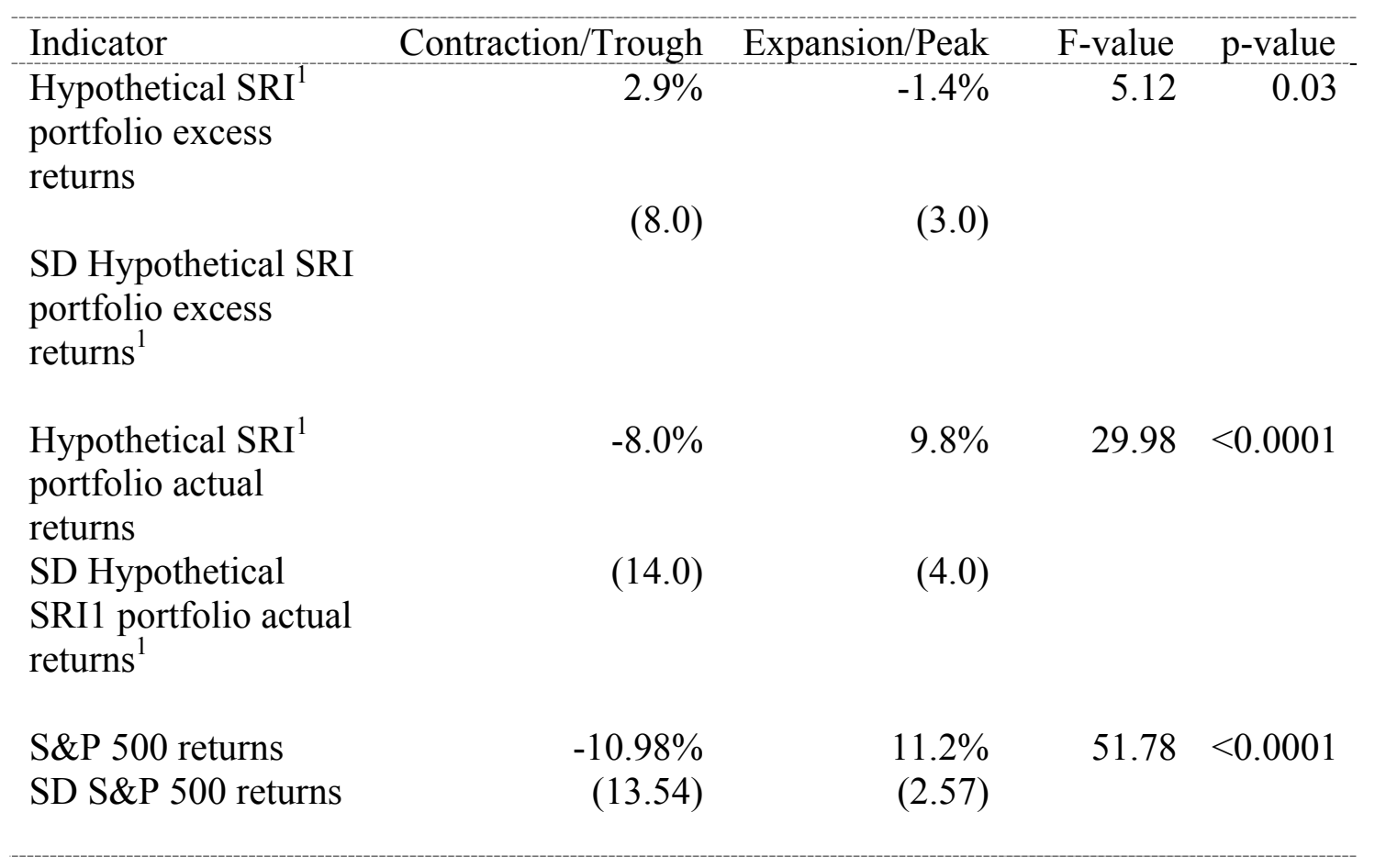

Note: 1. Based on means for each fund.

According to Table 10, the hypothetical SRI portfolio reported different patterns of volatility during the expansion/peak phases and the contraction/trough phases 
identified by the NBER between April 1991 and June 2009. During the contraction/trough phases, the standard deviation of the portfolio returns was 14.0, whereas during the expansion/peak phases, the standard deviation was 4.0. This is consistent with the conceptual model described previously, wherein a hypothetical SRI portfolio is expected to exhibit greater volatility during a contraction/trough phase than during an expansion/peak.

\section{Table 11}

Results of Tests of Homogeneity of Returns on a Hypothetical SRI Portfolio (April 1991 - June 2009).

\begin{tabular}{lrr}
\hline Test of Homogeneity of Variance & F-value & p-value \\
\hline Levene & 17.88 & 0.0001 \\
O'Brien & 16.93 & 0.0002 \\
Brown- Forsythe & 15.44 & 0.0003 \\
\hline
\end{tabular}

Note: Based on means for each fund.

According to Table 11, there was general agreement among the three tests of homogeneity of variance of the returns on the hypothetical SRI portfolio. The portfolio exhibited significantly greater volatility of returns during a contraction/trough phase than during an expansion/peak. A portfolio exhibiting more volatile returns may also be said to have less stable or less consistent returns. These findings are also as expected. The hypothetical SRI portfolio exhibits significantly greater volatility, hence less stable (less consistent) returns during contraction/troughs phase than during expansion/peaks. 


\section{Descriptive Statistics for the Portfolio Risk Factors and Control Variables}

This section describes the distribution and measures of central tendency of the risk factors related to the composition of the hypothetical portfolio and the control variables described in the conceptual model, during the contraction/trough and expansion/peak phases between April 1991 and June 2009. The risk factors are associated with the financial environment and describe elements of the environment that influence excess returns. They are: the differential in the returns on portfolios consisting of small versus large capitalization companies (SMB), the differential in the returns on portfolios consisting of stocks with high versus low book-to market value (HML), and the momentum factor (MOM). The control variables are the natural logarithmic form of fund size (SIZ) and expenses (EXP), style (STYLE), and objective (OBJ). 
Table 12

Descriptive Statistics of Portfolio Risk Factors and Control Variables by Expansion and Contraction Cycle Phase (April 1991 - June 2009).

\begin{tabular}{lrrrr} 
& Contraction/Trough & \multicolumn{1}{c}{ Expansion/Peak } \\
\hline Indicator & \multicolumn{1}{c}{ Mean } & SD & \multicolumn{1}{c}{ Mean } & \multicolumn{1}{c}{ SD } \\
& $0.79 \%$ & 0.03 & $0.13 \%$ & 0.03 \\
\hline Small vs. Large Firm (SMB) & $-0.29 \%$ & 0.04 & $0.45 \%$ & 0.03 \\
High vs. Low Book-to-Market Value & & & & \\
(HML) & $-1.23 \%$ & 0.1 & $0.92 \%$ & 0.05 \\
Momentum (MOM) & $\$ 532.90$ & 561.34 & $\$ 449.97$ & 801.65 \\
Net Asset Value (\$M) & 5.69 & 1.23 & 5.08 & 1.49 \\
Natural log Net Asset Value (SIZ) & $58.2 \%$ & 0.49 & $49.8 \%$ & 0.46 \\
Turnover (EXP) & & &
\end{tabular}

Notes: (1) Based on monthly data.

(2) The Net Asset Value was transformed to its natural logarithmic (ln) form for use in the model.

According to Table 12, the small vs. large firm risk factor (SMB) differed in magnitude during the contraction/trough and expansion/peak phases of the cycles represented between April 1991 and June 2009, with a higher mean observed during the contraction phase. Its standard deviation remained the same. The coefficient of variation or ratio of its mean to the standard deviation would be much higher during the contraction/trough than during an expansion/peak. The small vs. large firm difference (SMB) suggested that its contribution to portfolio excess returns may have been more relevant during the contraction/trough, when the skills of the portfolio manager become more relevant in delivering superior returns. 
The high vs. low Book-to-Market Value factor (HML) differed not only in magnitude, but in direction during both cycle phases. As its standard deviation remained consistent over both phases of the business cycle, and the coefficients of variations lay in different directions, it was difficult to determine its potential effect on portfolio excess returns. The mean of the momentum factor (MOM) lay in opposite directions, exhibiting greater variability during a contraction/trough than during an expansion/peak.

During the expansion/peak phases, the average Net Asset Value of the funds studied, a proxy for fund size, measured approximately $\$ 82 \mathrm{M}$ less than their value during the contraction/trough phases. The prolonged expansion phase of the 1990s coincided with the startup of many SRI mutual funds, when beginning Net Asset Values were low. However, Net Asset Value exhibited greater variability during the expansion/peak phase than during the contraction/troughs. This variability of the size of the funds may have been influenced by the bubble periods of the 'tech boom' of the 1990s and the period of high economic activity just before the Great Recession. In its natural logarithmic form, Net Asset Value (SIZ) exhibited far greater stability, with a more consistent mean. Fund turnover (EXP) remained within the region defined as active fund management (over $30 \%)$. Trading activity was higher during the contraction/troughs than during the expansion/peak phases. 


\section{Summary Statistics for a Hypothetical Ideological Portfolio for September}

\section{2 to June 2009}

The period analyzed under Hypotheses 3(b) and 3(c) covers 82 months from September 2002 to June 2009 for a hypothetical portfolio comprised of SRI equity mutual funds, organized by ideology (secular SRI principles and religious SRI principles) and the Vice Fund, a total of 11 funds. This analysis covers the period September 2002 to June 2009 because the Vice Fund commenced operations in September 2002. Table 13 reports the frequencies and composition of the hypothetical portfolio for Hypotheses 3(b) and 3(c). 
Table 13

Constituents of a Hypothetical Ideological Portfolio of Equity Mutual Funds - Hypotheses 3(b) and 3(c).

\begin{tabular}{|c|c|c|c|c|c|c|c|}
\hline Fund & Fund Sponsor & Symbol & Inception Date & Ideology & Objective & Style & Benchmark(s) \\
\hline $\begin{array}{l}\text { AHA/ CNI Diversified } \\
\text { Equity Institutional Class }\end{array}$ & $\begin{array}{l}\text { CCM Advisors, } \\
\text { LLC }\end{array}$ & AHDEX & Oct, 20,1988 & Secular & Growth & $\begin{array}{l}\text { Large } \\
\text { Growth }\end{array}$ & S\&P 500 \\
\hline Ariel Appreciation Fund & $\begin{array}{l}\text { Ariel Investments, } \\
\text { LLC }\end{array}$ & CAAPX & Dec. 1,1989 & Secular & Growth & Other & Russell Mid cap \\
\hline Amana Trust Growth & $\begin{array}{l}\text { Saturna Capital } \\
\text { Corp (Wash.) }\end{array}$ & AMAGX & Feb. 3, 1994 & Religious & Other & $\begin{array}{l}\text { Large } \\
\text { Growth }\end{array}$ & Russell 2000 \\
\hline Amana Trust Income & $\begin{array}{l}\text { Saturna Capital } \\
\text { Corp (Wash.) } \\
\end{array}$ & AMANX & June 23, 1986 & Religious & Other & $\begin{array}{l}\text { Large } \\
\text { Growth }\end{array}$ & S\&P \\
\hline $\begin{array}{l}\text { Calvert Social } \\
\text { Investment Equity A }\end{array}$ & $\begin{array}{l}\text { Calvert } \\
\text { Investments }\end{array}$ & CSIEX & Aug. 24, 1987 & Secular & Growth & Other & S\&P 500 \\
\hline $\begin{array}{l}\text { Calvert Social Index } \\
\text { Fund I }\end{array}$ & $\begin{array}{l}\text { Calvert } \\
\text { Investments } \\
\end{array}$ & CSIFX & circa 1982 & Secular & Other & $\begin{array}{l}\text { Large } \\
\text { Growth }\end{array}$ & S\&P 500 \\
\hline Domini Social Equity I & $\begin{array}{l}\text { Domini Social } \\
\text { Investments, LLC }\end{array}$ & DSEFX & June 3, 1991 & Secular & Growth & Other & S\&P 500 \\
\hline Parnassus Fund & $\begin{array}{l}\text { Parnassus } \\
\text { Investments }\end{array}$ & PARNX & Dec. 27,1984 & Secular & Growth & $\begin{array}{l}\text { Large } \\
\text { Growth }\end{array}$ & S\&P 500 \\
\hline New Alternatives & $\begin{array}{l}\text { New Alternatives } \\
\text { Fund, Inc. }\end{array}$ & NALFX & Sept. 3, 1982 & Secular & Growth & Other & $\begin{array}{l}\text { S\&P 500 } \\
\text { Russell } 2000\end{array}$ \\
\hline $\begin{array}{l}\text { Legg Mason Social } \\
\text { Aware B }\end{array}$ & $\begin{array}{l}\text { Legg Mason } \\
\text { Partners Fund } \\
\text { Advisor, LLC }\end{array}$ & SESIX & Feb. 2, 1987 & Secular & Growth & $\begin{array}{l}\text { Large } \\
\text { Growth }\end{array}$ & S\&P 500 \\
\hline Vice Fund & $\begin{array}{l}\text { Mutuals Advisors } \\
\text { Inc. }\end{array}$ & VICEX & Aug. 30, 2002 & Vice & Growth & $\begin{array}{l}\text { Large } \\
\text { Growth }\end{array}$ & S\&P 500 \\
\hline
\end{tabular}


Between September 2002 and June 2009, the U.S. economy experienced 64 months of expansion and 18 months of economic contraction. That is, $78 \%$ of the period under review represented periods of economic expansion, while $22 \%$ represented periods of economic contraction. Table 14 describes the period under review by expansion and contraction phase.

Table 14

Expansion and Contraction Cycle Phases (September 2002 - June 2009).

\begin{tabular}{lrr}
\hline Cycle phase & No of months & $\%$ of total \\
\hline Contraction phase/trough & 18 & 22 \\
Expansion phase/peak & 64 & 78 \\
Total & 82 & 100 \\
\hline
\end{tabular}

\section{Excess Returns of the Hypothetical Ideological Portfolio}

The excess returns of the hypothetical portfolio had no missing values for monthly returns. One outlier was identified during the expansion phase, the result of a $164 \%$ excess return delivered by The Parnassus Fund in November 2002. This may have been the result of the deferral of capital losses occurring in November 2002 to the start of the next financial year (The Parnassus Fund, 2002). The outlier was excluded from the analysis. The analysis spans part of one expansion/peak phase and the entire Great Recession. 


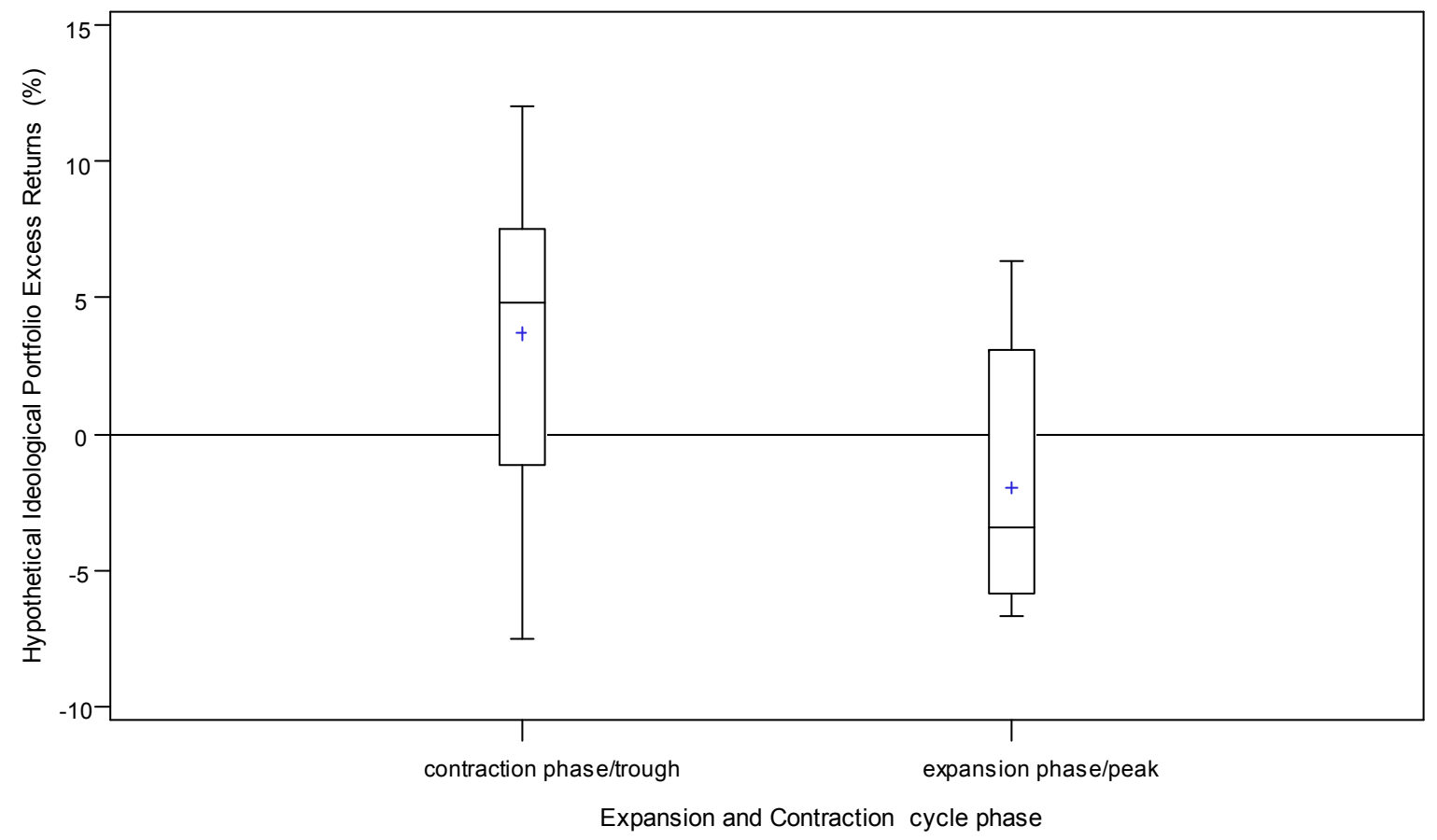

Figure 6. Hypothetical ideological portfolio excess returns by expansion and contraction cycle phase with outlier removed (September 2002 - June 2009).

Figure 6 summarizes the excess returns generated by the hypothetical ideological portfolio of eleven equity mutual funds, during the contraction/trough and expansion/peak phases between September 2002 and June 2009. During the periods of economic contraction, the average excess returns of the hypothetical ideological portfolio was $3.7 \%$. During the periods of economic expansion, the average excess returns of the hypothetical ideological portfolio was $-1.9 \%$. Welch's ANOVA, based on the means of each fund during each expansion/peak and contraction/trough phase, identified a statistically significant difference between the excess returns of the hypothetical ideological portfolio between the contraction/trough phases and the expansion/peak phases $\mathrm{F}(1,20)=6.68, p=0.02$. 


\section{Hypothetical Ideological Portfolio Actual Returns}

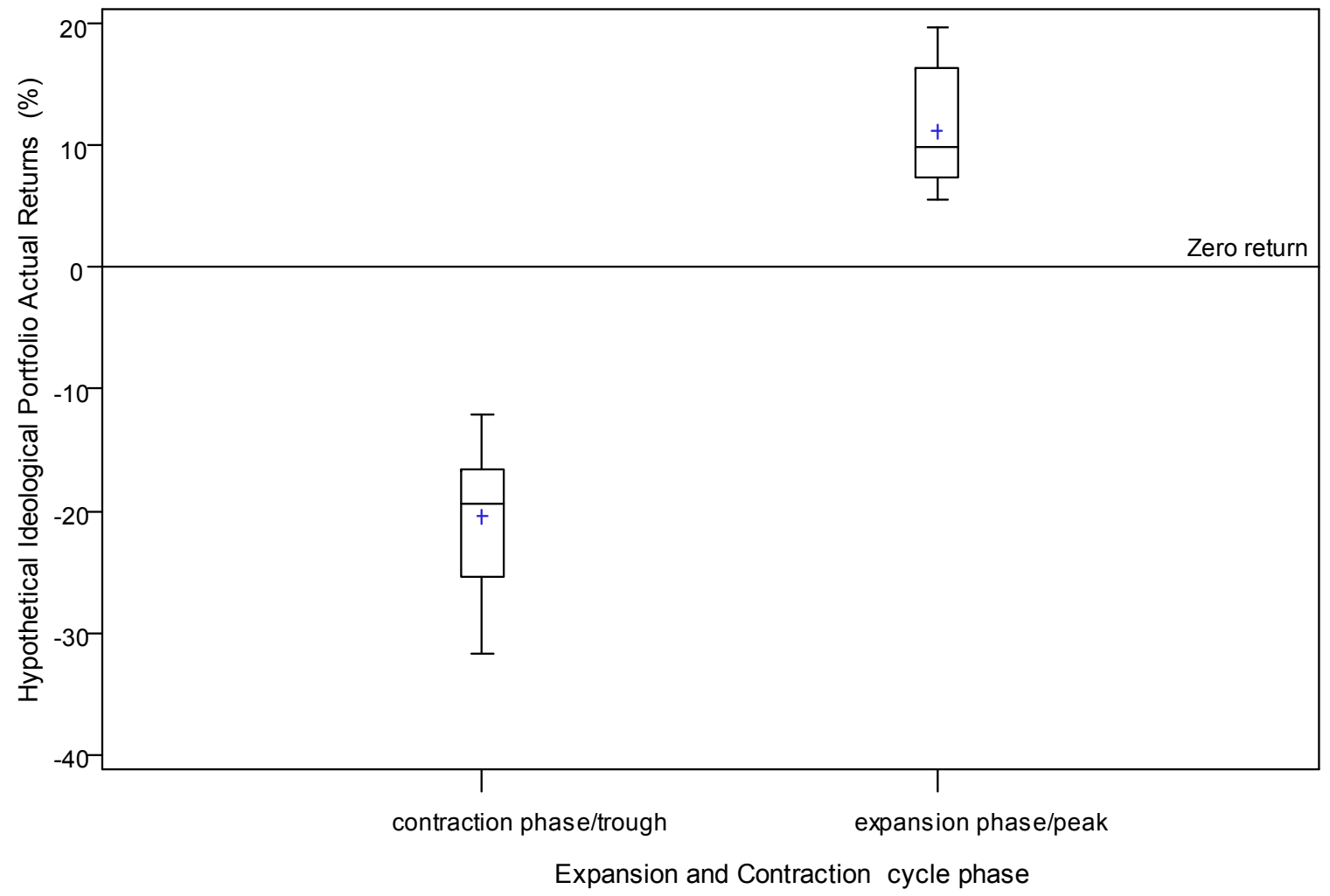

Figure 7. Hypothetical ideological portfolio actual returns by expansion and contraction cycle phase with outlier removed (September 2002 - June 2009).

Figure 7 summarizes the distribution and measures of central tendency of the actual returns on the hypothetical ideological portfolio of 11 equity mutual funds during the cycles identified between September 2002 and June 2009. On average, the hypothetical ideological portfolio yielded positive returns during the partial expansion/peak phase of September 2002 to December 2007 and negative returns during the contraction/trough phase of January 2008 to June 2009, also known as the Great Recession. Both phases exhibited a similar variability. During the period of economic contraction, the mean actual returns of the hypothetical ideological portfolio was $-20.4 \%$. 
During the period of economic expansion, the mean actual return of the hypothetical ideological portfolio was $11.2 \%$. The analysis yielded a standard deviation of 5.8 percentage points, or a variance of 33.64 percentage points during the contraction/trough phase. The expansion/peak phase is associated with a standard deviation of 4.5 percentage points, or a variance of 20.25 percentage points. This mean difference is statistically significant, $\mathrm{F}(1,21)=6.68, p=0.02$, according to Welch's ANOVA. The findings are also as expected.

\section{S\&P 500 Returns}

Like the actual returns on the hypothetical ideological portfolio, the S\&P 500 demonstrates a lower average return during the Great Recession of January 2008 to June 2009 than that of the partial expansion/peak phase of September 2002 to December 2007. During the Great Recession, the average return of the S\&P 500 was $-24.2 \%$. During the partial expansion/peak phase, the average return of the S\&P 500 was $13.2 \%$. As comparisons were based on the means by cycle phase, and there was only one contraction/trough and one expansion peak phase between September 2002 and June 2009, a standard deviation could not be computed based on the means by expansion/contraction cycle phase. Table 15 summarizes the findings discussed above. 
Table 15

Descriptive Statistics of the Hypothetical Ideological Portfolio and S\&P 500 Returns by Expansion and Contraction Cycle Phase (September 2002 - June 2009).

\begin{tabular}{|c|c|c|c|c|}
\hline Indicator & $\begin{array}{l}\text { Contraction/ } \\
\text { Trough }\end{array}$ & $\begin{array}{l}\text { Expansion/ } \\
\text { Peak }\end{array}$ & F-value & p-value \\
\hline $\begin{array}{l}\text { Hypothetical ideological } \\
\text { portfolio excess returns }\end{array}$ & $3.7 \%$ & $-1.9 \%$ & 6.68 & 0.02 \\
\hline $\begin{array}{l}\text { SD Hypothetical ideological } \\
\text { portfolio excess returns }{ }^{1}\end{array}$ & $(5.8)$ & $(4.4)$ & & \\
\hline $\begin{array}{l}\text { Hypothetical ideological } \\
\text { portfolio actual returns } 1\end{array}$ & $-20.4 \%$ & $11.2 \%$ & 204.10 & $<0.0001$ \\
\hline $\begin{array}{l}\text { SD Hypothetical ideological } \\
\text { portfolio actual returns }{ }^{1}\end{array}$ & $(5.8)$ & $(4.5)$ & & \\
\hline S\&P 500 returns & $-24.2 \%$ & $13.2 \%$ & & \\
\hline SD S\&P 500 returns & $\begin{array}{r}\text { not } \\
\text { applicable }\end{array}$ & $\begin{array}{r}\text { not } \\
\text { applicable }\end{array}$ & & \\
\hline
\end{tabular}

Note: Based on means for each fund.

Table 16

Results of Tests of Homogeneity of the Returns of a Hypothetical Ideological Portfolio (September 2002 - June 2009).

\begin{tabular}{lcr} 
& September 2002 to December 2007 \\
\cline { 2 - 2 } Test of Homogeneity of Variance & F-value & p-value \\
\hline Levene & 0.77 & 0.39 \\
O'Brien & 0.69 & 0.42 \\
Brown-Forsythe & 0.63 & 0.44 \\
\hline
\end{tabular}

Note: Based on means for each fund. 
Table 16 compares the variances of the hypothetical portfolio of ideological funds between the partial expansion/peak phase of September 2002 to December 2007 and the Great Recession of January 2008 to June 2009. The portfolio exhibited more consistent returns during the expansion/peak and contraction/trough phases between September 2002 and June 2009. There was general agreement among the tests that compared the volatility of the returns. That is, the hypothetical portfolio of ideological funds exhibited similar levels of volatility during the partial expansion/peak cycle phase of September 2002 to December 2007 and the Great Recession of January 2008 to June 2009.

These results are not consistent with the expectations of the conceptual model discussed earlier, wherein a hypothetical portfolio is expected to exhibit greater volatility during a contraction/trough phase than during an expansion/peak. The results suggest that individual business cycles may exhibit different characteristics time. The Great Recession was preceded by a relatively short period of high economic activity, There was general agreement among the three tests of homogeneity of variance of the returns on the hypothetical portfolio of ideological funds. The F-test for both Welch's ANOVA and the tests of homogeneity of variance could not be performed using the means for each cycle, as there was only one observation for the S\&P 500 during the contraction/trough and expansion/peak phases.

\section{Descriptive Statistics for the Portfolio Risk Factors and Control Variables}

This section describes the distribution and measures of central tendency of the risk factors related to the composition of the hypothetical portfolio of ideological funds and the control variables described in the conceptual model during the contraction/trough 
and expansion/peak phases between September 2002 and June 2009. The risk factors are the differential in the returns on portfolios consisting of small versus large capitalization companies, the differential in the returns on portfolios consisting of stocks with high versus low Book-to Market Value, and the momentum factor. The control variables measured are expenses, objective, fund size, and style.

Table 17

Descriptive Statistics of Portfolio Risk Factors and Control Variables by Expansion and Contraction Cycle Phase (September 2002 - June 2009).

\begin{tabular}{lrrrr} 
& Contraction/Trough & \multicolumn{1}{c}{ Expansion/Peak } \\
\hline Indicator & \multicolumn{1}{c}{ Mean } & \multicolumn{1}{c}{ SD } & \multicolumn{1}{c}{ Mean } & \multicolumn{1}{c}{ SD } \\
\hline Small vs. Large Firm (SMB) & $0.67 \%$ & 0.02 & $0.30 \%$ & 0.02 \\
High vs. Low Book-to-Market Value & $-0.44 \%$ & 0.04 & $0.26 \%$ & 0.02 \\
(HML) & & & & \\
Momentum (MOM) & $-1.77 \%$ & 0.1 & $0.13 \%$ & 0.04 \\
Net Asset Value (\$M) & $\$ 558.92$ & 609.31 & $\$ 833.92$ & 1185.36 \\
Natural log Net Asset Value (SIZ) & 5.72 & 1.22 & 5.61 & 1.67 \\
Turnover (EXP) & $55.6 \%$ & 0.38 & $49.3 \%$ & 0.44 \\
& & & &
\end{tabular}

Notes: (1) Based on monthly data.

(2) The Net Asset Value was transformed to its natural logarithmic (ln) form for use in the model.

According to Table 17, the portfolio risk factors and quantitative control variables measured during the sub-period September 2002 to June 2009 performed in almost the identical manner as the period April 1991 to June 2009. The analysis for April 1991 to 
June 2009 excluded the Vice Fund. The analysis of the sub-period September 2002 to June 2009 included the Vice Fund, which commenced trading in September 2002. The inclusion of the Vice Fund, therefore, did not make a qualitative difference to the indicators of performance when compared to the SRI portfolio. Although these are descriptive measures, and no comparative statistical tests were performed, the indicators suggest that there may be little difference between the excess returns generated by the Vice Fund and the SRI funds in general.

The small vs. large firm risk factor (SMB) differed in magnitude during the contraction/trough and expansion/peak phases of the cycles represented between September 2002 and June 2009, with a higher mean observed during the contraction phase. Its standard deviation remained the same. The coefficient of variation or ratio of its standard deviation to the mean would be much lower during the contraction/trough than during an expansion/peak. The difference suggests that its contribution to portfolio excess returns may be more relevant during the contraction/trough, when the skills of the portfolio manager become more relevant in delivering superior returns.

The high vs. low Book-to-Market Value (HML) factor differed in magnitude and direction during both cycle phases. Its standard deviation remained consistent over both phases of the business cycle, and the coefficients of variations lay in different directions. The mean of the momentum factor (MOM) lay in opposite directions. It was difficult to identify a potential effect on portfolio excess returns, though the momentum factor exhibited greater variability during a contraction/trough than during an expansion/peak.

The average Net Asset Value, a proxy for fund size, lost an average of $\$ 275 \mathrm{M}$ in value between the partial expansion/peak phase of September 2002 to December 2007 
and the Great Recession. Net Asset Value exhibits almost twice as much variability during the expansion/peak phase than during the contraction/trough phase. However, in its natural logarithmic form, Net Asset Value (SIZ) exhibited greater stability, with a more consistent mean. Fund turnover remained within the region defined as active fund management (over 30\%). Trading activity measured by fund turnover was slightly higher during the Great Recession than during the previous expansion/peak phase.

\section{Summary Statistics for Individual Cycle Phases}

This section compares the indicators of performance of the hypothetical SRI portfolio and market returns for the four (4) cycle phases between April 1991 and June 2009. Phase 1 represents a 120-month period of economic expansion beginning in April 1991, which peaked in March 2001. Phase 2 represents the eight-month period of economic contraction from April 2001 whose trough was announced by the NBER as November 2001. Phase 3 represents a 73-month period of economic expansion beginning in December 2001, which peaked in December 2007. Phase 4 represents the 18-month period of economic contraction beginning in January 2008 and lasting to June 2009, the end of the period of study. The expansion/peak of April 1991 to March 2001 spanned almost half of the period studied. The shortest phase was the contraction/trough of April to November 2001, which lasted only eight months. The Great Recession of January 2008 to June 2009 lasted 18 months, or less than $10 \%$ of the study period. As indicated earlier, there was no significant association between the length of individual cycle phases and the returns of the SRI portfolio $(\mathrm{r}=0.69, p=0.31)$. 


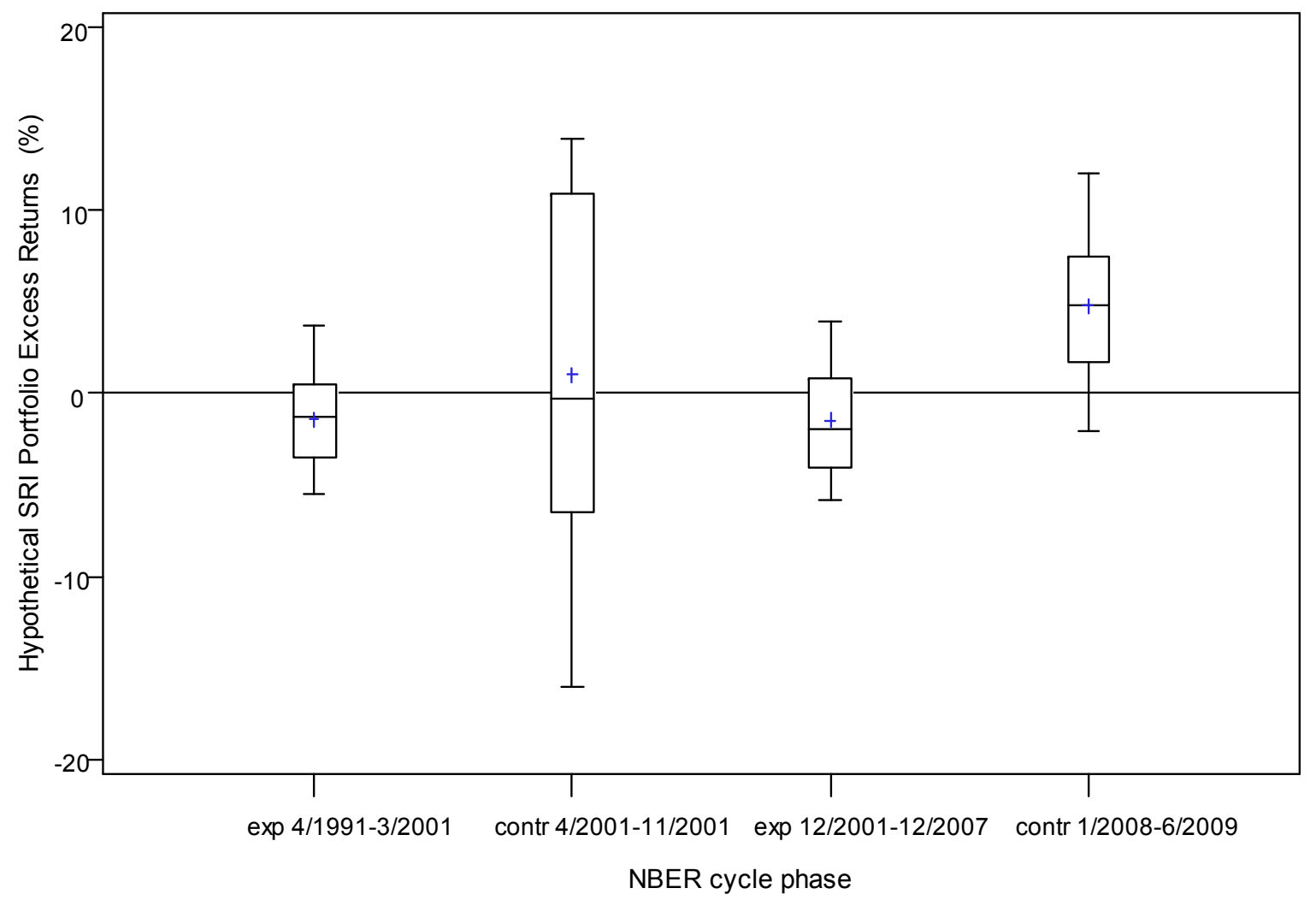

Figure 8. Hypothetical SRI portfolio excess returns by NBER cycle phase.

Figure 8 demonstrates that the hypothetical SRI portfolio experienced its highest excess returns during the Great Recession. During the expansion/peak phase of December 2001 to December 2007, the hypothetical SRI portfolio's excess returns hovered around zero returns. In comparing the two contraction/trough phases, the excess returns of the hypothetical SRI portfolio exhibited greater variability during the contraction/trough phase of April 2001 to November 2001, than during the Great Recession of January 2008 to December 2009. During the expansion/peak phase of April 1991 to March 2001, the excess returns of the portfolio exhibited greater variability than during the expansion/peak phase just before the Great Recession. 


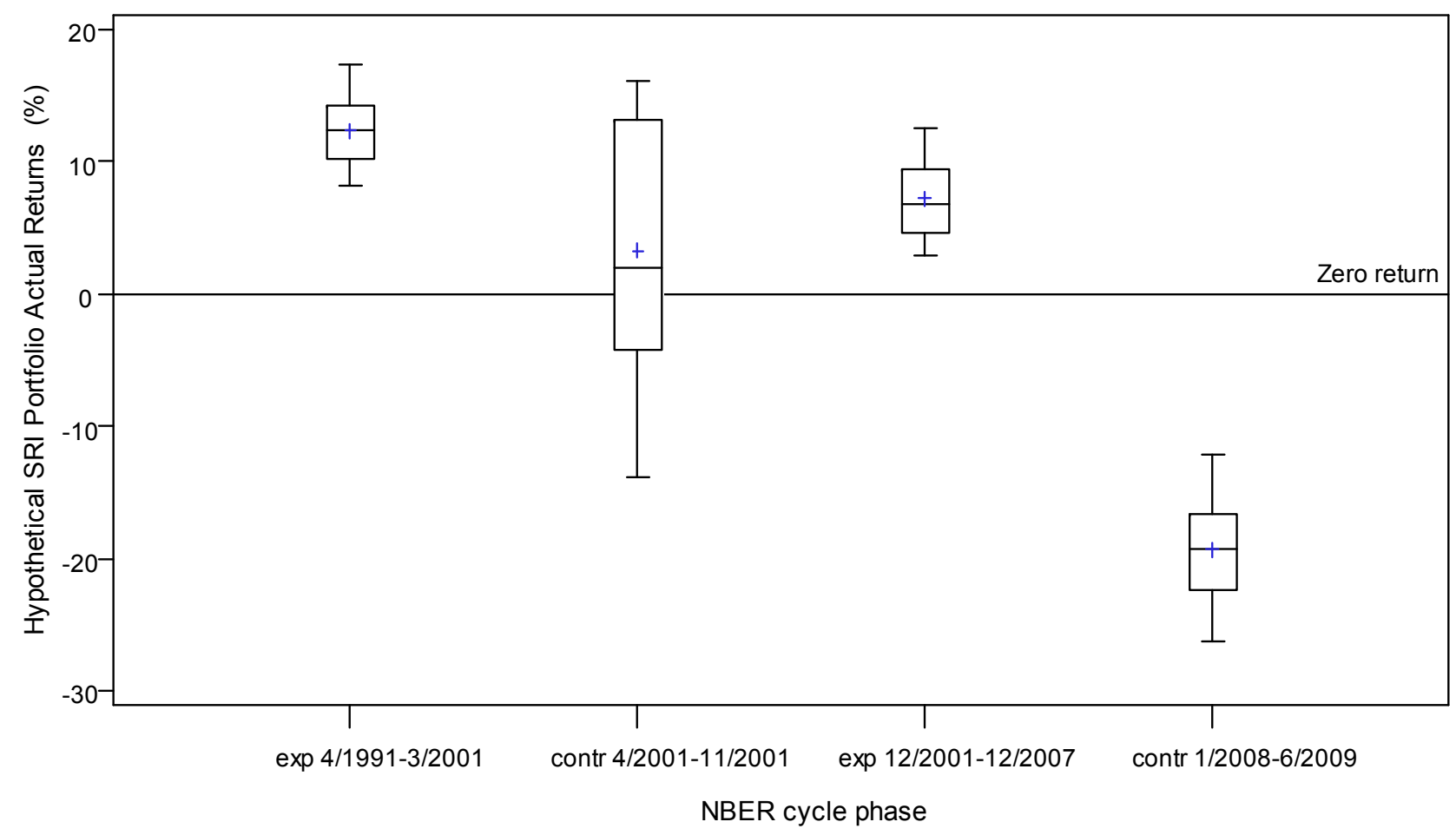

Figure 9. Hypothetical SRI portfolio actual returns by NBER cycle phase.

Figure 9 describes the returns of the hypothetical SRI portfolio by individual cycle phases. In comparing the contraction/trough of April to November 2001 with the Great Recession of January 2008 to June 2009, the returns of the hypothetical SRI portfolio, exhibited greater variability during the Great Recession of January 2008 to December 2009. Both expansion/peak phases saw positive returns on the hypothetical portfolio. 


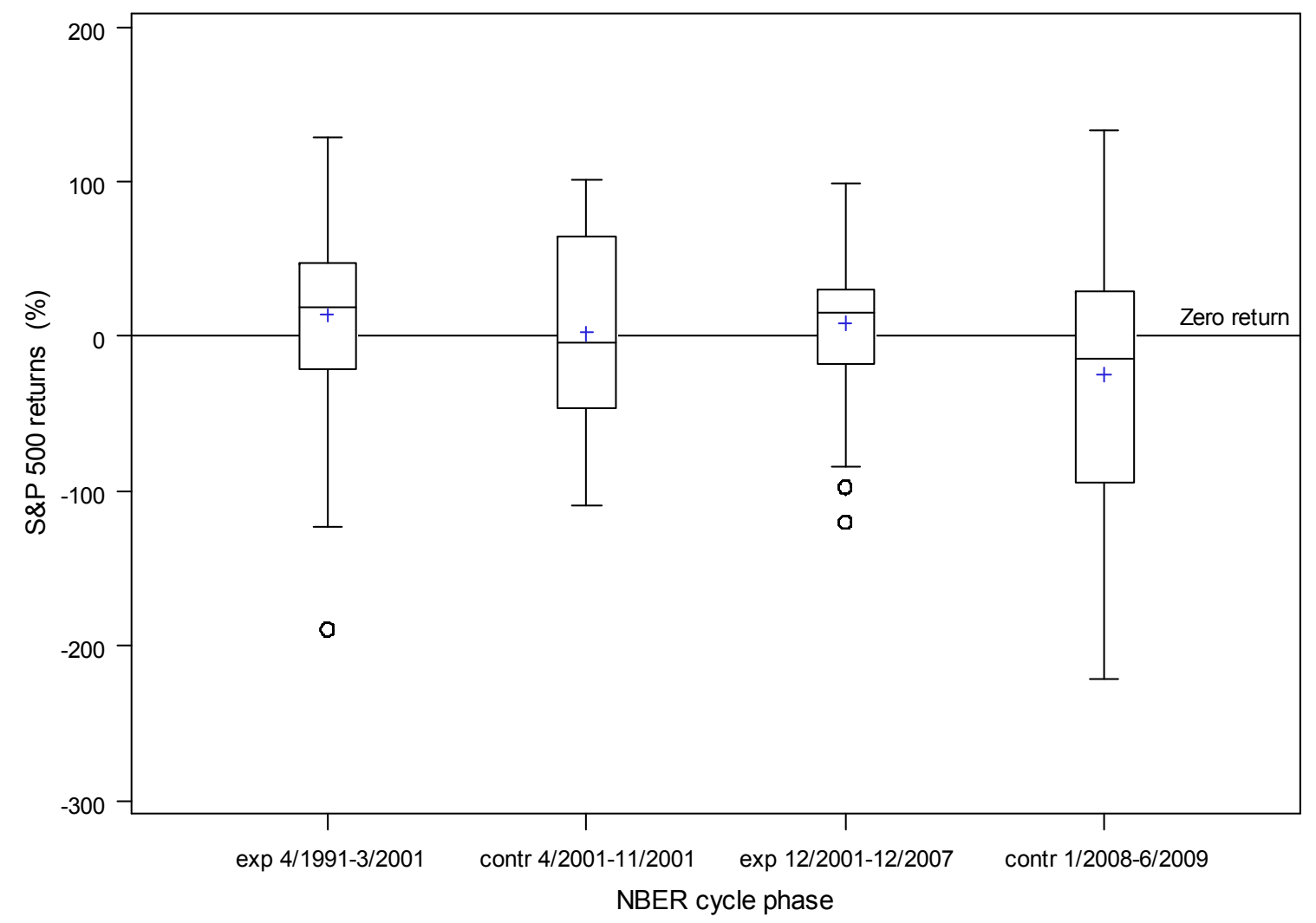

Figure 10. S\&P 500 returns by NBER cycle phase.

According to Figure 10, the S\&P 500 delivered average returns of around zero during each of the business cycle phases identified between April 1991 and June 2009. The box plot demonstrates that the returns of the S\&P 500 exhibited greater variability during the Great Recession of January 2008 to December 2009 than any other phase of the business cycle identified between April 1991 and June 2009. In comparing the expansion/peak phases, the returns of S\&P 500 also fluctuated more during the expansion/peak phase of April 1991 to March 2001, than during December 2001 to 2007. There were a few moderate outliers during both expansion/peak phases. 
Table 18

Descriptive Statistics by Individual Cycle Phase (April 1991 to June 2009).

\begin{tabular}{|c|c|c|c|c|c|c|}
\hline \multirow[b]{2}{*}{ Indicator } & \multicolumn{4}{|c|}{ Cycle phase } & \multirow[b]{2}{*}{ F-value } & \multirow[b]{2}{*}{$\mathrm{p}$-value } \\
\hline & $\begin{array}{r}\text { Expansion } \\
4 / 1991- \\
3 / 2001\end{array}$ & $\begin{array}{r}\text { Contraction } \\
4 / 2001- \\
11 / 2001\end{array}$ & $\begin{array}{r}\text { Expansion } \\
12 / 2001- \\
12 / 2007\end{array}$ & $\begin{array}{r}\text { Contraction } \\
1 / 2008- \\
6 / 2009\end{array}$ & & \\
\hline Excess Returns & $-1.4 \%$ & $1.1 \%$ & $-1.4 \%$ & $4.8 \%$ & 4.66 & 0.01 \\
\hline SD Excess Returns & $(2.7)$ & $(10.4)$ & $(3.4)$ & $(4.7)$ & & \\
\hline SRI fund returns & $12.4 \%^{\mathrm{a}}$ & $3.3 \%^{b}$ & $7.2 \%^{b}$ & $-19.3 \%^{c}$ & 107.92 & $<0.0001$ \\
\hline SD SRI fund returns & $(2.8)$ & $(10.4)$ & $(3.4)$ & $(4.7)$ & & \\
\hline S\&P 500 returns & $13.7 \%$ & $2.2 \%$ & $8.7 \%$ & $-24.2 \%$ & & \\
\hline
\end{tabular}

Note: Means with the same letter are not significantly different from each other, based on Bonferroni's correction and $\mathrm{p}=$ 0.05 . 
According to Table 18, the hypothetical SRI portfolio underperformed the S\&P 500 during both expansion/peak phases, in respect of the fund's returns. During both contraction/trough phases, the hypothetical SRI portfolio out-performed the S\&P 500. After Bonferroni's correction (Holm, 1979), the excess return did not differ across the individual cycle phases, indicating a stability of performance of the hypothetical SRI portfolio as compared with the S\&P 500. The returns on the hypothetical SRI portfolio differed across individual cycle phases, $\mathrm{F}(3,19.06)=107.92, p<0.0001$. The hypothetical SRI portfolio delivered its highest return $(M=12.4 \%)$ during the expansion/peak phase of April 1991 to March 2001. Gains in technology stocks made a significant contribution to the stock market's performance during the 1990s. After Bonferroni's correction, the returns on the hypothetical SRI portfolio did not differ significantly between the contraction/trough of April to November $2001(M=3.3 \%)$ and the expansion/peak phase of December 2001 to December 2007 ( $M=7.3 \%)$. However, the returns from both phases were significantly different from that of the earlier cycle of April 1991 to March 2001, and the Great Recession. During the Great Recession, the hypothetical SRI portfolio also delivered returns that were significantly different from the previous phases $(M=-19.3 \%)$.

The returns on the S\&P 500 differed across individual cycle phases, $\mathrm{F}(3,275.1)=$ $11.54, p<0.0001$. The S\&P 500 delivered its highest return $(M=13.7 \%)$ during the expansion/peak phase of April 1991 to March 2001. During the 1990s the performance of the S\&P 500 was influenced by the weighting assigned to technology stocks on the Index. After Bonferroni's correction, the returns on the hypothetical portfolio differed significantly between the Great Recession and all previous cycle phases. The S\&P 500 
delivered its lowest returns since April $1991(M=-24.2 \%)$ during the Great Recession. When the monthly returns of the S\&P 500, were evaluated, there were no significant difference between the returns generated by the S\&P 500 during the contraction/trough of April to November $2001(M=8.7 \%)$ and the expansion/peak phase of December 2001 to December $2007(M=2.2 \%)$.

\section{Results of the Tests of Hypotheses}

The current study evaluated Hypotheses 1, 2 and 3(a) simultaneously, based on Goldfeld and Quandt's switching regression model. The model extracted two regimes based on a binary state variable ' $s$ ' which assumes one of two values 1 or 2 , corresponding to the expansion and contraction phases of the business cycle. The above analysis indicated that the length of the cycle was not associated with the excess returns generated by the hypothetical portfolio of funds $(\mathrm{r}=0.68, p=0.31)$. Having eliminated this potential confound, there was a basis for testing the significance of the factors that influenced the excess return on the hypothetical SRI portfolio. Hypotheses 1 and 2 compared the fund-specific and market based factors that influenced the excess returns on a hypothetical SRI portfolio over expansion/peak phases and contraction/trough phases from April 1991 to June 2009. Hypothesis 3(a) compared the performance of religious and secular constituents of the hypothetical ideological portfolio. Hypothesis 3(b) compared the performance of the secular fund constituents of the hypothetical ideological portfolio with the Vice Fund, which was established in 2002. Hypothesis 3(c) compared the performance of the religious fund constituents of the Vice Fund. As a result, the subperiod of analysis for Hypotheses 3(a), 3(b), and 3(c) were adjusted to a start date of 
September 2002, to permit comparisons between secular funds and the Vice Fund and religious funds and the Vice Fund of the hypothetical ideological portfolio.

The period of comparison spanned the partial expansion/peak phase of September 2002 to December 2007 and the Great Recession of January 2008 to June 2009.The explanatory variables were the four factors identified by Carhart $(1997 ; 1995)$. The four factors were the excess return of the market over the risk free rate, the differential between the returns on portfolios based on high vs. low Book-to-Market Value, or large vs. small capitalization companies and momentum. In addition, the model controlled for differences based on fund style, objective, and the size of the fund measured by its Net Asset Value (NAV). The indicator of fund size was transformed to its natural logarithmic form because of the skewed nature of its distribution. The model also controlled for fund turnover (a measure of fund variable expenses). The findings of the tests of each Hypothesis follow. Chapter 5 discusses the conceptual and managerial implications of the findings.

\section{Hypothesis 1 Test of Business Cycle Effect}

Hypothesis 1 compared the average excess returns of the hypothetical SRI portfolio of ten equity mutual funds over the expansion/contraction cycle phases identified by the NBER between April 1991 and June 2009 based on the financial environmental variables identified by Carhart (1997; 1995). The study included controls for fund-specific factors such as turnover, fund size, style, and objective. Table 19 summarizes the findings of the test of Hypothesis 1 for the period April 1991 to June 2009. 
Table 19

Factors determining Excess Returns of a Hypothetical Portfolio of SRI Equity Mutual Funds (April 1991 to June 2009).

\begin{tabular}{|c|c|c|c|c|}
\hline \multirow[b]{2}{*}{ Parameter } & \multicolumn{2}{|c|}{ Contraction/Trough } & \multicolumn{2}{|c|}{ Expansion/Peak } \\
\hline & $\begin{array}{l}\text { Estimate } \\
\text { (t-value) }\end{array}$ & p-value & $\begin{array}{c}\text { Estimate } \\
\text { (t-value) }\end{array}$ & $\mathrm{p}$-value \\
\hline $\begin{array}{l}\text { Natural log of fund } \\
\text { size (SIZ) }\end{array}$ & $\begin{array}{r}-0.0003 \\
(-0.29)\end{array}$ & 0.77 & $\begin{array}{r}0.0002 \\
(0.31)\end{array}$ & 0.75 \\
\hline $\begin{array}{l}\text { Small vs. large firm \% } \\
\text { (SMB) }\end{array}$ & $\begin{array}{r}0.26 \\
(2.84)\end{array}$ & 0.005 & $\begin{array}{r}-0.10 \\
(-1.54)\end{array}$ & 0.12 \\
\hline $\begin{array}{l}\text { High vs. low Book-to- } \\
\text { Market Value \% } \\
\text { (HML) }\end{array}$ & $\begin{array}{r}0.39 \\
(5.53)\end{array}$ & $<0.0001$ & $\begin{array}{r}-0.08 \\
(-1.41)\end{array}$ & 0.16 \\
\hline $\begin{array}{l}\text { Market excess return } \\
\text { over the risk-free rate } \\
\text { (RMRF) }\end{array}$ & $\begin{array}{r}0.74 \\
(14.01)\end{array}$ & $<0.0001$ & $\begin{array}{r}0.93 \\
(24.92)\end{array}$ & $<0.0001$ \\
\hline $\begin{array}{l}\text { Fund objective }(\mathrm{OBJ}) \\
1=\text { Growth, } 0=\text { Other }\end{array}$ & $\begin{array}{r}0.01 \\
(2.31)\end{array}$ & 0.02 & $\begin{array}{r}-0.01 \\
(-2.11)\end{array}$ & 0.03 \\
\hline Turnover \% (EXP) & $\begin{array}{l}-0.004 \\
(-0.67)\end{array}$ & 0.50 & $\begin{array}{r}0.001 \\
(0.17)\end{array}$ & 0.86 \\
\hline $\begin{array}{l}\text { Momentum \% } \\
(\mathrm{MOM})\end{array}$ & $\begin{array}{r}-0.06 \\
(-1.63)\end{array}$ & 0.10 & $\begin{array}{r}-0.05 \\
(-1.68)\end{array}$ & 0.09 \\
\hline $\begin{array}{l}\text { Orientation (REL) } \\
1=\text { Religious, } \\
0=\text { Secular }\end{array}$ & $\begin{array}{l}-0.002 \\
(-0.31)\end{array}$ & 0.76 & $\begin{array}{r}0.002 \\
(0.42)\end{array}$ & 0.68 \\
\hline $\begin{array}{l}\text { Style (STYLE) } \\
1=\text { Large growth, } \\
0=\text { Value }\end{array}$ & $\begin{array}{l}-0.001 \\
(-0.16)\end{array}$ & 0.87 & $\begin{array}{l}-0.002 \\
(-0.07)\end{array}$ & 0.95 \\
\hline $\mathrm{S}$ & $5.2 \%$ & $<0.0001$ & $1.6 \%$ & $<0.0001$ \\
\hline
\end{tabular}


According to Table 19, the model identified two regimes characterized by low and high volatility. The regimes were associated with changes in the dividend yield. According to the model, the volatility of excess returns was 3.5 times higher during the high volatility period than during the low volatility period. The standard deviation of excess returns of the high volatility period mentioned previously $\left(\mathrm{s}_{1}=5.3, \mathrm{p}<0.001\right)$ was consistent with the characteristic of a contraction/trough phase of the business cycle (actual $\mathrm{s}_{1}=8.0$ ). The standard deviations of excess returns of the low volatility period $\left(\mathrm{s}_{2}=1.6, \mathrm{p}<0.001\right)$ was consistent with an expansion/peak phase (actual $\mathrm{s}_{2}=3.0$ ), shown in Table 10. The results were in accordance with previous work that examines the effect of Federal monetary policy on the stock market (Bernanke \& Kuttner, 2004; Davig \& Gerlach, 2006). The findings therefore, supported the presence of different responses of SRI excess returns to changes in the dividend yield. The findings also suggested that different factors influenced excess returns under different economic conditions. That is, the fund manager may emphasize different factors at different stages of the business cycle.

During contraction/trough periods, excess returns were explained by the portfolio's focus on the differential in returns between portfolios based on small and large capitalization companies (SMB) where $\mathrm{t}(2.84), p=0.005$, the differential in returns between portfolios based on high and low Book-to-Market Values (HML), where t(5.53), $p<0.0001$, the market excess return over the risk-free rate (RMRF), where $\mathrm{t}(14.01), p<$ 0.0001 , and the objective of the constituent funds (OBJ), where $\mathrm{t}(2.31), p=0.02$. During contraction/troughs, portfolios focused on smaller companies delivered superior returns than those focused on larger companies $\left(c_{1}=0.26\right)$. In addition, portfolios that focused on 
undervalued stocks delivered higher returns than portfolios that focused on growth stocks $\left(h_{1}=0.39\right)$. During a recession, SRI portfolios that focused on growth objectives delivered higher returns than portfolios with other objectives $\left(o_{1}=0.01\right)$.

During expansion/peaks, excess returns were explained by the market excess return over the risk-free rate (RMRF) where $\mathrm{t}(24.92), p<0.0001$, and the objective of the constituent funds (OBJ), where $\mathrm{t}(-2.1), p=0.03$. During an expansion, SRI portfolios that focused on growth objectives delivered lower returns than portfolios with other objectives $\left(o_{2}=-0.01\right)$.

During contraction/trough phases, the correlation between average SRI fund returns and the market's performance was $0.83(p<0.0001)$. During the expansion/peak phases the correlation was $0.65(p<0.0001)$. When compared using Fisher's $\mathrm{R}$ to $\mathrm{Z}$ transformation (Fisher, 1915), the difference between the two correlation coefficients ( $\mathrm{Z}$ $=-1.70, p=0.08)$ was not significant. The square of the correlation coefficient is known as the R-square. During the expansion/peak phases, the R-square was 0.64. The R-square was 0.40 during the contraction/trough phases. While SRI screening may reduce the available options for diversification, it appeared that the SRI fund manager's limited universe for stock selection did not result in significant differences in portfolio performance over the contraction/trough phases of the 1991 - 2009 period, when compared to the market.

The difference between the market return and the 30-day risk free alternative was a significant determinant of the excess returns of the hypothetical SRI portfolio during contraction/trough, where $\mathrm{t}(14.01), \mathrm{p}<0.0001$ and expansion/peak phases, where $\mathrm{t}(24.92), \mathrm{p}<0.0001$. According to the Lagrange Multiplier test equivalent of Rao's 
efficient score test statistic, the hypothetical SRI portfolio did not exhibit significantly different risk from the market during the expansion/peak phases $\left(b_{1}=0.93, \mathrm{LM}=3.25, p\right.$ $=0.07)$. During the contraction/trough phases, the hypothetical SRI portfolio exhibited significantly less risk than the market $\left(b_{2}=0.74, L M=20.82, p<0.0001\right)$. As hypotheses 3(b) and 3(c) are based on the sub-period September 2002 to June 2009, Table 20 evaluates the business cycle effect for the period September 2002 to June 2009. 
Table 20

Factors determining Excess Returns of a Hypothetical Portfolio of Equity Mutual Funds (September 2002 to June 2009).

\begin{tabular}{|c|c|c|c|c|}
\hline \multirow[b]{2}{*}{ Parameter } & \multicolumn{2}{|c|}{ Contraction/Trough } & \multicolumn{2}{|c|}{ Expansion/Peak } \\
\hline & $\begin{array}{l}\text { Estimate } \\
\text { (t-value) }\end{array}$ & p-value & $\begin{array}{l}\text { Estimate } \\
\text { (t-value) }\end{array}$ & p-value \\
\hline $\begin{array}{l}\text { Natural log of fund size } \\
\text { (SIZ) }\end{array}$ & $\begin{array}{r}0.001 \\
(0.82)\end{array}$ & 0.41 & $\begin{array}{l}-0.001 \\
(-1.73)\end{array}$ & 0.08 \\
\hline $\begin{array}{l}\text { Small vs. large firm \% } \\
(\mathrm{SMB})\end{array}$ & $\begin{array}{r}0.42 \\
(2.58)\end{array}$ & 0.01 & $\begin{array}{r}-0.08 \\
(-1.43)\end{array}$ & 0.15 \\
\hline $\begin{array}{l}\text { High vs. low Book-to- } \\
\text { Market Value \% (HML) }\end{array}$ & $\begin{array}{l}0.003 \\
(0.02)\end{array}$ & 0.98 & $\begin{array}{r}-0.05 \\
(-0.91)\end{array}$ & 0.36 \\
\hline $\begin{array}{l}\text { Market excess return } \\
\text { over the risk-free rate } \\
(\mathrm{RMRF})\end{array}$ & $\begin{array}{r}0.86 \\
(12.31)\end{array}$ & $<.0001$ & $\begin{array}{r}0.88 \\
(27.56)\end{array}$ & $<0.0001$ \\
\hline $\begin{array}{l}\text { Fund objective }(\mathrm{OBJ}) \\
1=\text { Growth, } 0=\text { Other }\end{array}$ & $\begin{array}{l}-0.001 \\
(-0.06)\end{array}$ & 0.95 & $\begin{array}{l}-0.002 \\
(-0.73)\end{array}$ & 0.46 \\
\hline Turnover \% (EXP) & $\begin{array}{r}0.01 \\
(0.68)\end{array}$ & 0.50 & $\begin{array}{l}-0.005 \\
(-1.76)\end{array}$ & 0.08 \\
\hline Momentum \% (MOM) & $\begin{array}{r}-0.06 \\
(-1.17)\end{array}$ & 0.24 & $\begin{array}{r}-0.01 \\
(-0.24)\end{array}$ & 0.80 \\
\hline $\begin{array}{l}\text { Orientation (REL) } \\
\text { 1=Religious, } 2=\text { Secular, } \\
3=\text { Vice }\end{array}$ & $\begin{array}{r}-0.01 \\
(-0.91)\end{array}$ & 0.36 & $\begin{array}{l}0.002 \\
(0.71)\end{array}$ & 0.48 \\
\hline $\begin{array}{l}\text { Style (STYLE) } \\
1=\text { Large growth, } \\
0=\text { Value }\end{array}$ & $\begin{array}{r}-0.01 \\
(1.18)\end{array}$ & 0.24 & $\begin{array}{l}0.004 \\
(2.66)\end{array}$ & 0.01 \\
\hline S & $4.5 \%$ & $<0.0001$ & $1.6 \%$ & $<0.0001$ \\
\hline
\end{tabular}

$\mathrm{R}^{2}=0.80$ 
The hypothetical ideological portfolio (Table 20) which was evaluated for the sub-period September 2002 to June 2009 consists of eleven equity mutual funds. One component is the Vice Fund, established in September 2002. With its focus on vice, the Vice Fund represents the contrary point of view to SRI investing. According to the model, there were two regimes characterized by low volatility (expansion/peak) and high volatility (contraction/trough). The statistics and parameters were somewhat different from those obtained for the full period. The volatility of excess returns, defined as $\mathrm{s}$ in the identified by the model is three times higher during the high volatility period than during the low volatility period. The standard deviation of the high volatility period $\left(\mathrm{s}_{1}=4.5\right.$, $\mathrm{p}<0.001)$ shown in Table 20 is consistent with the characteristic of a contraction/trough phase of the business cycle (actual $\mathrm{s}_{1}=5.8$ ) shown in Table 15 . The low volatility period $\left(\mathrm{s}_{2}=1.6, \mathrm{p}<0.001\right)$ is consistent with an expansion/peak phase (actual $\left.\mathrm{s}_{2}=4.4\right)$ shown in Table 15. Although somewhat different from the results of the full period, the findings of the sub-period also suggest that different factors explain excess returns under different phases of the business cycle.

During the Great Recession, the excess returns of the hypothetical ideological portfolio were explained by the portfolio's focus on the differential in returns between portfolios based on small and large companies (SMB), where $\mathrm{t}(2.58), p=0.01$, and the market excess return over the risk-free rate (RMRF), where $\mathrm{t}(12.31), p<0.0001$. The explanatory variables accounted for $80 \%$ of the variation in excess returns, a $10-$ percentage point improvement over the model fit for the full period April 1991 to June 2009. During the Great Recession, a portfolio that focused on smaller companies delivered superior returns $\left(c_{l}=0.42\right)$. During the partial expansion/peak phase of 
September 2002 to December 2007, the hypothetical ideological portfolio's excess returns were explained by the market excess return over the risk-free rate (RMRF), where $\mathrm{t}(27.56), p<0.0001$, and the style of the manager (STYLE), where $\mathrm{t}(2.66), p=0.01$. This is consistent with the 'bubble' that existed in the US stock market during the early 2000s. The hypothesis that the coefficient of the market excess return over the risk-free rate was one, was rejected, based on the results of the Lagrange Multiplier equivalent of the Cramer-Rao test, indicating that the hypothetical ideological portfolio was significantly less risky than the market during both contraction/trough $\left(b_{1}=0.86, L M=\right.$ 3.87, $p=0.49)$ and expansion/peak phases $\left(\mathrm{b}_{2}=0.88, \mathrm{LM}=12.74, p<0.0001\right)$. During the partial expansion/peak of September 2002 to December 2007, the returns generated from the large growth style of investing delivered superior results to other styles $\left(\mathrm{y}_{2}=\right.$ $0.004)$.

The findings supported the presence of different factors that explained SRI fund excess returns during contraction/trough and expansion/peak periods of the business cycle, although individual cycles appeared to exhibit unique characteristics. For the period April 1991 to June 2009, the findings supported Hypothesis 1.1(a), which states that the excess return of a hypothetical SRI portfolio is more sensitive to changes in the market during a contraction/trough than during an expansion/peak. According to Table 19 , the change in excess returns resulting from a unit change in market returns is 0.93 during an expansion/peak, as against 0.75 during a contraction/trough. For the period September 2002 to June 2009, the findings did not support either form of Hypothesis 1(a). The hypothetical ideological portfolio exhibited approximately equal sensitivity to changes in the market during the partial expansion/peak of September 2002 to December 
2007 and the Great Recession of January 2008 to June 2009. According to Table 20, the change in excess returns resulting from a unit change in market returns is 0.88 during an expansion/peak, and 0.88 during a contraction/trough.

The findings partially supported Hypothesis 1.1(b), for the period April 1991 to June 2009, as the incremental return on holdings of smaller vs. larger companies (SMB) made a positive and significant contribution to the excess returns of the hypothetical SRI fund only during the contraction/trough phases. Neither form of Hypothesis 1(b) was supported by the findings for the period September 2002 to June 2009. The findings supported Hypothesis 1(c) for the period April 1991 to June 2009 for the contraction/troughs, as the incremental return on holdings of under-valued vs. overvalued or fully priced stocks (HML) made a positive, significant contribution to the excess returns of the hypothetical SRI portfolio during contraction/troughs $\left(\mathrm{b}_{1}=0.39, \mathrm{p}<\right.$ $0.0001)$, but not during expansion/peaks $\left(\mathrm{b}_{2}=-0.08, p=0.16\right)$. Hypothesis $1(\mathrm{c})$ was not supported by the findings for the period September 2002 to June 2009 .

Hypothesis 1(d) which refers to the influence of momentum (MOM), was not supported by the findings for the full period, April 1991 to June 2009 and the sub-period of September 2002 to June 2009. This is consistent with the practice of SRI of balancing the goals of social performance with that of financial risk and return. SRI investing emphasizes the analysis of corporate data on financial and social performance. As such, the SRI fund manager is likely to have taken all available information into account at the time of the investment. 


\section{Hypothesis 2 Test of SRI Value Added Proposition}

Hypothesis 2 identified the value added by SRI screening, using Jensen's Alpha. Jensen's alpha is derived from the Capital Asset Pricing Model (CAPM). The CAPM posits that excess returns on a portfolio are explained by the market excess returns over the risk-free rate. The difference between actual and expected returns is Jensen's alpha. According to Table 21, Jensen's alpha was negative, and significantly different from zero during expansion/peak phases. Observing that Jensen's alpha was negative, it may be inferred that SRI screening detracts from the returns of the hypothetical SRI portfolio. The findings did not support either form of Hypothesis 2.

\section{Table 21}

Comparisons of Jensen's Alpha and the Beta Coefficient of a Hypothetical Portfolio of SRI Equity Mutual Funds (April 1991 - June 2009).

\begin{tabular}{|c|c|c|c|c|}
\hline \multirow{2}{*}{ Parameter } & \multicolumn{2}{|c|}{ Contraction/Trough } & \multicolumn{2}{|c|}{ Expansion/Peak } \\
\hline & $\begin{array}{l}\text { Estimate } \\
\text { (t-value) }\end{array}$ & p-value & $\begin{array}{l}\text { Estimate } \\
\text { (t-value) }\end{array}$ & $\mathrm{p}$-value \\
\hline Jensen’s Alpha & $\begin{array}{r}0.004 \\
(1.77)\end{array}$ & 0.08 & $\begin{array}{l}-0.003 \\
(-2.39)\end{array}$ & 0.02 \\
\hline Beta & $\begin{array}{r}0.83 \\
(18.51)\end{array}$ & $<0.0001$ & $\begin{array}{r}0.85 \\
(25.15)\end{array}$ & $<0.0001$ \\
\hline
\end{tabular}

Any study of Jensen's alpha must be accompanied by a study of the relevant beta coefficient. During expansion/peak and contraction/trough phases, the returns on the hypothetical portfolio of funds moved in the same direction as the market. The beta 
coefficient of a portfolio measures the extent of the influence of the market on the hypothetical portfolio's returns. The beta coefficient is the ratio of the covariance of the market's return and that of the portfolio to the variance of the market. A beta of approximately 1 suggests that the asset being studied is approximately as risky as the market. A beta of less than 1 suggests that the asset being studied is less risky than the market. During the expansion/peak phases, the beta coefficient of 0.85 , was significantly less than $1(\mathrm{LM}=19.1, p<0.0001)$. This means that the hypothetical SRI portfolio exhibited significantly less risk than the market, as a unit change in the market's returns resulted in a 0.85 change in the returns of the hypothetical SRI portfolio. Similarly, during the contraction/trough phases, the beta coefficient of 0.83 is significantly less than $1(\mathrm{LM}=33.8, p<0.0001)$. The hypothetical SRI portfolio was significantly less risky than the S\&P 500, during both phases of the business cycle. However, the value added is not 'true alpha' as defined by Siegel (2009), as it is the result of 'asset class exposure', rather than management skill.

\section{Hypothesis 3(a) Comparison of Religious and Secular SRI Funds}

Hypothesis 3(a) compared the average excess returns of religious and secular funds over the expansion/contraction cycle phases identified by the NBER between April 1991 and June 2009, after controlling for the financial environmental variables identified by Carhart $(1997 ; 1995)$ and fund-specific factors, such as turnover, fund size, style, and objective, as shown in Table 20. As such, the parameter of interest was the coefficient of the REL variable. The coefficient measured the average difference in excess returns of religious SRI funds (coded 1) compared to secular SRI funds (coded 0). The parameter 
was evaluated over the 219-month period covering the two expansion/peak and two contraction/trough phases between April 1991 and June 2009. For comparison, the parameter was also evaluated over the 82-month period from September 2002 to June 2009.

Table 22

Comparisons of the Performance of Religious and Secular SRI Equity Mutual Funds.

\begin{tabular}{|c|c|c|c|c|}
\hline \multirow[b]{2}{*}{ Parameter } & \multicolumn{2}{|c|}{ Contraction/Trough } & \multicolumn{2}{|c|}{ Expansion/Peak } \\
\hline & $\begin{array}{l}\text { Estimate } \\
\text { (t-value) }\end{array}$ & p-value & $\begin{array}{l}\text { Estimate } \\
\text { (t-value) }\end{array}$ & $\mathrm{p}$-value \\
\hline $\begin{array}{l}\text { Religious vs. secular } \\
\text { SRI funds } \\
\text { April 1991-June } 2009\end{array}$ & $\begin{array}{l}-0.002 \\
(-0.31)\end{array}$ & 0.76 & $\begin{array}{r}0.002 \\
(0.42)\end{array}$ & 0.68 \\
\hline $\begin{array}{l}\text { Religious vs. secular } \\
\text { SRI funds } \\
\text { Sept } 2002 \text {-June } 2009\end{array}$ & $\begin{array}{l}-0.006 \\
(-0.57)\end{array}$ & 0.57 & $\begin{array}{l}-0.001 \\
(-0.47)\end{array}$ & 0.63 \\
\hline
\end{tabular}

Note: 1 = Religious, $0=$ Secular.

Table 22 summarizes the findings of the test of Hypothesis 3(a) for the full period of April 1991 to June 2009 and the sub-period September 2002 to June 2009. According to Table 22, the model did not identify the presence of a business cycle effect in the comparative performance of religious SRI funds and secular SRI funds. During both the contraction/trough phase and the expansion/peak phase, there were no significant differences between the performance of religious and secular funds. The findings therefore did not support the either form of Hypothesis 3(a). 


\section{Hypothesis 3(b) Comparison of Secular SRI Funds and the Vice Fund}

Hypothesis 3(b) compared the average excess returns of secular SRI funds and the Vice Fund over the expansion/contraction cycle phases identified by the NBER, after controlling for the financial environmental variables identified by Carhart $(1997 ; 1995)$ and fund-specific factors such as turnover, fund size, style, and objective as shown in Table 20. The coefficient measured the average difference in excess returns of secular SRI funds (coded 1) compared to the Vice Fund (coded 0). The parameter was evaluated over 82 months from September 2002 and June 2009, because the Vice Fund started in September 2002 .

Table 23

Comparisons of the Performance of Secular SRI Equity Mutual Funds and the Vice Fund.

\begin{tabular}{|c|c|c|c|c|}
\hline \multirow[b]{2}{*}{ Parameter } & \multicolumn{2}{|c|}{ Contraction/Trough } & \multicolumn{2}{|c|}{ Expansion/Peak } \\
\hline & $\begin{array}{l}\text { Estimate } \\
\text { (t-value) }\end{array}$ & p-value & $\begin{array}{l}\text { Estimate } \\
\text { (t-value) }\end{array}$ & $\mathrm{p}$-value \\
\hline $\begin{array}{l}\text { Secular SRI funds vs. } \\
\text { the Vice Fund }\end{array}$ & $\begin{array}{r}-0.01 \\
(-0.58)\end{array}$ & 0.56 & $\begin{array}{l}-0.003 \\
(-0.95)\end{array}$ & 0.34 \\
\hline
\end{tabular}

Sept 2002-June 2009

Note: Secular $=1$, Vice $=0$.

According to Table 23, the model did not identify the presence of a business cycle effect in the comparative performance of secular SRI funds and the Vice Fund. During the Great Recession, there was no significant difference between the performance of secular funds and the Vice Fund. The findings therefore do not support Hypothesis 3(b). 


\section{Hypothesis 3(c) Comparison of Religious Funds and The Vice Fund}

Hypothesis 3(c) compared the average excess returns of religious SRI funds and the Vice Fund over the expansion/contraction cycle phases identified by the NBER, after controlling for the financial environmental variables identified by Carhart $(1997 ; 1995)$ and fund-specific factors such as turnover, fund size, style, and objective, as shown in Table 20. The parameter of interest was the coefficient of the REL variable. The coefficient measures the average difference in excess returns of religious SRI funds (coded 1) compared to the Vice Fund (coded 0). The parameter was evaluated over 82 months from September 2002 to June 2009.

\section{Table 24}

Comparisons of the Performance of Religious SRI Equity Mutual Funds and The Vice Fund.

\begin{tabular}{lrrrr} 
& Contraction/Trough & \multicolumn{1}{c}{ Expansion/Peak } \\
Parameter & $\begin{array}{l}\text { Estimate } \\
\text { (t-value })\end{array}$ & p-value & $\begin{array}{l}\text { Estimate } \\
(\text { t-value })\end{array}$ & p-value \\
\hline $\begin{array}{l}\text { Religious SRI funds } \\
\text { vs. The Vice Fund }\end{array}$ & -0.01 & 0.90 & -0.01 & 0.76 \\
Sept 2002-June 2009 & $(-0.13)$ & & $(-0.30)$ & \\
\hline-
\end{tabular}

Note: Vice $=1$, Religious $=0$.

According to Table 24, the model did not identify the presence of a business cycle effect in the comparative performance of religious SRI funds and the Vice Fund. During the contraction/trough phase and the expansion/peak phase, there were no significant 
differences between the performance of religious funds and the Vice Fund. The findings therefore, did not support Hypothesis 3(c).

\section{Validity of the Model}

The validity of the model relies on its adherence to the assumptions of regression analysis. Specifically, the model was evaluated by tests for a normally distributed error term and the absence of serial correlation or independence of the error terms. For the full period April 1991 to June 2009, the collinearity diagnostics revealed a maximum condition index of 17.9. This statistic exceeded the generally accepted critical value of 10 that indicates the presence of multicollinearity among the explanatory variables. The Marquardt-Levenberg method adapted the model to account for this collinearity (Marquardt, 1963). A normal probability plot of the standardized residuals lay within the limits of normality. The UNIVARIATE PROCEDURE reported a mean of 0 and standard deviation of 1. A plot of the standardized residuals and exhibited a constant variance, which mostly fell within one standard deviation of the zero mean. Neither the White test nor the modified Breusch-Pagan test of heteroscedasticity of the error term could be performed, as the model was based on a general likelihood. The Durbin-Watson test reported the absence of serial correlation ( $\mathrm{DW}=1.73, p=0.99)$ among the residuals. Collinearity was not an issue with the CAPM variation of the model, from which Jensen's alpha was derived, as there was only one explanatory variable. The normal probability plot of the standardized residuals lay within the limits of normality. A plot of the standardized residuals and exhibited a constant variance, which mostly fell within one standard deviation of the zero mean. The UNIVARIATE PROCEDURE reported a mean 
of 0 and standard deviation of 1 . The Durbin-Watson test, which diagnoses the presence of serial correlation among the error terms reported the absence of serial correlation (DW $=1.75, p=0.99)$ among the residuals.

For the partial period September 2002 to June 2009, the collinearity diagnostics revealed a maximum condition index of 18.9 , indicating the presence of multicollinearity among the explanatory variables. A normal probability plot of the standardized residuals lay within the limits of normality. The UNIVARIATE PROCEDURE reported a mean of 0 and standard deviation of 1 . A plot of the standardized residuals and exhibited a constant variance, which mostly fell within one standard deviation of the zero mean. The Durbin-Watson test reported the absence of serial correlation $(\mathrm{DW}=1.87, p=0.98)$ among the residuals.

\section{Supplementary Analyses}

The supplementary analysis compared the performance of the hypothetical SRI portfolio with that of the S\&P 500, an indicator of overall market performance. The Vice Fund was not included, as it did not exist prior to September 2002. In particular, the current study considered differences in the returns, volatility, and risk of the hypothetical SRI portfolio and the S\&P 500. Figure 11 compares the returns of the hypothetical SRI portfolio and that of the S\&P 500 graphically. Tables 25 and 26 compare the means and volatilities of the hypothetical SRI portfolio with that of the S\&P 500 . 

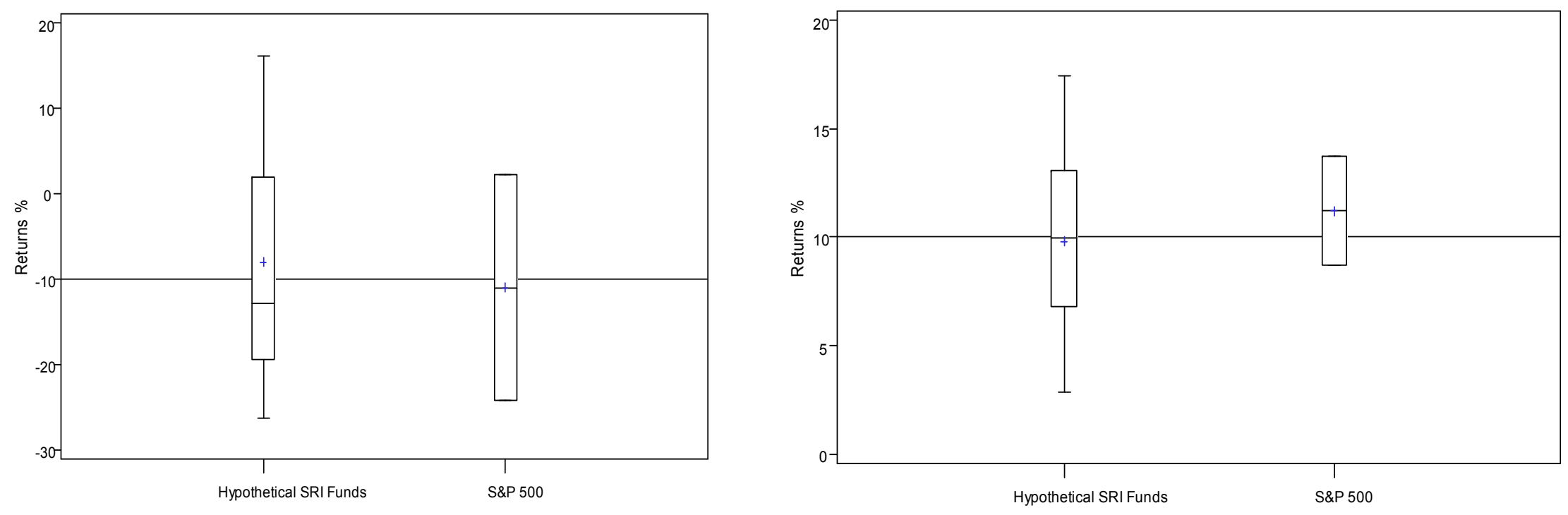

Contraction Phase

Expansion Phase

Figure 11. Comparisons of a hypothetical SRI portfolio returns and S\&P 500 returns (April 1991 - June 2009). 
Table 25 compares the means and standard deviation (volatility) of the returns of the hypothetical SRI portfolio and the S\&P 500. The returns of the S\&P 500 indicate the equity market's performance. Welch's ANOVA compares the means of both indicators. Welch's ANOVA takes into account different variances in the groups compared. The statistic delivers a more accurate p-value than the conventional ANOVA (Welch, 1951). The current study compared the variance of the hypothetical SRI portfolio and the S\&P 500 using three tests of homogeneity of variance. They are Levene's test (Levene, 1960), O'Brien's test (O'Brien, 1979), and the Brown- Forsythe test (Brown \& Forsythe, 1974). Table 25 provides the results of the comparison of the means of the hypothetical SRI portfolio and the S\&P 500.

Table 25

Comparisons of the Means of a Hypothetical Portfolio of SRI Equity Mutual Funds and the S\&P 500 (April 1991 - June 2009).

\begin{tabular}{lccc}
\hline Indicator & $\begin{array}{c}\text { Average } \\
\text { Difference }\end{array}$ & F statistic & p-value \\
\hline $\begin{array}{l}\text { SRI Fund vs. S\&P 500 returns } \\
\text { (contraction/trough phases compared) }\end{array}$ & $2.9 \%$ & $\mathrm{~F}(1,38)=0.46$ & 0.50 \\
$\begin{array}{l}\text { SD } \\
\text { SRI portfolio vs. S\&P 500 returns } \\
\text { (expansion/peak phases compared) }\end{array}$ & $-1.4 \%$ & $\mathrm{~F}(1,32.3)=1.71$ & 0.20 \\
SD & $3.0 \%$ & & \\
\hline
\end{tabular}

Notes:

(1) The F-statistic is based on Welch's ANOVA.

(2) SRI portfolio returns and S\&P 500 returns (cycle phases 1 - 4) are average returns over four cycle phases. 
According to Table 25, the hypothetical SRI portfolio delivered similar returns to the S\&P 500 during the contraction/trough and expansion/peak cycle phases separately, based on a time series ANOVA (Yang and Carter, 1983). This finding supported the argument that SRI does not affect portfolio returns in the long run. Table 26 summarizes the differences in volatility of the hypothetical SRI portfolio and the S\&P 500.

Table 26

Comparisons of the Volatilities of a Hypothetical SRI Portfolio and the S\&P 500 (April 1991-June 2009).

Indicator

Hypothetical SRI Fund and

S\&P 500 volatility

(contraction/trough phases)

Hypothetical SRI Fund and

S\&P 500 volatility (expansion/peak phases)
SD

14.0 (SRI)

13.5 (S\&P 500)

4.0 (SRI)

2.6 (S\&P 500)
F-Statistic

$\mathrm{F}(1,38)=0.09^{1}$

$\mathrm{F}(1,38)=0.08^{2}$

$\mathrm{F}(1,38)=0.72^{3}$

$\mathrm{F}(1,38)=6.01^{1}$

$\mathrm{F}(1,38)=5.69^{2}$

$\mathrm{F}(1,38)=2.47^{3}$ p-value

0.77

0.77

0.40

0.02

0.02

0.12

${ }^{1}$ Levene's test. ${ }^{2}$ O'Brien's test. ${ }^{3}$ Brown and Forsythe's test.

According to Table 26, there was general agreement among the tests of differences between the volatility/standard deviation of the hypothetical SRI portfolio and the S\&P 500 within the contraction phases identified by the NBER. There was no significant difference between the volatility of the hypothetical SRI portfolio and the S\&P 500. During the contraction phases, the volatility of the hypothetical SRI portfolio was $14 \%$, while that of the S\&P 500 was 13.5 . However, there were mixed findings among the tests of differences between the volatility/standard deviation of the 
hypothetical SRI portfolio and the S\&P 500 within the expansion phases identified by the NBER. Levene's test and O'Brien's test identified significant differences in the volatility of the hypothetical SRI portfolio and that of the S\&P 500. During the expansion phases, the volatility of the hypothetical SRI portfolio was $4 \%$, while that of the S\&P 500 was $2.6 \%$. Bartlett's test of the homogeneity of variance also identified no significant difference in the volatilities of the hypothetical SRI portfolio and the S\&P 500 index $\left(\chi^{2}\right.$ $=3.57, \mathrm{p}=0.06)$. The findings are therefore inconclusive regarding the differences in the volatility/standard deviation of the hypothetical SRI portfolio and the S\&P 500 during the expansion phases. 
Table 27

Comparisons of the Coefficients of Variation of a Hypothetical SRI Portfolio and the S\&P 500 .

Cycle phase

April 1991 - March 2001 (expansion/peak)

April 2001 - November 2001 (contraction/trough)

December 2001 - December 2007 (expansion/peak)

January 2008 - June 2009 (contraction/trough)

All contraction/trough All expansion/peak

\section{SRI funds S\&P 500}

$25 \% \quad 28 \%$

$5 \% \quad 3 \%$

$17 \% \quad 21 \%$

$-19 \% \quad-27 \%$

$-14 \% \quad-19 \%$

Note: Higher numbers are indicative of greater risk.

Table 27 compares the coefficient of variations of the hypothetical SRI portfolio and the S\&P 500, using their monthly returns. The coefficient of variation measures the amount of risk per unit of return embodied in the fund. The risk characteristic of the hypothetical SRI portfolio and the S\&P 500 is measured by the ratio of volatility per unit of return, or the coefficient of variation. The coefficient of variation is defined by the ratio of the standard deviation to the average return, with higher absolute values being indicative of greater risk. According to Table 27, there exist qualitatively similar riskreturn profiles for the hypothetical SRI portfolio and the market during both contraction/trough and expansion/peak phases of the business cycle. In general, the 
hypothetical SRI portfolio bore similar risk as the market but derived lesser returns, especially during the expansion/peak phase. When individual cycle phases are considered, the hypothetical SRI portfolio manager adopted a more conservative stance than the market during the contraction/trough cycle phase of April 2001 to November 2001. In other cycle phases, the managers of the hypothetical portfolio exhibited a risk profile similar to that of the S\&P 500 .

\section{Summary}

The findings supported Hypothesis 1.1(a) during the full period April 1991 to June 2009. However, the findings partially supported Hypothesis 1.1(a), 1.1(b) for the period April 1991 to June 2009. The findings supported Hypothesis 1(c) but did not support Hypothesis 1(d), 2, or 3(a), 3(b), or 3(c). The findings supported the presence of a business cycle effect on the performance of SRI funds measured by excess returns and volatility. There were significant differences in the excess returns delivered by the SRI funds over contraction and expansion cycle phases. The hypothetical portfolio of SRI equity mutual funds delivered significantly higher excess returns during the contraction/trough phases of the cycle than during the expansion/peak phases. The average difference in excess returns over the two phases was 4.4 percentage points. During both the contraction/trough and the expansion/peak phases, the hypothetical portfolio performed similar to the S\&P 500 .

The findings revealed differences in the volatility of the hypothetical portfolio of funds between expansion and contraction phases of the business cycle. The portfolio exhibited significantly higher volatility of returns during the contraction/trough phases 
than during the expansion/peak phases evaluated by the current study. The differences persisted during the individual cycle phases. Each contraction/trough cycle and each expansion/peak phase exhibited unique volatilities. The volatility of the hypothetical SRI portfolio was similar to that of the S\&P 500 under both expansion/peak and contraction/trough cycle phases. However, the volatility of the hypothetical SRI portfolio increased by 1.9 times that of the S\&P 500 between the contraction/trough cycle phase of April 2001 to November 2001 and the Great Recession of January 2008 to June 2009.

During the expansion/peak phases, the hypothetical SRI portfolio exhibited similar levels of changes in volatility (0.998 times) as the S\&P 500. While the model demonstrated a better fit to the data during September 2002 to June 2009, the religious SRI funds did not earn significantly higher excess returns than the secular SRI funds during the period studied. Similarly, there was no significant difference between the excess returns earned by religious SRI funds, secular SRI funds, and the Vice Fund. 


\section{CHAPTER V}

\section{DISCUSSION}

This final chapter describes the conclusions of the findings of the previous chapter and their implication for academic theory and SRI investment practice. SRI equity mutual funds are composed of stocks that meet specific social performance criteria according to the objectives of the fund. As described in Chapter 1, the main purpose of the current study was to evaluate the effect of the business cycle on the performance of SRI equity mutual funds. In particular, the study explored if the factors that explain the excess returns generated by a hypothetical portfolio of SRI equity mutual funds differed depending on the current business cycle. The analysis also considers the comparative performance of secular SRI funds and religious SRI funds and the Vice Fund.

Social performance screening evaluates corporate performance according to the ethical, social, or religious standards of a SRI fund. Under SRI investing, a stock is evaluated according the conventional risk-return criteria in addition to social performance criteria. Social performance is identified using screens. Positive screens allow the selection of stocks that meet the criteria of the fund. Examples of positive screening are the inclusion of stocks issued by companies whose corporate practices preserve the natural environment, have good employee relations, or promote diversity. Negative screens exclude the selection of stocks of companies that do not meet the social criteria of the fund. Examples of negative screening for religious funds are the exclusion of stocks issued by companies whose corporate practices support the use of contraceptives, abortions, the production of pork products, or which derive a significant income from interest on loans. Examples of negative screens for secular funds include the exclusion of 
the stocks of companies whose practices are harmful to the environment, which create unfavorable labor relations, or which do not promote diversity in the workplace.

The current study compared the performance of a hypothetical portfolio of US based SRI equity mutual funds over phases of the business cycle identified by the NBER between April 1991 and June 2009, and September 2002 and June 2009. The annualized monthly difference between the fund's return and that of the market measured the excess return on the fund. The S\&P 500 was a proxy for the performance of the US equity market. The volatility of the SRI portfolio, or the standard deviation of its returns, measured the stability of the returns generated by the SRI fund. The conceptual model included market and fund-specific factors. Its market-specific context was the Carhart four factor model $(1997 ; 1995)$, an extension of the three factor model originally proposed by Fama and French $(1989 ; 1993)$. The Carhart model proposes that the excess returns of a portfolio are explained by the market excess return over the risk-free rate, its focus on small or large capitalization firms, on companies trading at high or low book-tomarket values, and momentum, or the extent of over-reaction to corporate information.

The measurement model was based on a two-state switching regression (Goldfeld \& Quandt, 1973b). The state variable 's' assumed one of two values associated with the expansion/peak or contraction/trough cycle phases. The state variable tracks the business cycle through the dividend yield. The inclusion of the dividend yield as a source of information on the business cycle is similar to that used by previous studies of conventional mutual funds and the business cycle (Hamilton \& Lin, 1996; Lynch et al., 2002). Studies of conventional mutual funds provide evidence of the presence of a business cycle effect (Kosowski, 2006; Lynch et al., 2002). 
In an efficient market, the price of a stock reflects the FP of the firm. That is, the value of the hypothetical SRI portfolio reflects the FP of the companies whose stocks comprise the portfolio. Previous studies of the SP-FP relationship yielded mixed results. Some scholars identified a positive SP-FP relationship, while others identified a negative SP-FP relationship. Yet others found no relationship between SP and FP. The current research proposes that the mixed findings may be the result of the absence of a business cycle effect in previous research. A positive finding of the SP-FP relationship may have reflected the expansionary phase of the business cycle that dominated the 1990s and 2000's - the period evaluated by most empirical studies of the SP-FP relationship.

In keeping with the suggestions of previous scholars of SRI investing (Abramson \& Chung, 2000; Chong et al., 2006) the current study hypothesized that the hypothetical portfolio of SRI equity mutual funds also experienced a business cycle effect. The current study compared the excess returns and volatility of the hypothetical SRI portfolio during the individual cycle phases identified by the NBER in a supplementary analysis. The supplementary analysis also compared the business cycle effect on the volatility (standard deviation) of the hypothetical SRI portfolio with that of the market.

The current study established the presence of a business cycle effect by demonstrating that the excess returns generated by the hypothetical SRI portfolio differed significantly between the contraction/trough and expansion/peak cycle phases discussed. There was evidence of consistency in the excess returns during the contraction/trough and expansion/peak phases that occurred between April 1991 and June 2009. The returns on the portfolio of hypothetical SRI portfolio moved in the same direction as that of the S\&P throughout the period under study. The volatility of the hypothetical SRI portfolio was 
significantly higher during contraction/troughs than during expansion/peaks. The volatility of the hypothetical SRI portfolio was not significantly different from that of the S\&P 500 over both phases of the business cycle. After taking into account Carhart's four factors, and the controls for fund size, style, objective, and expenses, the absence of a significant difference in the returns of the hypothetical portfolio of SRI equity mutual funds and that of the S\&P 500 suggested that SRI screening does contribute to the hypothetical SRI portfolio's excess returns. In the same way, religious screening did not undermine the performance of the constituent religious SRI funds, when compared to secular funds and the Vice Fund, during contraction/trough and expansion/peak phases. Similarly, secular and vice screens did not create significant differences in the returns of the funds. During the expansion phases, social screening avoided investments in an industry that ultimately played a major role in the start of the Great Recession, and may even have avoided inefficient companies. However, the findings suggest that social screening detracts from value during an expansion, as some companies which perform well, such as defense contractors and some pharmaceutical companies, perform very well, but may be excluded from an SRI portfolio.

Traditionally, a low R-square (the square of the correlation coefficient) suggests poor management or the use of an inappropriate benchmark. Given the statistically insignificant differences in the correlation between the returns on the hypothetical SRI portfolio and the S\&P 500 during both phases of the business cycle, the current study found that the SRI fund manager's mandate may not conflict with the goal of maximizing portfolio returns. A low R-square reflects a high tracking error. In the case of the hypothetical portfolio of SRI equity mutual funds, the tracking errors may have been the 
result of high screening costs. Given that the SRI portfolio tracked the S\&P 500 similarly, during both phases of the business cycle, its portfolio is determined to be of equivalent risk, the current study found that the smaller universe that prevails because of the SRI screening process does not result in a more risky portfolio. The current study also found that the conventional definition of alpha as value added by investment management may not be adequate to describe the value added by SRI investing.

The results suggest that the hypothetical SRI portfolio had a more conservative or risk-averse portfolio than was usual for fund managers during an economic recession. A defensive strategy typically includes rebalancing the portfolio toward stocks that are less volatile than the market (Ferson \& Schadt, 1996), and this may have been practiced more by SRI fund managers, than by other fund managers. Alternatively, SRI screening may deliver a portfolio consisting of companies whose earnings perform better than other companies during a recession. This latter view is consistent with the view that social performance is a harbinger of efficient corporate practices (Dowell et al., 2000; Repetto \& Austin, 2000). In this way, positive SP might deliver improved FP.

The SRI fund manager operates within a universe of stocks that is limited by the social, religious, and ethnical criteria of the fund (Bauer et al., 2005; Maginn et al., 2007), and may have fewer opportunities for diversification than a conventional fund. The result of a restricted universe of stocks is a less diversified, more volatile portfolio (Copeland \& Weston, 1988; Renneboog, 2008). On the secondary market, the SRI fund manager retains the stock in a long-term portfolio because of its high SP rating, and the investors are more loyal. The application of SRI screens may therefore result in a portfolio with a risk-return characteristic unlike that of a conventional portfolio. 
The current study reveals that SRI fund managers shift their holdings toward firms with smaller capitalization and undervalued stocks during an economic contraction/trough, and establishes the presence of a business cycle effect on the volatility of the funds studied. According to conventional portfolio theory, as the opportunities for diversification become fewer in number, the portfolio assumes a more volatile characteristic (Copeland \& Weston, 1988). The funds studied exhibited a greater volatility during the contraction/trough phases than during the expansion phases. The most restrictive conditions for portfolio diversification appeared during the Great Recession of January 2008 to June 2009 when the hypothetical SRI portfolio exhibited its greatest volatility. The hypothetical SRI portfolio exhibited volatility similar to that of the S\&P 500. A portfolio constructed out of a restricted universe of stocks should be more risky than the market (Renneboog, 2008), but these findings do not support this view.

The supplementary analysis compares the performance of the hypothetical portfolio of funds with the S\&P 500, an indicator of overall market performance. As the returns on a stock are said to reflect anticipated corporate financial performance, (Del Guercio \& Tkac, 2002; Heinkel et al., 2001), it can be inferred that the hypothetical SRI portfolio out-performed the market during the Great Recession. This supports the earlier proposition that SRI screening may identify companies with more efficient operating practices, and hence better financial performance, during the contraction/trough phase of the business cycle. The results of the supplementary analyses identified similar volatility in the hypothetical SRI portfolio and the market during contraction/troughs, but mixed findings during expansion/peaks as shown in Table 26. 
The comparison of ideological funds revealed similar returns on secular SRI funds and religious SRI funds in spite of the smaller universe of stocks available to religious funds. The Vice Fund delivered similar returns as secular SRI funds during the partial expansion/peak of September 2002 to June 2009, despite its investments in companies that derived significant profits from the defense industry. In a war environment, the performance of these companies would benefit from government spending. The secular and religious SRI funds avoided these stocks based on social screens. While this exclusion did not adversely value added that could be attributed to the orientation of the fund, during the sub-period September 2002 to June 2009, it may explain the negative value added by SRI investing during expansion/peaks of the full period.

\section{Implications}

The current study offers implications for SRI investing and stakeholder theory. The SRI fund manager optimizes portfolio performance through a tradeoff between financial criteria (risk and reward) and social criteria (Domini, 2001; Lydenberg, 2009; Lydenberg, 2005; Roofe, 2010). The outcome of the attempt to generate optimal portfolio returns, subject to financial and social performance constraints, results in an attitude toward risk that may be unique to SRI fund managers. The current study submits that by including a third dimension - social performance -- the SRI fund manager can achieve returns approximately equal to returns obtained using the traditional risk-reward criteria.

If the behavior of the SRI fund manager may be described as being based on 'social criteria preference as behavior toward risk', then, following the paradigm described by 
Beal et al. (2005), there may be unique attitudes toward risk among SRI fund management.

During contraction/troughs, the hypothetical SRI portfolio derived higher excess returns from smaller companies and under-valued stocks than from larger companies and fully valued stocks. However, funds with growth objectives earned lower excess returns than other funds during contraction/troughs. During a contraction/trough, the hypothetical SRI portfolio also exhibited less risk than the market, as measured by the beta coefficient. During an expansion/peak, the hypothetical SRI portfolio did not derive higher excess returns from either smaller or larger companies. During expansion/peaks, over-valued or undervalued stocks did not make a significant contribution to the excess returns generated by the hypothetical SRI portfolio. Growth funds earned higher excess returns than funds with other objectives during an expansion/peak. During a contraction/trough, the hypothetical SRI portfolio also exhibited similar volatility as the market.

The current study's findings on the financial value added by social screens suggest that the SRI fund's risk-return profile is unlike that encountered in conventional portfolio theory. The findings offer evidence of different risk profiles of the SRI portfolio and the market, because of the more restricted universe from which SRI investments are selected. As the hypothetical SRI portfolio exhibited a higher volatility during contraction/troughs than during expansion/peaks, it is likely that the hypothetical SRI portfolio had similar risk and lower returns than the market during a contraction, despite the less diversified portfolio. During a recession, there is evidence of value added by the SRI fund manager's skill in creating a portfolio from a restricted universe that exhibits a similar risk-return profile as the market. However, the value added is not due to Jensen's 
alpha, as defined in the financial literature, which represents the stock selection ability of the manager. The value of SRI screening arises from the similar risk of the hypothetical SRI portfolio and the S\&P 500, despite the undiversified nature of the portfolio, by conventional portfolio management standards. The current research proposes that the SRI screening process is a form of stock selection, and results in value added which reduces the risk of a less than fully diversified portfolio, while generating returns which are comparable to the market.

If social screening detracted from value, as Friedman (1970) and others have suggested, then social performance screening would have eroded financial gains. But this was not observed. In spite of fewer opportunities for diversification, there was no significant difference between the excess returns generated by the hypothetical SRI portfolio and the market. Therefore, we may conclude that whatever costs are associated with social screening in order to achieve SRI objectives, are offset by the benefits gained from selecting well-performing stocks. This is especially true during the contraction/trough phase of the business cycle.

The current study suggests that the fund managers focused on social performance in anticipation of positive long-term financial performance, while holding a portfolio that was not fully diversified. As a key ingredient of SRI investing is social performance, which may be less responsive to changes in the overall economy, it may be expected that the SRI fund manager's choices will be more long-term oriented and less susceptible to transitory market trends then the choices of conventional portfolio managers. In a way, this parallels the observation that SRI investors, motivated partly by ideology, are more loyal than conventional investors, hence incur lower transactions costs by trading less 
frequently. Another related observation comes from previous scholars who argue that by focusing on companies with high social performance ratings the SRI fund manager effectively supports the price of the stock and diverts capital toward compliant firms (Edmans, 2009; Heinkel et al., 2001; Sauer, 1997). All of these observations suggest that SRI investing is a force leading to a slightly higher level of stability in capital markets, other factors being equal.

The current study offers implications for stakeholder theory as it applies to CSR. There was no significant difference between the hypothetical portfolio of SRI equity mutual funds and the S\&P 500 over the stages of the business cycle studied. Friedman (1962) refers to the goal of business as "making maximum profits (p.113). From this perspective financial goals are always more important than social goals or CSP. On the other hand, the managerial perspective assumes the goal of shareholder wealth maximization through share price increases which can result from either financial or social achievements, or a combination of both. It is possible to reconcile the social activist position with that of the stockholder approach (Gardberg \& Newburry, 2010; Jensen, 2001; Jones \& Wicks, 1999; Peloza, 2008; Porter, 2006). The current study submits that the impact of CSP on FP is variable, and is affected by economic conditions as expressed in the phase of the business cycle. Stakeholder theory should include financial interests, and should also include ethical or social criteria of interest to investors and to the general public. 


\section{Limitations of the Study and Directions for Future Research}

The current study is limited in its scope as it focused on equity mutual funds only. As excess returns varied depending on fund objective, it may be worth exploring other types of funds. The SRI mutual fund industry includes balanced and income funds. The population of funds was limited to members of the US Social Investment Forum (SIF) There are SRI funds that are not members of the SIF which could be included in an extension of this study. Similarly, the study is restricted to US based funds. The religious fund category is limited to two Islamic funds. A more diverse portfolio should include funds based outside of the USA, funds denominated in other currencies, and funds based on other religious values, such as Catholic, Mennonite and Evangelical.

The data consisted of an annualized monthly time series. A daily time series could capture greater variability in the performance of the funds. The study may also be replicated using time series of SRI indices rather than SRI funds. As the fit of the model improved from 0.7 to 0.8 approximately, when applied to the last cycle, it is likely that individual cycles may have different characteristics. The current study assumed a single rate of transition, which may not have captured the unique characteristics of each cycle. The model appears to be a better fit during the sub-period, and the factors influencing the excess returns of the hypothetical portfolio of eleven funds are different. The current study proposes that individual cycles may have different characteristics. Future research may extend the study to include more than one rate of transition across business cycles.

A more appropriate theoretical perspective would consider balancing three dimensions, namely, the effect of the smaller universe, with the financial risk embodied in the investment and the returns on the portfolio. The current study proposes that the 
definition of value added in the SRI context should compare the costs of SRI investing -screening costs and the fewer opportunities for diversification, with the risk embodied in the portfolio compared to the market and the returns earned by the portfolio with that of the market. 


\section{REFERENCES}

Abramson, L., \& Chung, D. (2000). Socially responsible investing: Viable for value investors? Journal of Investing, 9(3), 73-80.

Au, A., \& Shapiro, R. (2010). The changing beta of value and momentum stocks. Journal of Investing, $19(1), 25$.

B Lab. (2010). About B Corp. Retrieved March 13, 2010, from http://www.bcorporation.net/about

Barberis, N., Shleifer, A., \& Wurgler, J. (2002). Comovement.National Bureau of Economic Research, Inc.

Bauer, R., Derwall, J., Guenster, N., \& Koedijk, K. G. (2006). The economic value of corporate eco-efficiency. SSRN eLibrary, Retrieved March 30, 2010, from http://ssrn.com/paper $=675628$

Bauer, R., \& Hann, D. (2010). Corporate environmental management and credit risk. SSRN eLibrary, Retrieved June 23, 2011, from http://ssrn.com/paper=1660470

Bauer, R., Koedijk, K., \& Otten, R. (2005). International evidence on ethical mutual fund performance and investment style. Journal of Banking \& Finance, 29(7), 1751-1767.

Beal, D. J., Goyen, M., \& Phillips, P. (2005). Why do we invest ethically? Journal of Investing, 14(3), 66-77.

Bernanke, B. S., \& Kuttner, K. N. (2004). What explains the stock market's reaction to Federal Reserve policy? National Bureau of Economic Research Working Paper 10402, Retrieved June 8, 2011, from http://www.nber.org/papers/w10402

Berry, R. (2009). Value-at-Risk Primer. J.P. Morgan Investment Analytics \& Consulting. Retrieved February 9, 2010, from http://www.iacopal.com/ResearchCornerDocumentation/2009119142224 Value-AtRisk\%20Primer\%20November\%202009\%20Edition.pdf

Bollen, N. P. B. (2007). Mutual fund attributes and investor behavior. Journal of Financial and Quantitative Analysis, 42(03), 683-708.

Brammer, S. J., \& Pavelin, S. (2006). Corporate reputation and social performance: The importance of fit. Journal of Management Studies, 43(3), 435-455. 
Brammer, S., Williams, G. A., \& Zinkin, J. (2005). Religion and attitudes to corporate social responsibility in a large cross-country sample. SSRN eLibrary, Retrieved April 7, 2010, from http://ssrn.com/paper=905182

Brown, M. B. \& Forsythe, A. B. (1974). Robust tests for the equality of variances. Journal of the American Statistical Association, 69(346), pp. 364-367.

Carhart, M. M. (1997). On persistence in mutual fund performance. The Journal of Finance, 52(1), 57-82.

Carhart, M. M. (1995). Survivor bias and persistence in mutual fund performance. (Ph.D. Dissertation, The University of Chicago).

Carson, R. (1962). Silent Spring. Greenwich, Conn: Fawcett.

Center for Research in Security Prices. (2007). Survivor-bias-free US Mutual Fund Database Guide. Chicago, IL: Chicago Booth/CRSP.

Center for Research in Security Prices. (2008). Data description guide - CRSP US stock and CRSP US indices databases.

Chan, L. K., Jegadeesh, N., \& Lakonishok, J. (1995). Momentum Strategies. NBER Working Paper No. 5375, Cambridge, Mass.: NBER.

Chance, D. M., Grant, K., \& Marsland, J. (2007). Chapter 9: Risk management. In J. L. Maginn, D. L. Tuttle, J. E. Pinto \& D. W. McLeavey (Eds.), Managing Investment Portfolios: A Dynamic Process (3rd ed., pp. 579-636). Hoboken, NJ: John Wiley \& Sons.

Chong, J., Her, M., \& Phillips, G. M. (2006). To sin or not to $\sin$ ? Now that's the question. Journal of Asset Management, 6(6), 406.

Chordia, T., \& Shivakumar, L. (2002). Momentum, business cycle, and time-varying expected returns. The Journal of Finance, 57(2), 985-1019.

Clark, A. (2004). For benchmark-beating funds, does fund size affect performance? Thomson Reuters, Inc. Retrieved April 27, 2010 from http://www.lipperweb.com/Handlers/GetReport.ashx?reportId=2257

Conover, W. J., Johnson, M. E., \& Johnson, M. M. (1981). A comparative study of tests for homogeneity of variances, with applications to the outer continental shelf bidding data. Technometrics, 23(4), pp. 351-361.

Cooper, M. J., Gutierrez, R. C., \& Hameed, A. (2004). Market states and momentum. The Journal of Finance, 59(3), 1345-1365. 
Copeland, T. E., \& Weston, J. F. (1988). Financial theory and corporate policy (3rd ed.). Reading, Mass.: Addison-Wesley.

Davig, T., \& Gerlach, J. (2006). State-dependent stock market reactions to monetary policy: 'bubble' vs. fundamental states. SSRN eLibrary, Retrieved June 8, 2011 from http://ssrn.com/paper $=882151$

DeFusco, R. A., McLeavey, D. W., Pinto, J. E., \& Runkle, D. E. (2007). Quantitative Investment Analysis, Second Edition. CFA Institute Investment Books, 2007(2), 1600 .

Del Guercio, D. \& Tkac, P. A. (2002). The determinants of the flow of funds of managed portfolios: Mutual funds versus pension funds. Journal of Financial and Quantitative Analysis, 37, 523-557.

Dolan, K. (2010). A big fund cost you don't see: Expense ratios tell just one part of the story. Retrieved March 23, 2010, from http://news.morningstar.com/articlenet/article.aspx?id=330086

Domini, A. (2001). Socially responsible investing: Making a difference and making money. Chicago, IL: Dearborn Trade: A Kaplan Professional Company.

Donaldson, T., \& Preston, L. E. (1995). The stakeholder theory of the corporation: Concepts, evidence, and implications. The Academy of Management Review, 20(1), 65-91.

Dowell, G., Hart, S., \& Yeung, B. (2000). Do corporate global environmental standards create or destroy market value? Management Science, 46(8), 1059.

Edmans, A. (2009). Does the stock market fully value intangibles? Employee satisfaction and equity prices. SSRN e-Library. Retrieved March 30, 2010, from http://ssrn.com/paper=985735

Entine, J. (2007). Milton Friedman - Misunderstood or misguided? Ethical Corporation. Retrieved October 18, 2011 from http://www.jonentine.com/pdf/Milton\%20Friedman.pdf

Evan, W. M., \& Freeman, R. E. (1998). A stakeholder theory of the modern corporation: Kantian capitalism. In T. Beauchamp, \& N. Bowie (Eds.), Ethical theory and business. Englewood Cliffs, N.J.: Prentice Hall.

Eye of Dubai. (2010). Islamic Markets Measure - Preliminary Report. Retrieved January 27, 2010, from http://www.eyeofdubai.com/v1/news/newsdetail-38964.htm 
Fabozzi, F. J., Ma, K. C., \& Oliphant, B. J. (2008). Sin stock returns. The Journal of Portfolio Management, 35(1), 82-94.

Fama, E. F., \& French, K. R. (1989). Business conditions and expected returns on stocks and bonds. Journal of Financial Economics, 25(1), 23-49.

Fama, E. F., \& French, K. R. (1993). Common risk factors in the returns on stocks and bonds. Journal of Financial Economics, 33, 3-56.

Fama, E. F., \& French, K. R. (1996). Multifactor explanations for asset pricing anomalies. Journal of Finance, 51, 55-84.

Ferson, W. E., \& Schadt, R. W. (1996). Measuring fund strategy and performance in changing economic conditions. The Journal of Finance, 51(2), 425-461.

Fisher, I. (1954). The theory of interest as determined by impatience to spend income and opportunity to invest it. New York: Augustus M Kelley.

Fisher, R. A. (1915). Frequency distribution of the values of the correlation coefficient in samples from an indefinitely large population. Biometrika, 10(4), 507-521.

Freeman, E. R., \& Gilbert, D. R.Jr. (1988). Corporate strategy and the search for ethics . Englewood Cliffs, NJ: Prentice-Hall.

Freeman, E. R. (1984). Strategic management: A stakeholder approach. Boston: Pitman.

Friedman, J. (December 5, 2003). Vice fund parent faces charges on trading. Los Angeles Times. Retrieved September 9, 2011 from http://articles.latimes.com/2003/dec/05/business/fi-vice5

Friedman, M. (September 13, 1970). The social responsibility of business is to increase its profits. The New York Times Magazine, 32-33, 122, 126.

Friedman, M. (1962). Capitalism and Freedom. Chicago: The University of Chicago Press.

Gallant, A. R. (1987). Nonlinear statistical models. New York: John Wiley and Sons.

Gardberg, N., \& Newburry, W. (March 11, 2010). Who boycotts whom? Marginalization, Company Knowledge, and Strategic Issues. Business \& Society, 1-39. Retrieved March 13, 2010 from http://bas.sagepub.com/content/early/2010/03/04/0007650309352507.full.pdf + html 
Ghoul, W., \& Karam, P. (2007). MRI and SRI Mutual Funds: A Comparison of Christian, Islamic (Morally Responsible Investing), and Socially Responsible Investing (SRI) Mutual Funds. Journal of Investing, 16(2), 96-102.

Girard, E., Rahman, H., \& Stone, B. (2007). Socially responsible investments: Goodytwo-shoes or bad to the bone? Journal of Investing, 16(1), 96.

Goldfeld, S. M., \& Quandt, R. E. (1973a). The estimation of structural shifts by switching regressions. Annals of Economic and Social Measurement, 2(4)

Goldfeld, S. M., \& Quandt, R. E. (1973b). A Markov model for switching regressions. Journal of Econometrics, 1, 3-16.

Gompers, P., Ishii, J., \& Metrick, A. (2003). Corporate governance and equity prices. Quarterly Journal of Economics, 118(1), 107-155.

Grinblatt, M., Titman, S., \& Wermers, R. (1995). Momentum investment strategies, portfolio performance, and herding: A study of mutual fund behavior. American Economic Review, 85(5), 1088-1105.

Hamilton, J. D., \& Lin, G. (1996). Stock market volatility and the business cycle. Journal of Applied Econometrics, 11(5), Special Issue: Econometric Forecasting), 573-593.

Heinkel, R., Kraus, A., \& Zechner, J. (2001). The effect of green investment on corporate behavior. The Journal of Financial and Quantitative Analysis, 36(4), 431-449.

Hemley, D., Morris, D., \& Gilde, C. (2005). Antisocially conscious sectors: A benchmark for socially conscious investing. The Journal of Investing, 14(3), 78-82.

Henriksson, R. D., \& Merton, R. C. (1981). On market timing and investment performance II. Statistical procedures for evaluating forecasting skills. The Journal of Business, 54(4), 513-533.

Heuer, R. J. (1999). Psychology of Intelligence Analysis. VA: Central Intelligence Agency. Retrieved October 4, 2011, from https://www.cia.gov/library/center-for-thestudy-of-intelligence/csi-publications/books-and-monographs/psychology-ofintelligence-analysis/PsychofIntelNew.pdf

Hickman, K. A., Teets, W. R., \& Kohls, J. J. (1999). Social investing and modern portfolio theory. American Business Review, 17(1), 72.

Hoepner, A. G., \& Zeume, S. (2009). The dark enemy of responsible mutual funds: Does the Vice Fund offer more financial virtue? SSRN eLibrary, Retrieved February 16, 2010 from http://ssrn.com/paper=1485846 
Holm, S. (1979). A simple sequentially rejective multiple test procedure. Scandinavian Journal of Statistics, 6(2), 65-70.

Holmstrom, B., \& Milgrom, P. (1987). Aggregation and linearity in the provision of intertemporal incentives. Econometrica, 55(2), 303-328.

Jegadeesh, N., \& Titman, S. (1993). Returns to buying winners and selling losers: Implications for stock market efficiency. The Journal of Finance, 48(1), 65-91.

Jensen, M. C. (1969). Risk, the pricing of capital assets, and the evaluation of investment portfolios. The Journal of Business, 42(2), 167-247.

Jensen, M. C. (2001). Value maximization, stakeholder theory, and the corporate objective function. SSRN eLibrary, Retrieved January 19, 2010 from http://ssrn.com/paper=220671

Jones, T. M., \& Wicks, A. C. (1999). Convergent stakeholder theory. The Academy of Management Review, 24(2), 206-221.

Kinder, P. D., \& Domini, A. L. (1997). Social screening: Paradigms old and new. The Journal of Investing, 6(4), 12-19.

King, A. A., \& Lenox, M. J. (2001). Does it really pay to be green? An empirical study of firm environmental and financial performance. Journal of Industrial Ecology, 5(1), 105-116.

KLD Research \& Analytics, Inc. (2010). FTSE KLD Catholic Values 400 Index. Retrieved April 26, 2010, from http://www.kld.com/indexes/cv400index/index.html

Kletz, P. (2005). Stakeholder theory and normative approaches. In M. BonnafousBoucher, \& Y. Pesquex (Eds.), Stakeholder Theory - A European Perspective (pp. 58-72). New York: Palgrave McMillan.

Kosowski, R. (2006). Do mutual funds perform when it matters most to investors? US mutual fund performance and risk in recessions and expansions. SSRN eLibrary, Retrieved February 26, 2010 from http://ssrn.com/paper=926971

Krumsiek, B. J. (1997). The emergence of a new era in mutual fund investing. The Journal of Investing, 6(4), 25-30.

Kurtz, L., \& diBartolmeo, D. (2005). The KLD Catholic Values 400 Iindex. The Journal of Investing, 14(3), 101-104.

Lambert, R. A. (2001). Contracting theory and accounting. Journal of Accounting and Economics, 32(1-3), 3-87. 
Lee, Y., Nelder, J., \& Patiwan, Y. (2006). Generalized linear models with random effects. Boca Raton: Chapman \& Hall/CRC.

Levene, H. (1960). Robust tests for equality of variances. In I. Olkin, \& H. Hotelling (Eds.), Contributions to Probability and Statistics (pp. 278-292). Palo Alto, CA: Stanford University Press.

Lipper. (2003). Does fund size affect performance? New York: Thomson Reuters, Inc.

Louton, D., \& Saraoglu, H. (2008). How many mutual funds are needed to form a welldiversified asset allocated portfolio? The Journal of Investing, 17(3), 47-63.

Lydenberg, S. (2009). Markets at risk: The limits of modern portfolio theory. Paper presented at the 2nd Summit on the Future of the Corporation: Restoring the Primacy of the Real Economy, Quincy Market, Boston. , Paper No. $642-50$. Retrieved July 26, 2010, from http://www.summit2020.org/downloads/2nd Summit Paper Series.pdf

Lydenberg, S. (2005). Social and environmental data as new tools. The Journal of Investing, 14(3), 40-47.

Lydenberg, S., \& Paul, K. (1997). Stakeholder theory and socially responsible investing: Toward a convergence of theory and practice. Paper presented at the International Association of Business and Society Eighth Annual Conference, Destin, FL., 208213.

Lynch, A. W., Wachter, J. A., \& Boudry, W. (2002). Does mutual fund performance vary over the business cycle? Paper presented at the AFA 2004 San Diego Meetings, Retrieved February 26, 2010 from http://ssrn.com/abstract=470783

Maginn, J. L., Tuttle, D. L., Pinto, J. E., \& McLeavey, D. W. (2007). Managing investment portfolios: A dynamic process, Third Edition. CFA Institute Investment Books, 1-960.

Margolis, J. D., \& Walsh, J. P. (2001). People and profits?: The search for a link between a company's social and financial performance. Mahwah, N.J.: Lawrence Erlbaum Associates, Publishers.

Markowitz, H. (1952). Portfolio selection. Journal of Finance, 7(1), 77-91.

Marquardt, D. (1963). An algorithm for least-squares estimation of nonlinear parameters. SIAM Journal of Applied Mathematics, 11(2), 431-441. 
McGuire, J. B., Alison Sundgren, \& Schneeweis, T. (1988). Corporate social responsibility and firm financial performance. The Academy of Management Journal, 31(4), pp. 854-872.

McWilliams, A., \& Siegel, D. (1997). Event studies in management research: Theoretical and empirical issues. The Academy of Management Journal, 40(3), 626-657.

Morningstar. (2010). Morningstar Investing Glossary. Retrieved March 19, 2010, from http://www.morningstar.com/InvGlossary/

Moskowitz, M. (1972). Choosing socially-responsible stocks. Business and Society Review, 1, 71-75.

Moskowitz, T. J. (2000). Mutual fund performance: An empirical decomposition into stock-picking talent, style, transactions costs, and expenses: Discussion. The Journal of Finance, 55(4), 1695-1703.

Naber, M. (2001). Catholic investing: The effects of screens on financial returns. The Journal of Investing, 10(4), 58-65.

National Bureau of Economic Research. (2010a). Information on recessions and recoveries, the NBER business cycle dating committee, and related topics. Retrieved March 26, 2010, from http://www.nber.org/cycles/main.html

National Bureau of Economic Research. (2010b). Latest announcement relating to the current business cycle (9/20/10). Retrieved September 27, 2010, from http://www.nber.org/cycles/sept2010.html

O'Brien, R. G. (1979). A general ANOVA method for robust tests of additive models for variances. Journal of the American Statistical Association, 74(368), pp. 877-880.

Olejnik, S. F., \& Algina, J. (1987). Type I error rates and power estimates of selected parametric and nonparametric tests of scale. Journal of Educational Statistics, 12(1), pp. 45-61.

Orlitzky, M., Schmidt, F. L., \& Rynes, S. L. (2003). Corporate social and financial performance: A meta-analysis. Organization Studies, 24(3), 403-441.

Orlitzky, M., \& Swanson, D. L. (2008). Toward integrative corporate citizenship: Research advances in corporate social performance. NY: Palgrave Macmillan.

Patton, M. (2001). Qualitative Research \& Evaluation Methods. Thousand Oaks, CA: Sage Publications. 
Peifer, J. L. (2010). Morality in the financial market? A look at religiously affiliated mutual funds. Socio-Economic Review, 9(3), 235-259.

Peloza, J. (2008). The missing link between corporate social responsibility and financial performance: Stakeholder salience and identification. Corporate Reputation Review, 11(2), 169-183.

Porter, M. E. (2006). The link between competitive advantage and corporate social responsibility. Harvard Business Review, 84(12), 78-93.

Ray, P. H., \& Anderson, S. R. (2000). The cultural creatives: How 50 million people are changing the world. New York: Harmony Books.

Renneboog, L. (2008). The performance of socially responsible mutual funds. QFinance, Retrieved January 19, 2010, from http://www.qfinance.com/investmentmanagement-best-practice/the-performance-of-socially-responsible-mutual$\underline{\text { funds?full }}$

Renneboog, L., Ter Horst, J., \& Zhang, C. (2006). Is ethical money financially smart? No. 2006-09.Tilburg University, Center for Economic Research.

Renneboog, L., Ter Horst, J., \& Zhang, C. (2008). The price of ethics and stakeholder governance: The performance of socially responsible mutual funds. Journal of Corporate Finance, 14(3), 302-322.

Repetto, R., \& Austin, D. (2000). Pure profit: The financial implications of environmental performance. Unpublished manuscript. Retrieved March 30, 2010, from http://www.socialinvest.org/pdf/research/Moskowitz/2000\%20Winning\%20Paper\% 20-\%20Moskowitz.pdf

Roofe, A. J. (2010). Social criteria preference as behavior toward risk. SSRN eLibrary, Retrieved July 26, 2011 from http://ssrn.com/paper=1630926

Russell Investments. (2011). Russell Midcap ${ }^{\circledR}$ Value Index. Retrieved October 23, 2011, from http://www.russell.com/indexes/data/fact_sheets/us/russell_midcap_value index.asp

Standard \& Poor's Financial Services LLC. (2011). S\&P 500. Retrieved October 23, 2011, from http://www.standardandpoors.com/indices/sp-500/en/us/?indexId=spusa$\underline{500-u s d u f--p-u s-1--}$

Sauer, D. A. (1997). The impact of social-responsibility screens on investment performance: Evidence from the Domini 400 Social Index and Domini Equity Mutual Fund. Review of Financial Economics, 6(2), 137-149. 
Schueth, S. J. (2006). Socially responsible investing in the United States. Unpublished manuscript. Retrieved February 21, 2010, from

http://www.betterworldinvestments.com/new/betterworldinvestments/SRI\%20in $\% 20$ US\%20brochure.pdf

Shank, T. M., Manullang, D. K., \& Hill, R. P. (2005). Is it better to be naughty or nice? Journal of Investing, 14(3), 82-87.

Shanmugam, B., \& Zahari, Z. R. (2009). A primer on Islamic Finance. Research Foundation Publications, 2009(6), 1-121.

Sharpe, William F. (1964). Capital Asset Prices: A theory of market equilibrium under conditions of risk. Journal of Finance, 19(3) 425-442.

Shiller, R. J. (1995). Conversation, information, and herd behavior. AEA Papers and Proceedings, 181.

Shiller, R. J. (2010). Stock market data used in "Irrational Exuberance" Princeton University Press, 2000, 2005, updated. Retrieved January 25, 2011, from http://www.econ.yale.edu/ shiller/data/ie_data.xls

Siegel, L. B. (2009). Chapter 25: Distinguishing true Alpha from Beta. In P. Lawton, \& T. Jankowski (Eds.), Investment Performance Measurement: Evaluating and presenting results (pp. 591-603). Charlottesville, VA: CFA Institute Investment Books.

Social Investment Forum. (2009). Socially responsible mutual fund charts: Financial performance. Retrieved February 7, 2009, from http://www.socialinvest.org/resources/mfpc/

Social Investment Forum. (2010). Socially responsible investing facts. Retrieved February 24, 2010, from http://www.socialinvest.org/resources/sriguide/srifacts.cfm

Statman, M. (2005). The religions of social responsibility. The Journal of Investing, 14(3), 14-21.

Statman, M. (2006). Socially responsible indexes. Journal of Portfolio Management, (Spring), 100-109.

Statman, M. (2007). Socially responsible investments. Journal of Investing Consulting, $8(2), 17-37$.

Statman, M. (2008). Quiet conversations: The expressive nature of socially responsible investors. Journal of Financial Planning, February, 40-46. 
Statman, M., Fisher, K., \& Anginer, D. (2008). Affect in a behavioral asset-pricing model. Financial Analysts Journal, 64(2), 20.

Statman, M., \& Glushkov, D. (2008). The wages of social responsibility. SSRN eLibrary, Retrieved July 26, 2011 from http://ssrn.com/paper=1372848

Stone, B. K., Guerard, J. B.,Jr, Gulteki, M. N., \& Adams, G. (2001). Socially responsible investment screening: Strong evidence of no significant cost for actively managed portfolios. Unpublished manuscript. Retrieved March 30, 2010, from http://www.socialinvest.org/pdf/research/Moskowitz/2001\%20Honorable\%20Menti on $\% 20-\% 20$ Moskowitz.pdf

Tergesen, A., \& Young, L. (2004, April 19). Index funds aren't all equal. BusinessWeek Online, Retrieved from http://www.businessweek.com/magazine/content/04_16/b3879125_mz070.htm

The Conference Board. (2010). The Conference Board Leading Economic Index ${ }^{\circledR}($ LEI) for the United States and related Composite Economic Indexes for January 2010. New York: The Conference Board.

The Parnassus Fund. (2002). Annual Report December 31, 2002.

The Vice Fund. (2010). Quarterly report at December 31, 2010. Dallas, Texas: USAMutuals. Retrieved on February 7, 2010 from http://www.vicefund.com

The Vice Fund. (2011). Quarterly report at June 30, 2011. Dallas, Texas: USAMutuals. Retrieved on October 8, 2011 from http://www.vicefund.com

Thomson Reuters, I. (2009). Thomson Reuters Lipper Fund Awards 2009. Retrieved April 27, 2010, from http://excellence.thomsonreuters.com/media/163738/USA_WinnersList2009_3_25_ $\underline{09 . p d f}$

Thomson Reuters, I. (2010). Thomson Reuters Lipper Fund Awards 2010. Retrieved April 27, 2010, from http://excellence.thomsonreuters.com/media/1875901/US_WinnersList2010 7-Apr$\underline{10 . p d f}$

Timothy Partners, Ltd. (2007). Moral investing: What is it all about? Retrieved April 27, 2010, from http://www.timothyplan.com/ProActive/frame-ProActivemoralinvesting.htm

UNEP Finance Initiative Asset Management Working Group. (2006). Show me the money: Linking environmental, social and governance issues to company value.UNEP Finance Initiative. 
UNEP Finance Initiative Asset Management Working Group. (2007). Demystifying responsible investment performance: A review of key academic and broker research on ESG factors. New York: United Nations Environment Programme Finance Initiative and Mercer Consulting.

UNEP Finance Initiative Asset Management Working Group. (2009). Fiduciary responsibility: Legal and practical aspects of integrating environmental, social and governance issues into institutional investment. New York: UNEP Finance Initiative.

University of Dartmouth. (2009). The Kenneth R. French data library. Retrieved April 29,2010 , from http://mba.tuck.dartmouth.edu/pages/faculty/ken.french/data library.html

Waddock, S. A., \& Graves, S. B. (1997). The corporate social performance-financial performance link. Strategic Management Journal, 18(4), 303-319.

Welch, B. L. (1951). On the comparison of several mean values: An alternative approach. Biometrika, 38(3/4), pp. 330-336.

Wermers, R. (2000). Mutual fund performance: An empirical decomposition into stockpicking talent, style, transactions costs, and expenses. The Journal of Finance, 55(4), 1655-1703.

Wharton Research Data Services. (2010). WRDS Database. Retrieved 4/29, 2010, from http://wrds.wharton.upenn.edu/

Williams, G. A. (2005a). Are socially responsible investors different from conventional investors? A comparison across six countries. SSRN eLibrary,

Williams, G. A. (2005b). Some determinants of the socially responsible investment decision: A cross country study. SSRN eLibrary, Retrieved April 7, 2010, from http://ssrn.com/paper=905189

Williams, G. A. (2009). Green opportunities with CSR. Retrieved April 7, 2010, from http://www.eco-asia.info/content/p-geoffrey-williams

Wood, D. J., \& Jones, R. E. (1995). Stakeholder mismatching: A theoretical problem in empirical research on corporate social performance. International Journal of Organizational Analysis, 3(3), 229-267.

Yang, M. C. K., \& Carter, R. L. (1983). One-way analysis of variance with time-series data. Biometrics, 39(3), pp. 747-751. 
Yau, J. K., Schneeweis, T., Robinson, T. R., \& Weiss, L. R. (2007). Chapter 8: Alternative Investments Portfolio Management. In J. L. Maginn, D. L. Tuttle, D. W. McLeavey \& J. E. Pinto (Eds.), Managing Investment Portfolios: A Dynamic Process (3rd ed., p. 477-578). Hoboken, NJ: John Wiley \& Sons. 


\section{VITA}

Andrea Roofe Sattlethight

Florida International University, Miami, FL. ABD: Business Administration

Nova Southeastern University, Davie, FL. Master of Business Administration.

University of the West Indies, Kingston, Jamaica. Bachelor of Science (Honors) in

Economics.

\section{WORK EXPERIENCE}

FLORIDA INTERNATIONAL UNIVERSITY, Miami, FL

\section{Graduate Assistant (Statistical Consulting)}

Assisted graduate students and professors with survey instrument development, statistical analyses and data interpretation using SAS/STAT, SPSS and SAS Enterprise Guide, in the natural, social and behavioral sciences-compiled reports, charts, and tables based on cluster analysis, GLM, OLS, logistic and partial least squares regression analysis, t-tests, factor analysis, tests of reliability, Structural Equation Modeling.

\section{Graduate Assistant (Dept of Management \& International Business.)}

- SAS Programmer for Assurance of Learning Project - questionnaire design, made improvements to SAS code designed to determine the effectiveness of exams in evaluating student performance for the College of Business Administration.

- Developed and delivered a Workshop in Multivariate Statistics using SAS/STAT for $\mathrm{PhD}$ students of Advanced Research Methodology.

CARIBBEANPORTFOLIO.COM, Kingston, Jamaica

Providers of training and consulting services to small and medium sized companies.

Owner (firm closed to enter PhD program)

- Consultant Project Manager to an Initial Public Offer by Jamaica Money Market Brokers http://www.jmmb.com

- Consultant to the development of investment products for Today's Money Limited. Developed Business Plan and preparation of required documentation for submission to the local Securities Commission.

- Provider of entrepreneurial training, management support and consulting services to owners of micro enterprises social entrepreneurs, and NGOs under the Caribbean Development Bank's Small Business Initiative.

- Consultant to Micro Enterprise Development Agency for the preparation of feasibility studies for the development of business incubators in Jamaica. 


\section{PUBLICATIONS}

- Roofe, Andrea (2005). ICT and the Efficient Markets Hypothesis. In S. Marshall, W. Taylor \& X. Yu (eds.) "Encyclopedia of Developing Regional Communities with Information and Communication Technology". Publishers: The Idea Group: Hershey PA.

- Barrett, Sheila C., Huffman, Fatma G. \& Roofe, Andrea (under review). Assessment of Physical Activity and Relationship to Body Mass Index of Jamaican Adolescents.

- Weissman, J., Magnus, M., Niyonsenga, T. \& Roofe, Andrea. (under review) Validity and reliability of an instrument on sports nutrition knowledge and practices of personal trainers. Journal of the American Dietetic Association.

- Roofe Sattlethight, A. \& Armagan, S. (forthcoming). "Group Processes in the Virtual Work Environment: Evidence for an Alliance-Building Dimensionality", Book Chapter in press for "Managing Dynamic Technology-Oriented Business: High-Tech Organizations and Workplaces", edited by Dariusz Jemielniak, Kozminski University (Poland) and Abigail Marks, Heriot-Watt University (UK). Publishers: The Idea Group, Inc.. (analysis conducted using Structural Equation Modeling with Mplus software).

\section{CONFERENCE PRESENTATIONS}

- "The effect of the business cycle on the performance of Socially Responsible Investments". Paper presented at the FL Chapter Meeting of the American Statistical Association, Tampa FL, February 2011 and Joint Statistical Meeting 2011, Miami Beach, FL.

- "A Conceptual Model of Leadership and Team Processes in a Technology-Mediated Environment", Paper presented at the Eastern Academy of Management Meeting, May 2010, Portland, ME.

- "A Model of E-Leadership and Team Processes: A Multivariate Application". Poster Presentation at the Joint Statistical Meeting, Washington DC, August, 2009 Method: Structural Equation Modeling, Factor Analysis, Scale Development.

- "Development and Validation of a Measure of E-Leadership and Group Dynamics using SAS/STAT”. SAS Global Forum, San Antonio, TX, March 2008 Method: Factor Analysis, Scale Development.

- "Validation of a Measure Using SAS/STAT". SE SAS User Group Conference, Hilton Head, SC, November 2007 Method: Factor Analysis, Scale Development.

- "Multinationality and Performance-A Conceptual Overview". Poster presentation at the Academy of International Business Meeting, Beijing, China, June 2006.

\section{WORK IN PROGRESS}

- A comparison of the factors affecting the levels of direct foreign investment in high performing economies and under-performing economies in Latin America 1990-2005 (using SAS PROC PANEL)

- Validation of an instrument of team processes in a virtual environment.

- Social Criteria Preference as Behavior Toward Risk. 


\title{
SERVICE
}

- Member-Leadership Team (Spring, 2009) Chair pro tem, Career Development, with responsibilities for Community Service (Fall 2009) Delta Epsilon Iota Academic Honors Society-Team Leader-Light The Night Fundraising Walk, 2009.

- Member-International Business Honor Society.

- Volunteer Bi-lingual Administrative Assistant for the Joint Meeting of the Board of Governors of the Inter-American Development Bank (IDB) and the Inter-American Institute of International Co-operation (IIC), 2008.

- Session Coordinator, Statistics and Data Analysis Track-SE SAS User Group Conference, 2007 and SAS Global Forum, 2007, 2008.

- Student Member:

- American Statistical Association.

○ The Econometric Society.

- The International Institute of Forecasters.

- Joint Chairman, International Task Force for the study of the impact of globalization on the consulting profession, Institute of Management Consultants of the USA, 2004 (current Student Member).

- Vice-President, Membership (2003) \& Council Member (2003-2004), Jamaica Computer Society, Kingston, Jamaica.

\author{
AWARDS \\ Delta Epsilon Iota Academic Honors Society-Certificate of Achievement-Leadership \\ Team, Most Fundraised by a Member, Spring 2009. \\ Minority Student Travel Grant (American Statistical Association/Ely Lilly) 2009 \\ SAS software and book grant for Dissertation Research, 2008. \\ SAS Student Ambassador, SAS Global Forum, 2008. \\ SAS Scholar, Southeast SAS User Group (SESUG) 2007. \\ Academy of International Business - Doctoral Student Travel Grant, 2006 and 2007.
}

